\title{
A Stable Four-Membered N-Heterocyclic Carbene
}

\author{
Emmanuelle Despagnet-Ayoub, Robert H. Grubbs*
}

\section{SUPPORTING INFORMATION}

\section{Synthesis and Spectroscopic Data}

All manipulations were performed under an inert atmosphere of argon using standard Schlenk techniques. Dry, oxygen-free solvents were employed. ${ }^{1} \mathrm{H},{ }^{13} \mathrm{C},{ }^{31} \mathrm{P}$, and ${ }^{19} \mathrm{~F}$ NMR spectra were recorded on either a Varian Mercury-300, Varian Inova-500 or Varian Inova-600 NMR spectrometer. ${ }^{1} \mathrm{H}$ and ${ }^{13} \mathrm{C}$ NMR chemicals shifts are reported in ppm relative to $\mathrm{Me}_{4} \mathrm{Si}$ as an external standard. ${ }^{31} \mathrm{P}$ and ${ }^{19} \mathrm{~F}$ NMR chemical shifts are given relative to external standards of $\mathrm{H}_{3} \mathrm{PO}_{4}$ and $\mathrm{CFCl}_{3}$, respectively.

Synthesis of the iminium salt 2a: Aminodichlorophosphine $(0.25 \mathrm{~g}, 1.4 \mathrm{mmol})$ followed by trimethylsilyl trifluoromethanesulfonate $(0.32 \mathrm{~g}, 1.4 \mathrm{mmol})$ were added at room temperature to a dichloromethane solution of silylamidine $(0.5 \mathrm{~g}, 1.4 \mathrm{mmol})$. After 30 minutes, the solvent was removed under vacuum and the crude residue was washed with ether, affording a white powder $(0.5 \mathrm{~g}, 66 \%)$. Single crystals were obtained from a dichloromethane-toluene solution at $-20^{\circ} \mathrm{C}$. mp $133{ }^{\circ} \mathrm{C} \mathrm{dec} ;{ }^{31} \mathrm{P}\left\{{ }^{1} \mathrm{H}\right\}$ NMR $\left(\mathrm{CD}_{2} \mathrm{Cl}_{2}, 300 \mathrm{~K}\right): \mathrm{d} 126.9(\mathrm{~s}) ;{ }^{19} \mathrm{~F}$ NMR $\left(\mathrm{CD}_{2} \mathrm{Cl}_{2}, 300 \mathrm{~K}\right): \mathrm{d}-79.6$ (s, $\mathrm{CF}_{3} \mathrm{SO}_{3}^{-}$); ${ }^{1} \mathrm{H} \mathrm{NMR}\left(\mathrm{CD}_{2} \mathrm{Cl}_{2}, 300 \mathrm{~K}\right.$ ): d 0.98 (br., $3 \mathrm{H}, \mathrm{CH}_{3}$ ), 1.24 (br., $\left.3 \mathrm{H}, \mathrm{CH}_{3}\right), 2.34$ (s, $6 \mathrm{H}$, $\mathrm{CH}_{3}$ ), 2.44 (s, 12H, $\mathrm{CH}_{3}$ ), 3.37 (br.; 4H, $\mathrm{CH}_{2}$ ), 7.05 (s, 4H, $\mathrm{H}_{\text {arom }}$ ), $9.09\left(\mathrm{~d}, 1 \mathrm{H},{ }^{3} \mathrm{~J}_{\mathrm{HP}}=2.7 \mathrm{~Hz}\right.$, NCHN); ${ }^{13} \mathrm{C}\left\{{ }^{1} \mathrm{H}\right\}$ NMR $\left.\left(\mathrm{CD}_{2} \mathrm{Cl}_{2}, 300 \mathrm{~K}\right)\right)$ : d 13.5 (br., $\left.\mathrm{CH}_{3}\right), 15.5$ (br., $\left.\mathrm{CH}_{3}\right), 19.2\left(\mathrm{~d}, J_{\mathrm{CP}}=6 \mathrm{~Hz}\right.$, $\mathrm{CH}_{3}$ ), 20.9 (s, $\mathrm{CH}_{3}$ ), 41.8 (br., $\mathrm{CH}_{2}$ ), 44.4 (br., $\mathrm{CH}_{2}$ ), 120.9 (q, ${ }^{1} J_{\mathrm{CF}}=319 \mathrm{~Hz}, \mathrm{CF}_{3}$ ), 130.3 (s, $\left.\mathrm{C}_{\text {arom }}\right), 130.5\left(\mathrm{~s}, \mathrm{CH}_{\text {arom }}\right), 133.8\left(\mathrm{~s}, \mathrm{C}_{\text {arom }}\right), 139.8\left(\mathrm{~s}, \mathrm{C}_{\text {arom }}\right), 164.8\left(\mathrm{~d},{ }^{2} J_{\mathrm{CP}}=16 \mathrm{~Hz}, \mathrm{NCN}\right)$. 
Synthesis of the iminium salt $\mathbf{2 b}$ : As described for $\mathbf{2 a}$, a white powder was obtained (90\%). mp $163{ }^{\circ} \mathrm{C} \mathrm{dec} ;{ }^{31} \mathrm{P}\left\{{ }^{1} \mathrm{H}\right\}$ NMR $\left(\mathrm{CD}_{2} \mathrm{Cl}_{2}, 300 \mathrm{~K}\right): \mathrm{d} 135.0(\mathrm{~s}) ;{ }^{19} \mathrm{~F}$ NMR $\left(\mathrm{CD}_{2} \mathrm{Cl}_{2}, 300 \mathrm{~K}\right): \mathrm{d}-79.6$ (s, $\left.\mathrm{CF}_{3} \mathrm{SO}_{3}{ }^{-}\right) ;{ }^{1} \mathrm{H} \mathrm{NMR}\left(\mathrm{CD}_{2} \mathrm{Cl}_{2}, 300 \mathrm{~K}\right): \mathrm{d} 1.11\left(\mathrm{~d}, 6 \mathrm{H},{ }^{3} J_{\mathrm{HH}}=6.6 \mathrm{~Hz}, \mathrm{CH}_{3 i-\mathrm{Pr}}\right), 1.41\left(\mathrm{~d}, 6 \mathrm{H},{ }^{3} J_{\mathrm{HH}}=\right.$ $7.2 \mathrm{~Hz}, \mathrm{CH}_{3 i-\mathrm{Pr}}$ ), 2.33 (s, 6H, $\left.\mathrm{CH}_{3 \mathrm{Mes}}\right), 2.47$ (s, 12H, $\left.\mathrm{CH}_{3 \mathrm{Mes}}\right), 3.64(\mathrm{~m}, 1 \mathrm{H}, \mathrm{CH}), 3.91(\mathrm{~m}, 1 \mathrm{H}$, $\mathrm{CH}), 7.04\left(\mathrm{~s}, 4 \mathrm{H}, \mathrm{H}_{\text {arom }}\right), 8.97\left(\mathrm{~d}, 1 \mathrm{H},{ }^{3} \mathrm{~J}_{\mathrm{HP}}=2.2 \mathrm{~Hz}, \mathrm{NCHN}\right) ;{ }^{13} \mathrm{C}\left\{{ }^{1} \mathrm{H}\right\} \mathrm{NMR}\left(\mathrm{CD}_{2} \mathrm{Cl}_{2}, 300 \mathrm{~K}\right): \mathrm{d}$ $19.1\left(\mathrm{~d}, J_{\mathrm{CP}}=7 \mathrm{~Hz}, \mathrm{CH}_{3}\right), 20.9\left(\mathrm{~s}, \mathrm{CH}_{3}\right), 21.4\left(\mathrm{~s}, \mathrm{CH}_{3}\right), 27.2\left(\mathrm{~d}, J_{\mathrm{CP}}=13 \mathrm{~Hz}, \mathrm{CH}_{3}\right), 47.7\left(\mathrm{~d},{ }^{2} J_{\mathrm{CP}}\right.$ $=30 \mathrm{~Hz}, \mathrm{CH}), 51.6\left(\mathrm{~d},{ }^{2} J_{\mathrm{CP}}=9 \mathrm{~Hz}, \mathrm{CH}\right), 120.9\left(\mathrm{q},{ }^{1} J_{\mathrm{CF}}=319 \mathrm{~Hz}, \mathrm{CF}_{3}\right), 130.1\left(\mathrm{~s}, \mathrm{C}_{\text {arom }}\right), 130.6(\mathrm{~s}$, $\left.\mathrm{CH}_{\text {arom }}\right), 133.3$ (s, $\left.\mathrm{C}_{\text {arom }}\right), 139.6$ (s, $\left.\mathrm{C}_{\text {arom }}\right), 164.2\left(\mathrm{~d},{ }^{2} J_{\mathrm{CP}}=17 \mathrm{~Hz}, \mathrm{NCHN}\right)$.

Synthesis of the iminium salt 2c: As described for 2a, white powder (96\%). mp $154{ }^{\circ} \mathrm{C}$ dec; ${ }^{31} \mathrm{P}\left\{{ }^{1} \mathrm{H}\right\}$ NMR $\left(\mathrm{CD}_{2} \mathrm{Cl}_{2}, 300 \mathrm{~K}\right)$ : d $136.5(\mathrm{~s}) ;{ }^{19} \mathrm{~F} \mathrm{NMR}\left(\mathrm{CD}_{2} \mathrm{Cl}_{2}, 300 \mathrm{~K}\right):-79.6\left(\mathrm{~s}, \mathrm{CF}_{3} \mathrm{SO}_{3}{ }^{-}\right),{ }^{1} \mathrm{H}$ $\operatorname{NMR}\left(\mathrm{CD}_{2} \mathrm{Cl}_{2}, 300 \mathrm{~K}\right): \mathrm{d} 1.15\left(\mathrm{~d}, 6 \mathrm{H},{ }^{3} J_{\mathrm{HH}}=6.3 \mathrm{~Hz}, \mathrm{CH}_{3 \mathrm{~N} i \mathrm{-Pr}}\right), 1.35\left(\mathrm{~d}, 24 \mathrm{H},{ }^{3} J_{\mathrm{HH}}=6.6 \mathrm{~Hz}\right.$, $\left.\mathrm{CH}_{3 \mathrm{Ar}}\right), 1.42\left(\mathrm{~d}, 6 \mathrm{H},{ }^{3} J_{\mathrm{HH}}=6.6 \mathrm{~Hz}, \mathrm{CH}_{3 \mathrm{Ni}-\mathrm{Pr}}\right), 3.20$ (sept.d, $4 \mathrm{H},{ }^{3} J_{\mathrm{HH}}=6.6 \mathrm{~Hz},{ }^{5} J_{\mathrm{HP}}=2.7 \mathrm{~Hz}$, $\mathrm{CH}), 3.68(\mathrm{~m}, 1 \mathrm{H}, \mathrm{CH}), 3.89\left(\mathrm{~m}, 1 \mathrm{H}, \mathrm{CH}_{\mathrm{i}-\mathrm{Pr}}\right), 7.36\left(\mathrm{~d}, 4 \mathrm{H},{ }^{3} J_{\mathrm{HH}}=7.5 \mathrm{~Hz}, \mathrm{H}_{\mathrm{arom}}\right), 7.49\left(\mathrm{t}, 2 \mathrm{H},{ }^{3} J_{\mathrm{HH}}\right.$ $\left.=7.5 \mathrm{~Hz}, \mathrm{H}_{\text {arom }}\right), 8.65\left(\mathrm{~d}, 1 \mathrm{H},{ }^{3} \mathrm{~J}_{\mathrm{HP}}=2.1 \mathrm{~Hz}, \mathrm{NCHN}\right) ;{ }^{13} \mathrm{C}\left\{{ }^{1} \mathrm{H}\right\} \mathrm{NMR}\left(\mathrm{CD}_{2} \mathrm{Cl}_{2}, 300 \mathrm{~K}\right): \mathrm{d} 22.0(\mathrm{~s}$, $\left.\mathrm{CH}_{3}\right), 24.4$ (br., $\left.\mathrm{CH}_{3}\right), 27.4\left(\mathrm{~d}, J_{\mathrm{CP}}=13 \mathrm{~Hz}, \mathrm{CH}_{3}\right), 29.9\left(\mathrm{~d}, J_{\mathrm{CP}}=7 \mathrm{~Hz}, \mathrm{CH}\right), 48.0\left(\mathrm{~d},{ }^{2} J_{\mathrm{CP}}=28\right.$ $\mathrm{Hz}, \mathrm{CH}), 120.9\left(\mathrm{q},{ }^{1} J_{\mathrm{CF}}=319 \mathrm{~Hz}, \mathrm{CF}_{3}\right), 125.1\left(\mathrm{~s}, \mathrm{CH}_{\mathrm{arom}}\right), 129.4\left(\mathrm{~d}, J_{\mathrm{CP}}=2 \mathrm{~Hz}, \mathrm{C}_{\text {arom }}\right), 130.6(\mathrm{~s}$, $\left.\mathrm{CH}_{\text {arom }}\right), 144.8\left(\mathrm{~s}, \mathrm{C}_{\text {arom }}\right), 163.0\left(\mathrm{~d},{ }^{2} J_{\mathrm{CP}}=17 \mathrm{~Hz}, \mathrm{NCHN}\right)$.

Reaction of the iminium salt $\mathbf{2} \mathbf{b}$ with potassium tert-butoxide (3): Potassium tert-butoxide (0.012 $\mathrm{g}, 0.1 \mathrm{mmol})$ was added at room temperature to a toluene solution of iminium salt $2 \mathbf{b}(0.06 \mathrm{~g}, 0.1$ mmol). After 30 minutes, the solution was filtered and evaporated under vacuum, affording a yellow powder (0.041 g, 86\%). mp $165{ }^{\circ} \mathrm{C} ;{ }^{31} \mathrm{P}\left\{{ }^{1} \mathrm{H}\right\}$ NMR $\left(\mathrm{C}_{6} \mathrm{D}_{6}, 300 \mathrm{~K}\right)$ : d 124.6 (s); ${ }^{1} \mathrm{H}$ NMR 
$\left(\mathrm{C}_{6} \mathrm{D}_{6}, 300 \mathrm{~K}\right.$ ): d 0.90 (s, 9H, $\mathrm{CH}_{3 t-\mathrm{Bu}}$ ), 0.96 (br., 6H, $\mathrm{CH}_{3}$ ), 1.09 (br., 6H, $\mathrm{CH}_{3}$ ), 2.14 (s, 3H, $\mathrm{CH}_{3}$ ), 2.15 (s, 3H, $\mathrm{CH}_{3}$ ), 2.28 (s, 6H, $\mathrm{CH}_{3}$ ), 2.55 (s, 3H, $\mathrm{CH}_{3}$ ), 2.57 (s, 3H, $\mathrm{CH}_{3}$ ), 4.73 (br., $2 \mathrm{H}$, $\mathrm{CH}), 6.83\left(\mathrm{~s}, 2 \mathrm{H}, \mathrm{H}_{\text {trom }}\right), 6.84\left(\mathrm{~s}, 1 \mathrm{H}, \mathrm{H}_{\text {arom }}\right), 6.88\left(\mathrm{~s}, 1 \mathrm{H}, \mathrm{H}_{\text {trom }}\right), 7.87\left(\mathrm{~d}, 1 \mathrm{H},{ }^{3} J_{\mathrm{HP}}=3.6 \mathrm{~Hz}\right.$, NCHN); ${ }^{13} \mathrm{C}\left\{{ }^{1} \mathrm{H}\right\}$ NMR $\left(\mathrm{C}_{6} \mathrm{D}_{6}, 300 \mathrm{~K}\right): \mathrm{d} 19.3\left(\mathrm{~s}, \mathrm{CH}_{3}\right), 19.5\left(\mathrm{~s}, \mathrm{CH}_{3}\right), 19.8\left(\mathrm{~s}, \mathrm{CH}_{3}\right), 20.8(\mathrm{~s}$, $\mathrm{CH}_{3}$ ), 20.9 (s, $\mathrm{CH}_{3}$ ), 24.3 (br., $\mathrm{CH}_{3}$ ), 29.9 (d, $J_{\mathrm{CP}}=8 \mathrm{~Hz}, \mathrm{CH}_{3}$ ), 44.8 (br., $\mathrm{CH}$ ), $76.6\left(\mathrm{~d},{ }^{2} J_{\mathrm{CP}}=15\right.$ Hz, $\left.\mathrm{C}_{\mathrm{t}-\mathrm{Bu}}\right), 128.5$ (s), 128.9 (s), 129.2 (s), 130.8 (s), 136.0 (s), 136.5 (s), 139.5 (s), 149.5 (s), $150.9\left(\mathrm{~d},{ }^{2} J_{\mathrm{CP}}=10 \mathrm{~Hz}, \mathrm{NCHN}\right)$.

Reaction of the iminium salt $\mathbf{2 b}$ with mesityllithium or potassium hexamethyldisilazide (4): Mesityllithium (0.092 g, $0.73 \mathrm{mmol})$ or potassium hexamethyldisilazide $(0.14 \mathrm{~g}, 0.73 \mathrm{mmol})$ was added at room temperature to a toluene solution of iminium salt $\mathbf{2 b}(0.37 \mathrm{~g}, 0.66 \mathrm{mmol})$. After one hour, the solution was filtered and evaporated under vacuum, affording a yellow powder $(0.24 \mathrm{~g}, 45 \%)$. Single crystals were obtained by slow evaporation of a pentane solution at room temperature. mp $174{ }^{\circ} \mathrm{C} ;{ }^{31} \mathrm{P}\left\{{ }^{1} \mathrm{H}\right\}$ NMR $\left(\mathrm{C}_{6} \mathrm{D}_{6}, 300 \mathrm{~K}\right)$ : d 155.7 (s); ${ }^{1} \mathrm{H}$ NMR $\left(\mathrm{C}_{6} \mathrm{D}_{6}, 300 \mathrm{~K}\right)$ : d $0.82\left(\mathrm{~d}, 12 \mathrm{H},{ }^{3} J_{\mathrm{HH}}=6.0 \mathrm{~Hz}, \mathrm{CH}_{3}\right), 1.09\left(\mathrm{~d}, 12 \mathrm{H},{ }^{3} J_{\mathrm{HH}}=6.5 \mathrm{~Hz}, \mathrm{CH}_{3}\right), 2.10\left(\mathrm{~s}, 12 \mathrm{H}, \mathrm{CH}_{3}\right), 2.29$ (s, 12H, $\left.\mathrm{CH}_{3}\right), 2.92\left(\mathrm{~s}, 12 \mathrm{H}, \mathrm{CH}_{3}\right), 4.70(\mathrm{~m}, 4 \mathrm{H}, \mathrm{CH}), 6.32\left(\mathrm{~s}, 4 \mathrm{H}, \mathrm{H}_{\text {arom }}\right), 6.66$ (s, 4H, $\mathrm{H}_{\text {arom }}$ ); ${ }^{13} \mathrm{C}\left\{{ }^{1} \mathrm{H}\right\}$ NMR $\left(\mathrm{C}_{6} \mathrm{D}_{6}, 300 \mathrm{~K}\right): \mathrm{d} 20.7\left(\mathrm{~s}, \mathrm{CH}_{3}\right), 21.1\left(\mathrm{~d}, J_{\mathrm{CP}}=9 \mathrm{~Hz}, \mathrm{CH}_{3}\right), 21.5\left(\mathrm{~d}, J_{\mathrm{CP}}=16 \mathrm{~Hz}\right.$, $\left.\mathrm{CH}_{3}\right), 21.7\left(\mathrm{~d}, J_{\mathrm{CP}}=17 \mathrm{~Hz}, \mathrm{CH}_{3}\right), 21.9\left(\mathrm{~d}, J_{\mathrm{CP}}=7 \mathrm{~Hz}, \mathrm{CH}_{3}\right), 27.0\left(\mathrm{~d}, J_{\mathrm{CP}}=13 \mathrm{~Hz}, \mathrm{CH}_{3}\right), 27.1(\mathrm{~d}$, $\left.J_{\mathrm{CP}}=14 \mathrm{~Hz}, \mathrm{CH}_{3}\right), 44.5\left(\mathrm{~d},{ }^{2} J_{\mathrm{CP}}=9 \mathrm{~Hz}, \mathrm{CH}\right), 44.7\left(\mathrm{~d},{ }^{2} J_{\mathrm{CP}}=5 \mathrm{~Hz}, \mathrm{CH}\right), 126.5\left(\mathrm{~d}, J_{\mathrm{CP}}=8 \mathrm{~Hz}\right.$, $\mathrm{NCN}), 129.1\left(\mathrm{~d}, J_{\mathrm{CP}}=23 \mathrm{~Hz}\right), 129.7\left(\mathrm{~d}, J_{\mathrm{CP}}=6 \mathrm{~Hz}\right), 132.9\left(\mathrm{~d}, J_{\mathrm{CP}}=2 \mathrm{~Hz}\right), 134.5(\mathrm{~s}), 136.2(\mathrm{~s})$, $137.5\left(\mathrm{~d}, J_{\mathrm{CP}}=5 \mathrm{~Hz}\right), \mathrm{C}_{\text {arom }}$ under the $\mathrm{C}_{6} \mathrm{D}_{6}$ peak. 
Reaction of the iminium salt $\mathbf{2 c}$ with mesityllithium or potassium hexamethyldisilazide (5): Mesityllithium (0.011 g, $0.086 \mathrm{mmol})$ or potassium hexamethyldisilazide $(0.017 \mathrm{~g}, 0.086 \mathrm{mmol})$ was added at room temperature to a toluene solution of iminium salt $2 \mathbf{c}(0.05 \mathrm{~g}, 0.078 \mathrm{mmol})$. After 10 minutes, pentane was added and the solution was filtered. The solvents were removed under vacuum affording a white powder $(0.022 \mathrm{~g}, 47 \%)$. Single crystals were obtained from a saturated pentane solution at $-50{ }^{\circ} \mathrm{C}$. mp: the crystals were not stable 2 hours at room temperature; ${ }^{31} \mathrm{P}\left\{{ }^{1} \mathrm{H}\right\}$ NMR $\left(\mathrm{C}_{7} \mathrm{D}_{8}, 278 \mathrm{~K}\right)$ : d $157.2(\mathrm{~s}) ;{ }^{1} \mathrm{H}$ NMR $\left(\mathrm{C}_{7} \mathrm{D}_{8}, 278 \mathrm{~K}\right)$ : d 1.39 (d, 6H, $\left.J_{\mathrm{CP}}=8.2 \mathrm{~Hz}, \mathrm{CH}_{3}\right), 1.05\left(\mathrm{~d}, 6 \mathrm{H}, J_{\mathrm{CP}}=9.0 \mathrm{~Hz}, \mathrm{CH}_{3}\right), 1.32\left(\mathrm{~d}, 3 \mathrm{H}, J_{\mathrm{CP}}=8.4 \mathrm{~Hz}, \mathrm{CH}_{3}\right), 1.46(\mathrm{~d}$, $\left.12 \mathrm{H}, J_{\mathrm{CP}}=8.4 \mathrm{~Hz}, \mathrm{CH}_{3}\right), 1.54\left(\mathrm{~d}, 9 \mathrm{H}, J_{\mathrm{CP}}=8.5 \mathrm{~Hz}, \mathrm{CH}_{3}\right), 2.87(\mathrm{~m}, 1 \mathrm{H}, \mathrm{CH}), 4.04(\mathrm{~m}, 4 \mathrm{H}, \mathrm{CH})$, $4.24(\mathrm{~m}, 1 \mathrm{H}, \mathrm{CH}), 7.00-7.10\left(\mathrm{~m}, 6 \mathrm{H}, \mathrm{H}_{\text {arom }}\right) ;{ }^{13} \mathrm{C}\left\{{ }^{1} \mathrm{H}\right\} \mathrm{NMR}\left(\mathrm{C}_{7} \mathrm{D}_{8}, 278 \mathrm{~K}\right): \mathrm{d} 22.1\left(\mathrm{~s}, \mathrm{CH}_{3}\right), 23.8$ (br., $\left.\mathrm{CH}_{3}\right), 25.50$ (br., $\left.\mathrm{CH}_{3}\right), 26.8\left(\mathrm{~d}, J_{\mathrm{CP}}=13 \mathrm{~Hz}, \mathrm{CH}_{3}\right), 29.1\left(\mathrm{~d}, J_{\mathrm{CP}}=8 \mathrm{~Hz}, \mathrm{CH}\right), 44.6\left(\mathrm{~d},{ }^{2} J_{\mathrm{CP}}=\right.$ $27 \mathrm{~Hz}, \mathrm{CH}), 48.7\left(\mathrm{~d},{ }^{2} J_{\mathrm{CP}}=8 \mathrm{~Hz}, \mathrm{CH}\right), 123.6(\mathrm{~s}), 125.2(\mathrm{~s}), 126.9(\mathrm{~s}), 128.1(\mathrm{~s}), 129.0(\mathrm{~s}), 137,1$ (s), $145.5(\mathrm{~s}), 285.0\left(\mathrm{~d},{ }^{2} J_{\mathrm{CP}}=13 \mathrm{~Hz}, \mathrm{NCN}\right)$. 


\section{X-Ray Crystallographic Data}

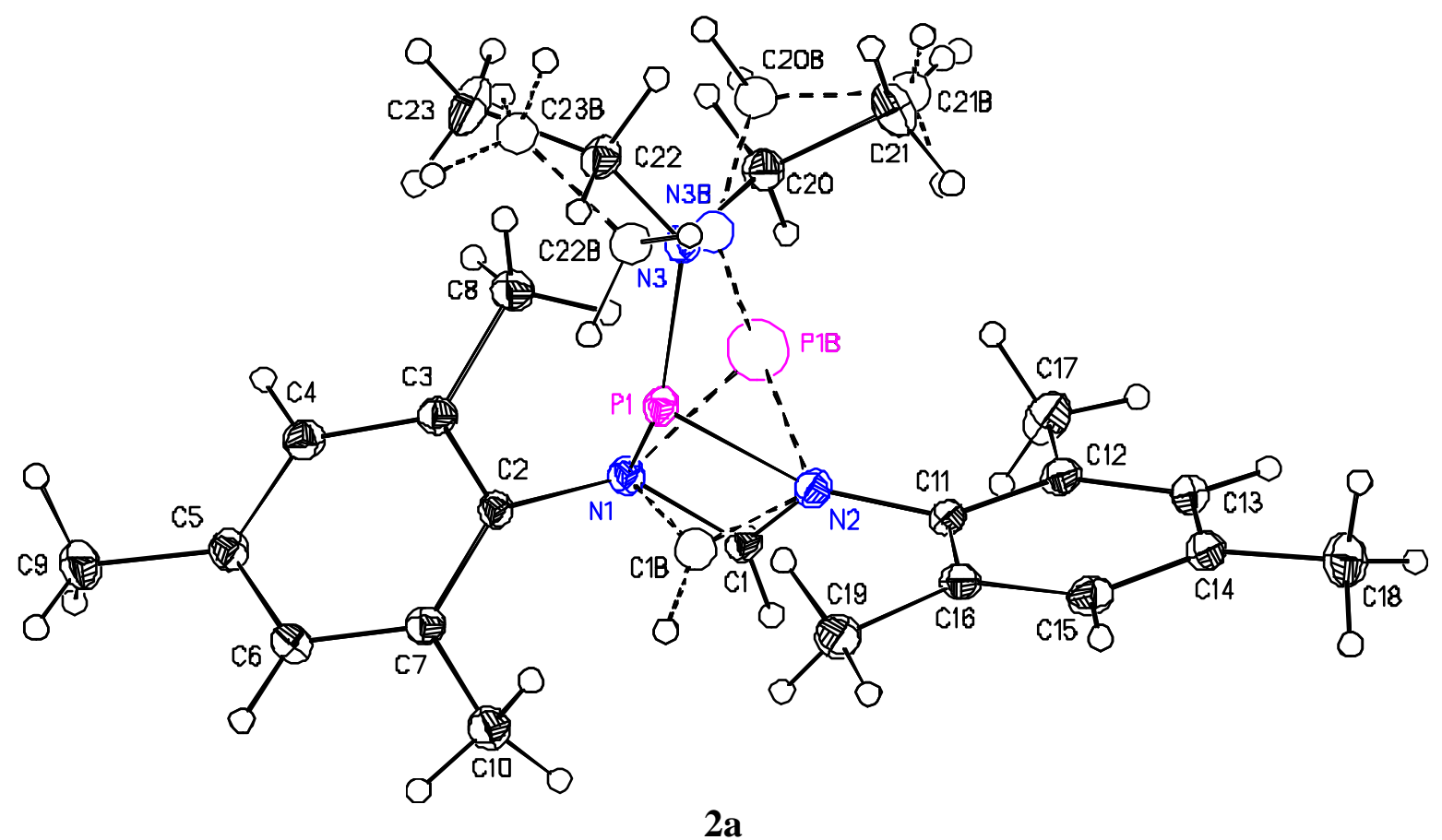

\section{Special Refinement Details}

The crystals contain two different conformationaly distinct compounds. The two conformations differ by what might be called an inversion of the tetrahedral geometry around phosphorous but both share N1, N2 and the aromatic constituents.. Although one conformation comprises only 5\% of the structure (see Table 2 and Figure 2) it is clear in the electron density maps and is included in the model with restraints. These include one common isotropic temperature factor, bond distance and angle restraints and planarity restraints for C1B, N1, P1B and N2.

Refinement of $\mathrm{F}^{2}$ against ALL reflections. The weighted R-factor $(w \mathrm{R})$ and goodness of fit $(\mathrm{S})$ are based on $\mathrm{F}^{2}$, conventional R-factors $(\mathrm{R})$ are based on $\mathrm{F}$, with $\mathrm{F}$ set to zero for negative $\mathrm{F}^{2}$. The threshold expression of $\mathrm{F}^{2}>$ $2 \sigma\left(\mathrm{F}^{2}\right)$ is used only for calculating R-factors $(\mathrm{gt})$ etc. and is not relevant to the choice of reflections for refinement. $\mathrm{R}$-factors based on $\mathrm{F}^{2}$ are statistically about twice as large as those based on $\mathrm{F}$, and $\mathrm{R}$-factors based on ALL data will be even larger.

All esds (except the esd in the dihedral angle between two l.s. planes) are estimated using the full covariance matrix. The cell esds are taken into account individually in the estimation of esds in distances, angles and torsion angles; correlations between esds in cell parameters are only used when they are defined by crystal symmetry. An approximate (isotropic) treatment of cell esds is used for estimating esds involving l.s. planes. 
Table 1. Crystal data and structure refinement for $\mathbf{2 a}$.

Identification code

Empirical formula

Formula weight

Crystal size

Crystal color

Wavelength

Data Collection Temperature

Unit cell dimensions

Volume

Z

Crystal system

Space group

Density (calculated)

$\mathrm{F}(000)$

$\theta$ range for data collection

Completeness to $\theta=41.76^{\circ}$

Index ranges

Reflections collected

Independent reflections

Absorption coefficient

Absorption correction

Max. and min. transmission

Refinement method

Data / restraints / parameters

Goodness-of-fit on $\mathrm{F}^{2}$

Final $R$ indices [I>2 $\sigma(\mathrm{I}), 10187$ reflections]

$\mathrm{R}$ indices (all data)

Largest diff. peak and hole 2a

$\left[\mathrm{C}_{23} \mathrm{H}_{33} \mathrm{~N}_{3} \mathrm{P}\right]^{+}\left[\mathrm{SO}_{3} \mathrm{CF}_{3}\right]$ ?

531.56

$0.37 \times 0.26 \times 0.25 \mathrm{~mm}^{3}$

Colorless

$0.71073 \AA \mathrm{MoK} \alpha$

98(2) K

$\mathrm{a}=10.5668(3) \AA$

$\alpha=67.7490(10)^{\circ}$

$\beta=65.7880(10)^{\circ}$

$\mathrm{b}=11.8758(4) \AA$

$\mathrm{c}=12.7952(4) \AA$

$\gamma=67.4890(10)^{\circ}$

1305.19(7) $\AA^{3}$

2

Triclinic

P-1

$1.353 \mathrm{Mg} / \mathrm{m}^{3}$

560

1.81 to $41.76^{\circ}$

$83.8 \%$

$-19 \leq \mathrm{h} \leq 19,-20 \leq \mathrm{k} \leq 21,-22 \leq 1 \leq 22$

50465

$15049\left[\mathrm{R}_{\mathrm{int}}=0.0566\right]$

$0.237 \mathrm{~mm}^{-1}$

None

0.9430 and 0.9173

Full matrix least-squares on $\mathrm{F}^{2}$

$15049 / 9 / 348$

1.703

$\mathrm{R} 1=0.0450, w \mathrm{R} 2=0.0829$

$\mathrm{R} 1=0.0719, w \mathrm{R} 2=0.0850$

0.996 and -0.805 e. $\AA^{-3}$ 
Table 2. Atomic coordinates $\left(\mathrm{x}^{10^{4}}\right)$ and equivalent isotropic displacement parameters $\left(\AA^{2} \times 1^{3}\right)$ for $2 a$. $U(e q)$ is defined as the trace of the orthogonalized $U^{i j}$ tensor.

\begin{tabular}{|c|c|c|c|c|c|}
\hline & $\mathrm{x}$ & $\mathrm{y}$ & $\mathrm{z}$ & $\mathrm{U}_{\mathrm{eq}}$ & Occ \\
\hline$S(1)$ & 7789(1) & 7832(1) & $2538(1)$ & $16(1)$ & 1 \\
\hline $\mathrm{F}(1)$ & 7076(1) & $6400(1)$ & 1849(1) & $25(1)$ & 1 \\
\hline $\mathrm{F}(2)$ & $6513(1)$ & 6011(1) & 3751(1) & $27(1)$ & 1 \\
\hline $\mathrm{F}(3)$ & $5261(1)$ & 7674(1) & 2784(1) & $29(1)$ & 1 \\
\hline $\mathrm{O}(1)$ & $9138(1)$ & $6886(1)$ & 2542(1) & $30(1)$ & 1 \\
\hline $\mathrm{O}(2)$ & 7761(1) & $8765(1)$ & $1422(1)$ & $25(1)$ & 1 \\
\hline $\mathrm{O}(3)$ & 7078(1) & $8349(1)$ & $3559(1)$ & $22(1)$ & 1 \\
\hline $\mathrm{C}(24)$ & $6596(1)$ & 6939(1) & 2739(1) & $17(1)$ & 1 \\
\hline $\mathrm{P}(1)$ & $4533(1)$ & $3200(1)$ & $1785(1)$ & $13(1)$ & $0.947(1)$ \\
\hline $\mathrm{N}(1)$ & $5943(1)$ & $2276(1)$ & 2484(1) & $14(1)$ & 1 \\
\hline $\mathrm{N}(2)$ & $4395(1)$ & $1589(1)$ & $2468(1)$ & $15(1)$ & 1 \\
\hline $\mathrm{N}(3)$ & $3245(1)$ & 4079(1) & 2612(1) & $14(1)$ & $0.947(1)$ \\
\hline $\mathrm{C}(1)$ & $5660(1)$ & $1210(1)$ & 2653(1) & $13(1)$ & $0.947(1)$ \\
\hline $\mathrm{C}(2)$ & 7281(1) & 2538(1) & $2228(1)$ & $13(1)$ & 1 \\
\hline $\mathrm{C}(3)$ & $7346(1)$ & 3094(1) & 2990(1) & $15(1)$ & 1 \\
\hline $\mathrm{C}(4)$ & $8567(1)$ & $3500(1)$ & 2654(1) & $17(1)$ & 1 \\
\hline $\mathrm{C}(5)$ & $9664(1)$ & 3399(1) & 1591(1) & $16(1)$ & 1 \\
\hline$C(6)$ & 9581(1) & $2809(1)$ & 874(1) & $17(1)$ & 1 \\
\hline$C(7)$ & $8395(1)$ & $2366(1)$ & 1174(1) & $15(1)$ & 1 \\
\hline$C(8)$ & 6130(1) & $3303(1)$ & 4104(1) & $20(1)$ & 1 \\
\hline $\mathrm{C}(9)$ & $10906(1)$ & 3953(1) & $1216(1)$ & $23(1)$ & 1 \\
\hline$C(10)$ & 8339(1) & $1746(1)$ & $365(1)$ & $19(1)$ & 1 \\
\hline $\mathrm{C}(11)$ & $3517(1)$ & $877(1)$ & $2530(1)$ & $14(1)$ & 1 \\
\hline$C(12)$ & $2778(1)$ & $217(1)$ & $3645(1)$ & $15(1)$ & 1 \\
\hline $\mathrm{C}(13)$ & 1830(1) & $-365(1)$ & $3677(1)$ & $18(1)$ & 1 \\
\hline$C(14)$ & 1611(1) & $-297(1)$ & 2651(1) & $18(1)$ & 1 \\
\hline $\mathrm{C}(15)$ & $2420(1)$ & $318(1)$ & $1558(1)$ & $18(1)$ & 1 \\
\hline$C(16)$ & $3387(1)$ & 901(1) & 1474(1) & $15(1)$ & 1 \\
\hline $\mathrm{C}(17)$ & 3013(1) & $110(1)$ & $4764(1)$ & $23(1)$ & 1 \\
\hline $\mathrm{C}(18)$ & $507(1)$ & $-859(1)$ & 2718(1) & $28(1)$ & 1 \\
\hline$C(19)$ & 4284(1) & $1517(1)$ & 272(1) & $22(1)$ & 1 \\
\hline$C(20)$ & $2605(1)$ & $3697(1)$ & 3917(1) & $17(1)$ & $0.947(1)$ \\
\hline $\mathrm{C}(21)$ & $1074(2)$ & $3603(2)$ & $4277(1)$ & 24(1) & $0.947(1)$ \\
\hline$C(22)$ & $2776(1)$ & $5447(1)$ & 2015(1) & $17(1)$ & $0.947(1)$ \\
\hline$C(23)$ & $3530(1)$ & $6227(1)$ & $2158(1)$ & $27(1)$ & $0.947(1)$ \\
\hline $\mathrm{P}(1 \mathrm{~B})$ & $4263(5)$ & $2270(5)$ & $3669(5)$ & $26(1)$ & $0.053(1)$ \\
\hline $\mathrm{N}(3 \mathrm{~B})$ & $3251(17)$ & 3703(15) & $3252(14)$ & $26(1)$ & $0.053(1)$ \\
\hline $\mathrm{C}(1 \mathrm{~B})$ & $5674(9)$ & $1778(5)$ & 1872(8) & $26(1)$ & $0.053(1)$ \\
\hline$C(20 B)$ & 2138(18) & $4190(20)$ & 4196(16) & $26(1)$ & $0.053(1)$ \\
\hline$C(21 B)$ & 950(30) & $3530(40)$ & $4590(30)$ & $26(1)$ & $0.053(1)$ \\
\hline$C(22 B)$ & $3400(20)$ & $4547(15)$ & 2099(16) & $26(1)$ & $0.053(1)$ \\
\hline$C(23 B)$ & $3320(20)$ & $5898(17)$ & $2060(20)$ & $26(1)$ & $0.053(1)$ \\
\hline
\end{tabular}


Table 3. Bond lengths $[\AA \AA]$ and angles $\left[{ }^{\circ}\right]$ for $2 a$

\begin{tabular}{|c|c|c|c|}
\hline $\mathrm{S}(1)-\mathrm{O}(1)$ & $1.4393(7)$ & $\mathrm{F}(3)-\mathrm{C}(24)-\mathrm{F}(1)$ & $107.72(7)$ \\
\hline $\mathrm{S}(1)-\mathrm{O}(2)$ & $1.4422(7)$ & $\mathrm{F}(3)-\mathrm{C}(24)-\mathrm{F}(2)$ & $107.67(7)$ \\
\hline $\mathrm{S}(1)-\mathrm{O}(3)$ & $1.4478(7)$ & $\mathrm{F}(1)-\mathrm{C}(24)-\mathrm{F}(2)$ & $107.37(7)$ \\
\hline$S(1)-C(24)$ & $1.8259(9)$ & $\mathrm{F}(3)-\mathrm{C}(24)-\mathrm{S}(1)$ & $111.68(6)$ \\
\hline $\mathrm{F}(1)-\mathrm{C}(24)$ & $1.3386(10)$ & $\mathrm{F}(1)-\mathrm{C}(24)-\mathrm{S}(1)$ & $111.33(6)$ \\
\hline$F(2)-C(24)$ & $1.3414(11)$ & $\mathrm{F}(2)-\mathrm{C}(24)-\mathrm{S}(1)$ & $110.88(6)$ \\
\hline $\mathrm{F}(3)-\mathrm{C}(24)$ & $1.3358(10)$ & $\mathrm{N}(3)-\mathrm{P}(1)-\mathrm{N}(2)$ & $107.97(4)$ \\
\hline $\mathrm{P}(1)-\mathrm{N}(3)$ & $1.6219(8)$ & $\mathrm{N}(3)-\mathrm{P}(1)-\mathrm{N}(1)$ & $109.67(4)$ \\
\hline $\mathrm{P}(1)-\mathrm{N}(2)$ & $1.8136(8)$ & $\mathrm{N}(2)-\mathrm{P}(1)-\mathrm{N}(1)$ & $70.49(3)$ \\
\hline $\mathrm{P}(1)-\mathrm{N}(1)$ & $1.8237(8)$ & $\mathrm{C}(1 \mathrm{~B})-\mathrm{N}(1)-\mathrm{C}(1)$ & $43.1(3)$ \\
\hline $\mathrm{N}(1)-\mathrm{C}(1 \mathrm{~B})$ & $1.307(9)$ & $\mathrm{C}(1 \mathrm{~B})-\mathrm{N}(1)-\mathrm{C}(2)$ & $126.4(4)$ \\
\hline $\mathrm{N}(1)-\mathrm{C}(1)$ & $1.3306(11)$ & $\mathrm{C}(1)-\mathrm{N}(1)-\mathrm{C}(2)$ & $131.05(7)$ \\
\hline $\mathrm{N}(1)-\mathrm{C}(2)$ & $1.4427(10)$ & $\mathrm{C}(1 \mathrm{~B})-\mathrm{N}(1)-\mathrm{P}(1 \mathrm{~B})$ & $95.4(5)$ \\
\hline $\mathrm{N}(1)-\mathrm{P}(1 \mathrm{~B})$ & $1.801(5)$ & $\mathrm{C}(1)-\mathrm{N}(1)-\mathrm{P}(1 \mathrm{~B})$ & $74.02(17)$ \\
\hline $\mathrm{N}(2)-\mathrm{C}(1 \mathrm{~B})$ & $1.310(9)$ & $\mathrm{C}(2)-\mathrm{N}(1)-\mathrm{P}(1 \mathrm{~B})$ & $137.88(17)$ \\
\hline $\mathrm{N}(2)-\mathrm{C}(1)$ & $1.3279(11)$ & $\mathrm{C}(1 \mathrm{~B})-\mathrm{N}(1)-\mathrm{P}(1)$ & 61.1(2) \\
\hline $\mathrm{N}(2)-\mathrm{C}(11)$ & $1.4395(10)$ & $\mathrm{C}(1)-\mathrm{N}(1)-\mathrm{P}(1)$ & $91.02(5)$ \\
\hline $\mathrm{N}(2)-\mathrm{P}(1 \mathrm{~B})$ & $1.927(5)$ & $\mathrm{C}(2)-\mathrm{N}(1)-\mathrm{P}(1)$ & $127.89(6)$ \\
\hline $\mathrm{N}(3)-\mathrm{C}(20)$ & $1.4780(13)$ & $\mathrm{P}(1 \mathrm{~B})-\mathrm{N}(1)-\mathrm{P}(1)$ & $74.17(17)$ \\
\hline $\mathrm{N}(3)-\mathrm{C}(22)$ & $1.4903(12)$ & $\mathrm{C}(1 \mathrm{~B})-\mathrm{N}(2)-\mathrm{C}(1)$ & $43.1(3)$ \\
\hline$C(2)-C(3)$ & $1.4028(11)$ & $\mathrm{C}(1 \mathrm{~B})-\mathrm{N}(2)-\mathrm{C}(11)$ & $139.6(4)$ \\
\hline$C(2)-C(7)$ & $1.4031(11)$ & $\mathrm{C}(1)-\mathrm{N}(2)-\mathrm{C}(11)$ & $130.79(7)$ \\
\hline$C(3)-C(4)$ & $1.3952(12)$ & $\mathrm{C}(1 \mathrm{~B})-\mathrm{N}(2)-\mathrm{P}(1)$ & $61.4(2)$ \\
\hline$C(3)-C(8)$ & $1.5052(12)$ & $\mathrm{C}(1)-\mathrm{N}(2)-\mathrm{P}(1)$ & $91.55(5)$ \\
\hline$C(4)-C(5)$ & $1.3897(12)$ & $\mathrm{C}(11)-\mathrm{N}(2)-\mathrm{P}(1)$ & $135.89(6)$ \\
\hline$C(5)-C(6)$ & $1.3940(12)$ & $\mathrm{C}(1 \mathrm{~B})-\mathrm{N}(2)-\mathrm{P}(1 \mathrm{~B})$ & $89.6(4)$ \\
\hline$C(5)-C(9)$ & $1.5127(12)$ & $\mathrm{C}(1)-\mathrm{N}(2)-\mathrm{P}(1 \mathrm{~B})$ & $69.62(16)$ \\
\hline$C(6)-C(7)$ & $1.3971(12)$ & $\mathrm{C}(11)-\mathrm{N}(2)-\mathrm{P}(1 \mathrm{~B})$ & $128.67(16)$ \\
\hline$C(7)-C(10)$ & $1.5083(12)$ & $\mathrm{P}(1)-\mathrm{N}(2)-\mathrm{P}(1 \mathrm{~B})$ & 71.43(16) \\
\hline$C(11)-C(16)$ & $1.4010(12)$ & $\mathrm{C}(20)-\mathrm{N}(3)-\mathrm{C}(22)$ & $116.49(7)$ \\
\hline $\mathrm{C}(11)-\mathrm{C}(12)$ & $1.4033(12)$ & $\mathrm{C}(20)-\mathrm{N}(3)-\mathrm{P}(1)$ & $126.69(7)$ \\
\hline $\mathrm{C}(12)-\mathrm{C}(13)$ & $1.3985(12)$ & $\mathrm{C}(22)-\mathrm{N}(3)-\mathrm{P}(1)$ & $116.43(7)$ \\
\hline$C(12)-C(17)$ & $1.5033(12)$ & $\mathrm{N}(2)-\mathrm{C}(1)-\mathrm{N}(1)$ & $104.29(7)$ \\
\hline$C(13)-C(14)$ & $1.3921(13)$ & $\mathrm{C}(3)-\mathrm{C}(2)-\mathrm{C}(7)$ & $122.50(7)$ \\
\hline $\mathrm{C}(14)-\mathrm{C}(15)$ & $1.3941(13)$ & $\mathrm{C}(3)-\mathrm{C}(2)-\mathrm{N}(1)$ & $117.55(7)$ \\
\hline$C(14)-C(18)$ & $1.5112(12)$ & $\mathrm{C}(7)-\mathrm{C}(2)-\mathrm{N}(1)$ & $119.55(7)$ \\
\hline $\mathrm{C}(15)-\mathrm{C}(16)$ & $1.3897(12)$ & $C(4)-C(3)-C(2)$ & $117.41(8)$ \\
\hline$C(16)-C(19)$ & $1.5112(12)$ & $C(4)-C(3)-C(8)$ & $120.43(8)$ \\
\hline $\mathrm{C}(20)-\mathrm{C}(21)$ & $1.5267(15)$ & $C(2)-C(3)-C(8)$ & $122.11(7)$ \\
\hline $\mathrm{C}(22)-\mathrm{C}(23)$ & $1.5305(13)$ & $C(5)-C(4)-C(3)$ & 121.91(8) \\
\hline $\mathrm{P}(1 \mathrm{~B})-\mathrm{N}(3 \mathrm{~B})$ & $1.647(17)$ & $C(4)-C(5)-C(6)$ & $118.95(8)$ \\
\hline $\mathrm{N}(3 \mathrm{~B})-\mathrm{C}(22 \mathrm{~B})$ & $1.420(9)$ & $C(4)-C(5)-C(9)$ & $119.99(8)$ \\
\hline $\mathrm{N}(3 \mathrm{~B})-\mathrm{C}(20 \mathrm{~B})$ & $1.421(9)$ & $C(6)-C(5)-C(9)$ & $121.04(8)$ \\
\hline $\mathrm{C}(20 \mathrm{~B})-\mathrm{C}(21 \mathrm{~B})$ & $1.546(10)$ & $C(5)-C(6)-C(7)$ & $121.60(8)$ \\
\hline \multirow[t]{2}{*}{$\mathrm{C}(22 \mathrm{~B})-\mathrm{C}(23 \mathrm{~B})$} & $1.556(10)$ & $C(6)-C(7)-C(2)$ & $117.53(8)$ \\
\hline & & $C(6)-C(7)-C(10)$ & 119.91(8) \\
\hline $\mathrm{O}(1)-\mathrm{S}(1)-\mathrm{O}(2)$ & $115.76(5)$ & $C(2)-C(7)-C(10)$ & $122.56(7)$ \\
\hline $\mathrm{O}(1)-\mathrm{S}(1)-\mathrm{O}(3)$ & $115.25(4)$ & $\mathrm{C}(16)-\mathrm{C}(11)-\mathrm{C}(12)$ & $121.97(7)$ \\
\hline $\mathrm{O}(2)-\mathrm{S}(1)-\mathrm{O}(3)$ & $114.03(4)$ & $\mathrm{C}(16)-\mathrm{C}(11)-\mathrm{N}(2)$ & $118.88(7)$ \\
\hline $\mathrm{O}(1)-\mathrm{S}(1)-\mathrm{C}(24)$ & $103.24(4)$ & $\mathrm{C}(12)-\mathrm{C}(11)-\mathrm{N}(2)$ & $119.11(7)$ \\
\hline $\mathrm{O}(2)-\mathrm{S}(1)-\mathrm{C}(24)$ & $103.38(4)$ & $\mathrm{C}(13)-\mathrm{C}(12)-\mathrm{C}(11)$ & $117.44(8)$ \\
\hline $\mathrm{O}(3)-\mathrm{S}(1)-\mathrm{C}(24)$ & $102.70(4)$ & $\mathrm{C}(13)-\mathrm{C}(12)-\mathrm{C}(17)$ & $120.95(8)$ \\
\hline
\end{tabular}




$\begin{array}{llll}\mathrm{C}(11)-\mathrm{C}(12)-\mathrm{C}(17) & 121.60(8) & \mathrm{N}(3)-\mathrm{C}(22)-\mathrm{C}(23) & 111.74(8) \\ \mathrm{C}(14)-\mathrm{C}(13)-\mathrm{C}(12) & 122.07(8) & \mathrm{N}(3 \mathrm{~B})-\mathrm{P}(1 \mathrm{~B})-\mathrm{N}(1) & 102.2(6) \\ \mathrm{C}(13)-\mathrm{C}(14)-\mathrm{C}(15) & 118.41(8) & \mathrm{N}(3 \mathrm{~B})-\mathrm{P}(1 \mathrm{~B})-\mathrm{N}(2) & 98.4(6) \\ \mathrm{C}(13)-\mathrm{C}(14)-\mathrm{C}(18) & 120.96(8) & \mathrm{N}(1)-\mathrm{P}(1 \mathrm{~B})-\mathrm{N}(2) & 68.43(18) \\ \mathrm{C}(15)-\mathrm{C}(14)-\mathrm{C}(18) & 120.62(8) & \mathrm{C}(22 \mathrm{~B})-\mathrm{N}(3 \mathrm{~B})-\mathrm{C}(20 \mathrm{~B}) & 115.8(16) \\ \mathrm{C}(16)-\mathrm{C}(15)-\mathrm{C}(14) & 121.87(8) & \mathrm{C}(22 \mathrm{~B})-\mathrm{N}(3 \mathrm{~B})-\mathrm{P}(1 \mathrm{~B}) & 129.2(13) \\ \mathrm{C}(15)-\mathrm{C}(16)-\mathrm{C}(11) & 118.05(8) & \mathrm{C}(20 \mathrm{~B})-\mathrm{N}(3 \mathrm{~B})-\mathrm{P}(1 \mathrm{~B}) & 114.9(14) \\ \mathrm{C}(15)-\mathrm{C}(16)-\mathrm{C}(19) & 120.28(8) & \mathrm{N}(2)-\mathrm{C}(1 \mathrm{~B})-\mathrm{N}(1) & 106.7(7) \\ \mathrm{C}(11)-\mathrm{C}(16)-\mathrm{C}(19) & 121.66(8) & \mathrm{N}(3 \mathrm{~B})-\mathrm{C}(20 \mathrm{~B})-\mathrm{C}(21 \mathrm{~B}) & 105.5(18) \\ \mathrm{N}(3)-\mathrm{C}(20)-\mathrm{C}(21) & 111.86(8) & \mathrm{N}(3 \mathrm{~B})-\mathrm{C}(22 \mathrm{~B})-\mathrm{C}(23 \mathrm{~B}) & 113.1(16)\end{array}$

Symmetry transformations used to generate equivalent atoms: 
Table 4. Anisotropic displacement parameters $\left(\AA^{2} \times 10^{4}\right)$ for $2 \mathrm{a}$. The anisotropic displacement factor exponent takes the form: $-2 \pi^{2}\left[h^{2} a^{* 2} U^{11}+\ldots+2 h k^{*} b^{*} U^{12}\right]$

\begin{tabular}{|c|c|c|c|c|c|c|}
\hline & $\mathrm{U}^{11}$ & $\mathrm{U}^{22}$ & $\mathrm{U}^{33}$ & $\mathrm{U}^{23}$ & $\mathrm{U}^{13}$ & $\mathrm{U}^{12}$ \\
\hline $\mathrm{S}(1)$ & $164(1)$ & $146(1)$ & $180(1)$ & $-50(1)$ & $-55(1)$ & $-42(1)$ \\
\hline $\mathrm{F}(1)$ & $343(3)$ & 241(3) & $243(3)$ & $-129(2)$ & $-91(2)$ & $-83(2)$ \\
\hline $\mathrm{F}(2)$ & $347(3)$ & $207(3)$ & $203(3)$ & $-27(2)$ & $-11(2)$ & $-136(2)$ \\
\hline $\mathrm{F}(3)$ & $156(3)$ & $324(3)$ & $408(4)$ & $-149(3)$ & $-81(3)$ & $-34(2)$ \\
\hline $\mathrm{O}(1)$ & $165(3)$ & $272(4)$ & $455(5)$ & $-140(3)$ & $-115(3)$ & 7(3) \\
\hline $\mathrm{O}(2)$ & $345(4)$ & $219(4)$ & $180(3)$ & $-8(3)$ & $-57(3)$ & $-139(3)$ \\
\hline $\mathrm{O}(3)$ & $334(4)$ & $173(3)$ & $209(3)$ & $-81(3)$ & $-122(3)$ & $-39(3)$ \\
\hline $\mathrm{C}(24)$ & $188(4)$ & 161(4) & 171(4) & $-66(3)$ & $-38(3)$ & $-40(3)$ \\
\hline $\mathrm{P}(1)$ & $136(1)$ & $114(1)$ & 143(1) & $-16(1)$ & $-55(1)$ & $-37(1)$ \\
\hline $\mathrm{N}(1)$ & $129(3)$ & $138(3)$ & $150(3)$ & $-36(3)$ & $-44(3)$ & $-37(2)$ \\
\hline $\mathrm{N}(2)$ & $153(3)$ & 139(3) & 177(3) & $-46(3)$ & $-57(3)$ & $-43(3)$ \\
\hline $\mathrm{N}(3)$ & 144(3) & $106(4)$ & $162(4)$ & $-10(3)$ & $-56(3)$ & $-29(3)$ \\
\hline $\mathrm{C}(1)$ & $140(4)$ & 101(4) & $139(4)$ & $-20(3)$ & $-51(3)$ & $-25(3)$ \\
\hline$C(2)$ & $118(3)$ & $118(4)$ & $156(4)$ & $-27(3)$ & $-50(3)$ & $-33(3)$ \\
\hline $\mathrm{C}(3)$ & $139(4)$ & $133(4)$ & $163(4)$ & $-39(3)$ & $-51(3)$ & $-26(3)$ \\
\hline$C(4)$ & $157(4)$ & $169(4)$ & 201(4) & $-70(3)$ & $-73(3)$ & $-32(3)$ \\
\hline$C(5)$ & $130(4)$ & 161(4) & $200(4)$ & $-39(3)$ & $-67(3)$ & $-35(3)$ \\
\hline$C(6)$ & $135(4)$ & $186(4)$ & $163(4)$ & $-53(3)$ & $-28(3)$ & $-41(3)$ \\
\hline$C(7)$ & $153(4)$ & $134(4)$ & $143(4)$ & $-32(3)$ & $-53(3)$ & $-27(3)$ \\
\hline $\mathrm{C}(8)$ & 189(4) & $227(5)$ & 193(4) & $-99(4)$ & $-18(3)$ & $-72(3)$ \\
\hline $\mathrm{C}(9)$ & $159(4)$ & $279(5)$ & $268(5)$ & $-94(4)$ & $-44(4)$ & $-89(4)$ \\
\hline$C(10)$ & 194(4) & $243(5)$ & $174(4)$ & $-88(4)$ & $-31(3)$ & $-85(3)$ \\
\hline $\mathrm{C}(11)$ & $133(4)$ & $124(4)$ & $165(4)$ & $-54(3)$ & $-41(3)$ & $-35(3)$ \\
\hline$C(12)$ & $180(4)$ & $134(4)$ & $143(4)$ & $-47(3)$ & $-39(3)$ & $-36(3)$ \\
\hline $\mathrm{C}(13)$ & $174(4)$ & 161(4) & $174(4)$ & $-50(3)$ & $-10(3)$ & $-67(3)$ \\
\hline$C(14)$ & $138(4)$ & $174(4)$ & $241(4)$ & $-88(4)$ & $-46(3)$ & $-39(3)$ \\
\hline$C(15)$ & 191(4) & $185(4)$ & $180(4)$ & $-78(3)$ & $-74(3)$ & $-34(3)$ \\
\hline$C(16)$ & $156(4)$ & $140(4)$ & $144(4)$ & $-49(3)$ & $-35(3)$ & $-27(3)$ \\
\hline $\mathrm{C}(17)$ & $360(5)$ & $201(5)$ & $165(4)$ & $-23(4)$ & $-96(4)$ & $-119(4)$ \\
\hline $\mathrm{C}(18)$ & $219(5)$ & $331(6)$ & $350(6)$ & $-135(5)$ & $-64(4)$ & $-130(4)$ \\
\hline C(19) & $262(5)$ & $227(5)$ & $155(4)$ & $-62(4)$ & $-22(4)$ & $-95(4)$ \\
\hline $\mathrm{C}(20)$ & $173(4)$ & $164(5)$ & $157(4)$ & $-37(4)$ & $-47(4)$ & $-44(3)$ \\
\hline $\mathrm{C}(21)$ & $204(5)$ & $304(6)$ & 193(6) & $-34(6)$ & $-19(5)$ & $-115(4)$ \\
\hline $\mathrm{C}(22)$ & $167(4)$ & $113(4)$ & $233(5)$ & $-14(3)$ & $-96(4)$ & $-24(3)$ \\
\hline $\mathrm{C}(23)$ & $330(6)$ & $173(5)$ & $372(6)$ & $-21(5)$ & $-169(5)$ & $-119(4)$ \\
\hline
\end{tabular}

Table 5. Torsion angles $\left[{ }^{\circ}\right]$ for $2 a$.

\begin{tabular}{lc}
\hline $\mathrm{C}(3)-\mathrm{C}(2)-\mathrm{N}(1)-\mathrm{P}(1)$ & $100.02(9)$ \\
$\mathrm{C}(3)-\mathrm{C}(2)-\mathrm{N}(1)-\mathrm{P}(1 \mathrm{~B})$ & $-10.2(3)$ \\
& \\
$\mathrm{C}(12)-\mathrm{C}(11)-\mathrm{N}(2)-\mathrm{P}(1)$ & $-126.93(8)$ \\
$\mathrm{C}(12)-\mathrm{C}(11)-\mathrm{N}(1)-\mathrm{P}(1 \mathrm{~B})$ & $-37.8(2)$ \\
\hline
\end{tabular}




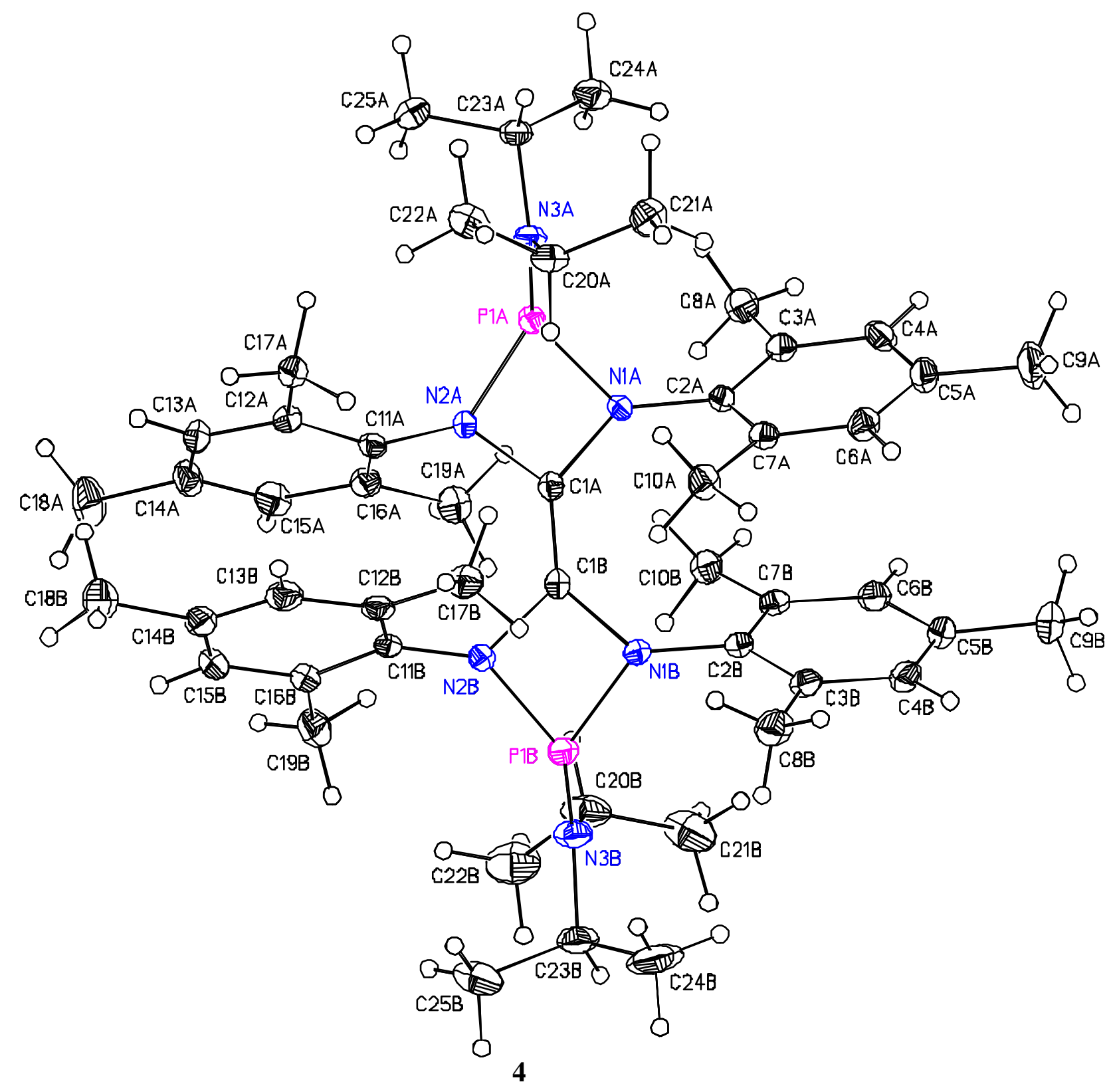

\section{Special Refinement Details}

Refinement of $\mathrm{F}^{2}$ against ALL reflections. The weighted R-factor $(w \mathrm{R})$ and goodness of fit $(\mathrm{S})$ are based on $\mathrm{F}^{2}$, conventional $\mathrm{R}$-factors (R) are based on $\mathrm{F}$, with $\mathrm{F}$ set to zero for negative $\mathrm{F}^{2}$. The threshold expression of $F^{2}>2 \sigma\left(F^{2}\right)$ is used only for calculating R-factors(gt) etc. and is not relevant to the choice of reflections for refinement. R-factors based on $\mathrm{F}^{2}$ are statistically about twice as large as those based on $\mathrm{F}$, and R-factors based on ALL data will be even larger.

All esds (except the esd in the dihedral angle between two 1.s. planes) are estimated using the full covariance matrix. The cell esds are taken into account individually in the estimation of esds in distances, angles and torsion angles; correlations between esds in cell parameters are only used when they are defined by crystal symmetry. An approximate (isotropic) treatment of cell esds is used for estimating esds involving l.s. planes. 
Table 1. Crystal data and structure refinement for EMD05 (CCDC 231890).

Identification code

Empirical formula

Formula weight

Crystal size

Crystal color

Wavelength

Data Collection Temperature

Unit cell dimensions

Volume

$\mathrm{Z}$

Crystal system

Space group

Density (calculated)

$\mathrm{F}(000)$

$\theta$ range for data collection

Completeness to $\theta=31.93^{\circ}$

Index ranges

Reflections collected

Independent reflections

Absorption coefficient

Absorption correction

Max. and min. transmission

Refinement method

Data / restraints / parameters

Goodness-of-fit on $\mathrm{F}^{2}$

Final $R$ indices [I>2 $\sigma(\mathrm{I}), 8893$ reflections]

$\mathrm{R}$ indices (all data)

Largest diff. peak and hole
4

$\mathrm{C}_{50} \mathrm{H}_{72} \mathrm{~N}_{6} \mathrm{P}_{2}$

819.08

$0.33 \times 0.31 \times 0.21 \mathrm{~mm}^{3}$

Yellow

$0.71073 \AA \mathrm{MoK} \alpha$

$100(2) \mathrm{K}$

$\mathrm{a}=13.7626(6) \AA$

$\mathrm{b}=16.2123(8) \AA$

$\mathrm{c}=21.7085(10) \AA$

$\beta=101.3420(10)^{\circ}$

4749.1(4) $\AA^{3}$

4

Monoclinic

$\mathrm{P}_{1} / \mathrm{c}$

$1.146 \mathrm{Mg} / \mathrm{m}^{3}$

1776

1.58 to $31.93^{\circ}$

$88.9 \%$

$-20 \leq \mathrm{h} \leq 20,-21 \leq \mathrm{k} \leq 23,-28 \leq 1 \leq 31$

76278

$14587\left[\mathrm{R}_{\mathrm{int}}=0.0787\right]$

$0.131 \mathrm{~mm}^{-1}$

None

0.9730 and 0.9580

Full matrix least-squares on $\mathrm{F}^{2}$

14587 / 0 / 811

1.445

$\mathrm{R} 1=0.0500, w \mathrm{R} 2=0.0728$

$\mathrm{R} 1=0.0950, w \mathrm{R} 2=0.0770$

0.698 and -0.521 e. $\AA^{-3}$ 


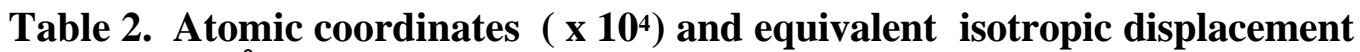
parameters $\left(\AA^{2} \times 10^{3}\right)$ for 4 . $U(e q)$ is defined as the trace of the orthogonalized $U^{i j}$ tensor.

\begin{tabular}{|c|c|c|c|c|}
\hline & $\mathrm{x}$ & $\mathrm{y}$ & $\mathrm{Z}$ & $\mathrm{U}_{\text {eq }}$ \\
\hline $\mathrm{P}(1 \mathrm{~A})$ & $3675(1)$ & $2692(1)$ & $196(1)$ & $15(1)$ \\
\hline $\mathrm{N}(1 \mathrm{~A})$ & $2622(1)$ & $2659(1)$ & $536(1)$ & $15(1)$ \\
\hline $\mathrm{N}(2 \mathrm{~A})$ & $4045(1)$ & $3153(1)$ & $937(1)$ & $14(1)$ \\
\hline $\mathrm{N}(3 \mathrm{~A})$ & $4103(1)$ & $1732(1)$ & $205(1)$ & $16(1)$ \\
\hline $\mathrm{C}(1 \mathrm{~A})$ & $3045(1)$ & $3175(1)$ & $1058(1)$ & $14(1)$ \\
\hline $\mathrm{C}(2 \mathrm{~A})$ & $1716(1)$ & $2215(1)$ & $366(1)$ & $15(1)$ \\
\hline$C(3 \mathrm{~A})$ & $1197(1)$ & $2243(1)$ & $-259(1)$ & $17(1)$ \\
\hline$C(4 A)$ & $325(1)$ & $1787(1)$ & $-430(1)$ & $22(1)$ \\
\hline$C(5 \mathrm{~A})$ & $-63(1)$ & 1319(1) & $-3(1)$ & $23(1)$ \\
\hline$C(6 A)$ & $468(1)$ & $1298(1)$ & $609(1)$ & $21(1)$ \\
\hline$C(7 A)$ & $1358(1)$ & $1716(1)$ & $803(1)$ & $17(1)$ \\
\hline $\mathrm{C}(8 \mathrm{~A})$ & 1532(1) & $2762(1)$ & $-755(1)$ & $22(1)$ \\
\hline $\mathrm{C}(9 \mathrm{~A})$ & $-1024(1)$ & $852(1)$ & $-189(1)$ & $35(1)$ \\
\hline$C(10 A)$ & 1919(1) & 1582(1) & $1462(1)$ & $21(1)$ \\
\hline$C(11 A)$ & $4770(1)$ & $3807(1)$ & $1025(1)$ & $16(1)$ \\
\hline $\mathrm{C}(12 \mathrm{~A})$ & $5750(1)$ & $3584(1)$ & $1296(1)$ & $18(1)$ \\
\hline$C(13 A)$ & $6479(1)$ & 4191(1) & 1381(1) & 21(1) \\
\hline $\mathrm{C}(14 \mathrm{~A})$ & $6274(1)$ & $5005(1)$ & $1207(1)$ & $22(1)$ \\
\hline$C(15 A)$ & $5314(1)$ & $5199(1)$ & 914(1) & $22(1)$ \\
\hline$C(16 A)$ & $4554(1)$ & $4616(1)$ & $812(1)$ & $18(1)$ \\
\hline $\mathrm{C}(17 \mathrm{~A})$ & $6022(1)$ & 2712(1) & $1482(1)$ & $21(1)$ \\
\hline $\mathrm{C}(18 \mathrm{~A})$ & $7066(1)$ & $5658(1)$ & $1340(1)$ & $36(1)$ \\
\hline$C(19 A)$ & $3535(1)$ & $4869(1)$ & $476(1)$ & $22(1)$ \\
\hline $\mathrm{C}(20 \mathrm{~A})$ & $4037(1)$ & 1102(1) & $689(1)$ & $20(1)$ \\
\hline $\mathrm{C}(21 \mathrm{~A})$ & $3281(1)$ & 437(1) & $434(1)$ & $26(1)$ \\
\hline $\mathrm{C}(22 \mathrm{~A})$ & $5036(1)$ & 717(1) & $968(1)$ & $25(1)$ \\
\hline $\mathrm{C}(23 \mathrm{~A})$ & $4520(1)$ & 1451(1) & $-345(1)$ & $19(1)$ \\
\hline $\mathrm{C}(24 \mathrm{~A})$ & $3789(1)$ & $1517(1)$ & $-963(1)$ & $26(1)$ \\
\hline$C(25 A)$ & $5497(1)$ & $1875(1)$ & $-368(1)$ & $30(1)$ \\
\hline $\mathrm{P}(1 \mathrm{~B})$ & 2181(1) & $4122(1)$ & $2386(1)$ & $17(1)$ \\
\hline $\mathrm{N}(1 \mathrm{~B})$ & 1729(1) & $3657(1)$ & 1661(1) & $15(1)$ \\
\hline $\mathrm{N}(2 \mathrm{~B})$ & $3183(1)$ & $4125(1)$ & 1992(1) & $15(1)$ \\
\hline $\mathrm{N}(3 \mathrm{~B})$ & $1672(1)$ & $5054(1)$ & $2364(1)$ & $23(1)$ \\
\hline $\mathrm{C}(1 \mathrm{~B})$ & 2681(1) & $3602(1)$ & $1488(1)$ & $14(1)$ \\
\hline $\mathrm{C}(2 \mathrm{~B})$ & 751(1) & $3461(1)$ & $1340(1)$ & $17(1)$ \\
\hline $\mathrm{C}(3 \mathrm{~B})$ & 121(1) & $3016(1)$ & 1659(1) & 19(1) \\
\hline$C(4 B)$ & $-841(1)$ & $2843(1)$ & $1343(1)$ & $24(1)$ \\
\hline $\mathrm{C}(5 \mathrm{~B})$ & $-1193(1)$ & $3075(1)$ & 727(1) & $24(1)$ \\
\hline $\mathrm{C}(6 \mathrm{~B})$ & $-558(1)$ & $3520(1)$ & $427(1)$ & $21(1)$ \\
\hline $\mathrm{C}(7 \mathrm{~B})$ & 397(1) & $3731(1)$ & $720(1)$ & $17(1)$ \\
\hline $\mathrm{C}(8 \mathrm{~B})$ & $450(1)$ & $2698(1)$ & 2319(1) & $27(1)$ \\
\hline $\mathrm{C}(9 \mathrm{~B})$ & $-2222(1)$ & $2852(1)$ & 383(1) & $34(1)$ \\
\hline $\mathrm{C}(10 \mathrm{~B})$ & 1010(1) & $4257(1)$ & 373(1) & $20(1)$ \\
\hline $\mathrm{C}(11 \mathrm{~B})$ & $4189(1)$ & $4023(1)$ & $2325(1)$ & $16(1)$ \\
\hline $\mathrm{C}(12 \mathrm{~B})$ & $4567(1)$ & $3262(1)$ & $2570(1)$ & $19(1)$ \\
\hline $\mathrm{C}(13 \mathrm{~B})$ & $5559(1)$ & $3215(1)$ & $2868(1)$ & $24(1)$ \\
\hline
\end{tabular}




$\begin{array}{lrrrr}\mathrm{C}(14 \mathrm{~B}) & 6180(1) & 3900(1) & 2933(1) & 26(1) \\ \mathrm{C}(15 \mathrm{~B}) & 5770(1) & 4648(1) & 2725(1) & 25(1) \\ \mathrm{C}(16 \mathrm{~B}) & 4782(1) & 4731(1) & 2426(1) & 20(1) \\ \mathrm{C}(17 \mathrm{~B}) & 3933(1) & 2503(1) & 2530(1) & 22(1) \\ \mathrm{C}(18 \mathrm{~B}) & 7272(1) & 3811(2) & 3215(1) & 41(1) \\ \mathrm{C}(19 \mathrm{~B}) & 4369(1) & 5566(1) & 2231(1) & 28(1) \\ \mathrm{C}(20 \mathrm{~B}) & 1435(1) & 5589(1) & 1803(1) & 32(1) \\ \mathrm{C}(21 \mathrm{~B}) & 328(2) & 5615(1) & 1542(1) & 43(1) \\ \mathrm{C}(22 \mathrm{~B}) & 1851(2) & 6458(1) & 1912(1) & 40(1) \\ \mathrm{C}(23 \mathrm{~B}) & 1350(1) & 5357(1) & 2943(1) & 27(1) \\ \mathrm{C}(24 \mathrm{~B}) & 691(2) & 4739(1) & 3194(1) & 55(1) \\ \mathrm{C}(25 \mathrm{~B}) & 2227(2) & 5612(1) & 3445(1) & 35(1)\end{array}$


Table 3. Bond lengths $[\AA]$ and angles $\left[{ }^{\circ}\right]$ for 4 .

\begin{tabular}{|c|c|c|c|}
\hline $\mathrm{P}(1 \mathrm{~A})-\mathrm{N}(3 \mathrm{~A})$ & $1.6626(11)$ & $\mathrm{C}(20 \mathrm{~A})-\mathrm{C}(22 \mathrm{~A})$ & $1.523(2)$ \\
\hline $\mathrm{P}(1 \mathrm{~A})-\mathrm{N}(1 \mathrm{~A})$ & $1.7513(11)$ & $\mathrm{C}(20 \mathrm{~A})-\mathrm{C}(21 \mathrm{~A})$ & $1.526(2)$ \\
\hline $\mathrm{P}(1 \mathrm{~A})-\mathrm{N}(2 \mathrm{~A})$ & $1.7557(11)$ & $\mathrm{C}(20 \mathrm{~A})-\mathrm{H}(20 \mathrm{~A})$ & $1.003(12)$ \\
\hline $\mathrm{P}(1 \mathrm{~A})-\mathrm{C}(1 \mathrm{~A})$ & $2.3478(14)$ & $\mathrm{C}(21 \mathrm{~A})-\mathrm{H}(21 \mathrm{~A})$ & $0.978(14)$ \\
\hline $\mathrm{N}(1 \mathrm{~A})-\mathrm{C}(2 \mathrm{~A})$ & $1.4239(15)$ & $\mathrm{C}(21 \mathrm{~A})-\mathrm{H}(21 \mathrm{~B})$ & $1.030(14)$ \\
\hline N(1A)-C(1A) & $1.4374(16)$ & $\mathrm{C}(21 \mathrm{~A})-\mathrm{H}(21 \mathrm{C})$ & $0.994(15)$ \\
\hline $\mathrm{N}(2 \mathrm{~A})-\mathrm{C}(11 \mathrm{~A})$ & $1.4436(16)$ & $\mathrm{C}(22 \mathrm{~A})-\mathrm{H}(22 \mathrm{~A})$ & $1.011(14)$ \\
\hline $\mathrm{N}(2 \mathrm{~A})-\mathrm{C}(1 \mathrm{~A})$ & $1.4520(15)$ & $\mathrm{C}(22 \mathrm{~A})-\mathrm{H}(22 \mathrm{~B})$ & $1.008(15)$ \\
\hline $\mathrm{N}(3 \mathrm{~A})-\mathrm{C}(20 \mathrm{~A})$ & $1.4798(17)$ & $\mathrm{C}(22 \mathrm{~A})-\mathrm{H}(22 \mathrm{C})$ & $0.960(15)$ \\
\hline $\mathrm{N}(3 \mathrm{~A})-\mathrm{C}(23 \mathrm{~A})$ & $1.4937(16)$ & $C(23 A)-C(24 A)$ & $1.515(2)$ \\
\hline $\mathrm{C}(1 \mathrm{~A})-\mathrm{C}(1 \mathrm{~B})$ & $1.3335(17)$ & $\mathrm{C}(23 \mathrm{~A})-\mathrm{C}(25 \mathrm{~A})$ & $1.520(2)$ \\
\hline $\mathrm{C}(2 \mathrm{~A})-\mathrm{C}(3 \mathrm{~A})$ & $1.4056(18)$ & $\mathrm{C}(23 \mathrm{~A})-\mathrm{H}(23 \mathrm{~A})$ & $0.982(12)$ \\
\hline $\mathrm{C}(2 \mathrm{~A})-\mathrm{C}(7 \mathrm{~A})$ & $1.4085(18)$ & $\mathrm{C}(24 \mathrm{~A})-\mathrm{H}(24 \mathrm{~A})$ & $0.990(14)$ \\
\hline $\mathrm{C}(3 \mathrm{~A})-\mathrm{C}(4 \mathrm{~A})$ & $1.3953(18)$ & $\mathrm{C}(24 \mathrm{~A})-\mathrm{H}(24 \mathrm{~B})$ & $0.999(14)$ \\
\hline $\mathrm{C}(3 \mathrm{~A})-\mathrm{C}(8 \mathrm{~A})$ & $1.508(2)$ & $\mathrm{C}(24 \mathrm{~A})-\mathrm{H}(24 \mathrm{C})$ & $0.962(15)$ \\
\hline $\mathrm{C}(4 \mathrm{~A})-\mathrm{C}(5 \mathrm{~A})$ & $1.386(2)$ & $\mathrm{C}(25 \mathrm{~A})-\mathrm{H}(25 \mathrm{~A})$ & $0.998(17)$ \\
\hline $\mathrm{C}(4 \mathrm{~A})-\mathrm{H}(4 \mathrm{~A})$ & $0.979(12)$ & $\mathrm{C}(25 \mathrm{~A})-\mathrm{H}(25 \mathrm{~B})$ & $0.971(15)$ \\
\hline$C(5 A)-C(6 A)$ & $1.385(2)$ & $\mathrm{C}(25 \mathrm{~A})-\mathrm{H}(25 \mathrm{C})$ & $1.020(15)$ \\
\hline$C(5 A)-C(9 A)$ & $1.509(2)$ & $\mathrm{P}(1 \mathrm{~B})-\mathrm{N}(3 \mathrm{~B})$ & $1.6630(12)$ \\
\hline$C(6 A)-C(7 A)$ & $1.3898(18)$ & $\mathrm{P}(1 \mathrm{~B})-\mathrm{N}(1 \mathrm{~B})$ & $1.7451(11)$ \\
\hline $\mathrm{C}(6 \mathrm{~A})-\mathrm{H}(6 \mathrm{~A})$ & $0.979(13)$ & $\mathrm{P}(1 \mathrm{~B})-\mathrm{N}(2 \mathrm{~B})$ & $1.7595(11)$ \\
\hline $\mathrm{C}(7 \mathrm{~A})-\mathrm{C}(10 \mathrm{~A})$ & $1.501(2)$ & $\mathrm{P}(1 \mathrm{~B})-\mathrm{C}(1 \mathrm{~B})$ & $2.3482(14)$ \\
\hline $\mathrm{C}(8 \mathrm{~A})-\mathrm{H}(8 \mathrm{~A})$ & $0.967(15)$ & $\mathrm{N}(1 \mathrm{~B})-\mathrm{C}(2 \mathrm{~B})$ & $1.4237(16)$ \\
\hline $\mathrm{C}(8 \mathrm{~A})-\mathrm{H}(8 \mathrm{~B})$ & $0.981(16)$ & $\mathrm{N}(1 \mathrm{~B})-\mathrm{C}(1 \mathrm{~B})$ & $1.4358(15)$ \\
\hline $\mathrm{C}(8 \mathrm{~A})-\mathrm{H}(8 \mathrm{C})$ & $0.969(14)$ & $\mathrm{N}(2 \mathrm{~B})-\mathrm{C}(11 \mathrm{~B})$ & $1.4387(15)$ \\
\hline $\mathrm{C}(9 \mathrm{~A})-\mathrm{H}(9 \mathrm{~A})$ & $0.980(19)$ & $\mathrm{N}(2 \mathrm{~B})-\mathrm{C}(1 \mathrm{~B})$ & $1.4490(16)$ \\
\hline $\mathrm{C}(9 \mathrm{~A})-\mathrm{H}(9 \mathrm{~B})$ & $0.974(19)$ & $\mathrm{N}(3 \mathrm{~B})-\mathrm{C}(20 \mathrm{~B})$ & $1.4797(19)$ \\
\hline $\mathrm{C}(9 \mathrm{~A})-\mathrm{H}(9 \mathrm{C})$ & $0.994(19)$ & $\mathrm{N}(3 \mathrm{~B})-\mathrm{C}(23 \mathrm{~B})$ & $1.4947(18)$ \\
\hline $\mathrm{C}(10 \mathrm{~A})-\mathrm{H}(10 \mathrm{~A})$ & $1.003(14)$ & $\mathrm{C}(2 \mathrm{~B})-\mathrm{C}(7 \mathrm{~B})$ & $1.4082(18)$ \\
\hline $\mathrm{C}(10 \mathrm{~A})-\mathrm{H}(10 \mathrm{~B})$ & $0.998(14)$ & $\mathrm{C}(2 \mathrm{~B})-\mathrm{C}(3 \mathrm{~B})$ & $1.4088(18)$ \\
\hline $\mathrm{C}(10 \mathrm{~A})-\mathrm{H}(10 \mathrm{C})$ & $0.956(15)$ & $C(3 B)-C(4 B)$ & $1.3947(19)$ \\
\hline $\mathrm{C}(11 \mathrm{~A})-\mathrm{C}(16 \mathrm{~A})$ & $1.4021(18)$ & $\mathrm{C}(3 \mathrm{~B})-\mathrm{C}(8 \mathrm{~B})$ & $1.507(2)$ \\
\hline $\mathrm{C}(11 \mathrm{~A})-\mathrm{C}(12 \mathrm{~A})$ & $1.4083(17)$ & $\mathrm{C}(4 \mathrm{~B})-\mathrm{C}(5 \mathrm{~B})$ & $1.382(2)$ \\
\hline $\mathrm{C}(12 \mathrm{~A})-\mathrm{C}(13 \mathrm{~A})$ & $1.3909(18)$ & $\mathrm{C}(4 \mathrm{~B})-\mathrm{H}(4 \mathrm{~B})$ & $0.970(13)$ \\
\hline $\mathrm{C}(12 \mathrm{~A})-\mathrm{C}(17 \mathrm{~A})$ & $1.4987(19)$ & $C(5 B)-C(6 B)$ & $1.388(2)$ \\
\hline $\mathrm{C}(13 \mathrm{~A})-\mathrm{C}(14 \mathrm{~A})$ & $1.386(2)$ & $C(5 B)-C(9 B)$ & $1.509(2)$ \\
\hline $\mathrm{C}(13 \mathrm{~A})-\mathrm{H}(13 \mathrm{~A})$ & $0.990(12)$ & $\mathrm{C}(6 \mathrm{~B})-\mathrm{C}(7 \mathrm{~B})$ & $1.3851(18)$ \\
\hline $\mathrm{C}(14 \mathrm{~A})-\mathrm{C}(15 \mathrm{~A})$ & $1.3845(19)$ & $\mathrm{C}(6 \mathrm{~B})-\mathrm{H}(6 \mathrm{~B})$ & $0.953(12)$ \\
\hline $\mathrm{C}(14 \mathrm{~A})-\mathrm{C}(18 \mathrm{~A})$ & $1.507(2)$ & $\mathrm{C}(7 \mathrm{~B})-\mathrm{C}(10 \mathrm{~B})$ & $1.5019(19)$ \\
\hline$C(15 A)-C(16 A)$ & 1.3959(19) & $\mathrm{C}(8 \mathrm{~B})-\mathrm{H}(8 \mathrm{D})$ & $0.938(19)$ \\
\hline $\mathrm{C}(15 \mathrm{~A})-\mathrm{H}(15 \mathrm{~A})$ & $0.936(13)$ & $\mathrm{C}(8 \mathrm{~B})-\mathrm{H}(8 \mathrm{E})$ & $0.961(16)$ \\
\hline$C(16 A)-C(19 A)$ & $1.5043(19)$ & $\mathrm{C}(8 \mathrm{~B})-\mathrm{H}(8 \mathrm{~F})$ & $0.954(18)$ \\
\hline $\mathrm{C}(17 \mathrm{~A})-\mathrm{H}(17 \mathrm{~A})$ & $1.002(14)$ & $\mathrm{C}(9 \mathrm{~B})-\mathrm{H}(9 \mathrm{D})$ & $0.989(16)$ \\
\hline $\mathrm{C}(17 \mathrm{~A})-\mathrm{H}(17 \mathrm{~B})$ & $1.004(13)$ & $\mathrm{C}(9 \mathrm{~B})-\mathrm{H}(9 \mathrm{E})$ & $1.005(18)$ \\
\hline $\mathrm{C}(17 \mathrm{~A})-\mathrm{H}(17 \mathrm{C})$ & $0.973(14)$ & $\mathrm{C}(9 \mathrm{~B})-\mathrm{H}(9 \mathrm{~F})$ & $0.974(18)$ \\
\hline $\mathrm{C}(18 \mathrm{~A})-\mathrm{H}(18 \mathrm{~A})$ & $0.988(18)$ & $\mathrm{C}(10 \mathrm{~B})-\mathrm{H}(10 \mathrm{D})$ & $0.976(14)$ \\
\hline $\mathrm{C}(18 \mathrm{~A})-\mathrm{H}(18 \mathrm{~B})$ & $0.957(16)$ & $\mathrm{C}(10 \mathrm{~B})-\mathrm{H}(10 \mathrm{E})$ & $0.961(14)$ \\
\hline $\mathrm{C}(18 \mathrm{~A})-\mathrm{H}(18 \mathrm{C})$ & $0.98(2)$ & $\mathrm{C}(10 \mathrm{~B})-\mathrm{H}(10 \mathrm{~F})$ & $1.025(15)$ \\
\hline C(19A)-H(19A) & $1.003(13)$ & $\mathrm{C}(11 \mathrm{~B})-\mathrm{C}(16 \mathrm{~B})$ & $1.4002(18)$ \\
\hline $\mathrm{C}(19 \mathrm{~A})-\mathrm{H}(19 \mathrm{~B})$ & $0.976(14)$ & $\mathrm{C}(11 \mathrm{~B})-\mathrm{C}(12 \mathrm{~B})$ & $1.4035(18)$ \\
\hline $\mathrm{C}(19 \mathrm{~A})-\mathrm{H}(19 \mathrm{C})$ & $0.986(15)$ & $\mathrm{C}(12 \mathrm{~B})-\mathrm{C}(13 \mathrm{~B})$ & $1.3922(18)$ \\
\hline
\end{tabular}




\begin{tabular}{|c|c|c|c|}
\hline $\mathrm{C}(12 \mathrm{~B})-\mathrm{C}(17 \mathrm{~B})$ & $1.502(2)$ & $\mathrm{C}(1 \mathrm{~B})-\mathrm{C}(1 \mathrm{~A})-\mathrm{P}(1 \mathrm{~A})$ & $168.05(10)$ \\
\hline$C(13 B)-C(14 B)$ & $1.391(2)$ & $\mathrm{N}(1 \mathrm{~A})-\mathrm{C}(1 \mathrm{~A})-\mathrm{P}(1 \mathrm{~A})$ & $48.06(6)$ \\
\hline $\mathrm{C}(13 \mathrm{~B})-\mathrm{H}(13 \mathrm{~B})$ & $0.989(13)$ & $\mathrm{N}(2 \mathrm{~A})-\mathrm{C}(1 \mathrm{~A})-\mathrm{P}(1 \mathrm{~A})$ & $48.27(6)$ \\
\hline $\mathrm{C}(14 \mathrm{~B})-\mathrm{C}(15 \mathrm{~B})$ & $1.376(2)$ & $\mathrm{C}(3 \mathrm{~A})-\mathrm{C}(2 \mathrm{~A})-\mathrm{C}(7 \mathrm{~A})$ & $119.37(12)$ \\
\hline$C(14 B)-C(18 B)$ & $1.515(2)$ & $\mathrm{C}(3 \mathrm{~A})-\mathrm{C}(2 \mathrm{~A})-\mathrm{N}(1 \mathrm{~A})$ & $119.15(12)$ \\
\hline$C(15 B)-C(16 B)$ & $1.3929(19)$ & $C(7 A)-C(2 A)-N(1 A)$ & $121.40(12)$ \\
\hline $\mathrm{C}(15 \mathrm{~B})-\mathrm{H}(15 \mathrm{~B})$ & $0.941(14)$ & $C(4 A)-C(3 A)-C(2 A)$ & $119.17(13)$ \\
\hline$C(16 B)-C(19 B)$ & $1.497(2)$ & $\mathrm{C}(4 \mathrm{~A})-\mathrm{C}(3 \mathrm{~A})-\mathrm{C}(8 \mathrm{~A})$ & $118.28(13)$ \\
\hline $\mathrm{C}(17 \mathrm{~B})-\mathrm{H}(17 \mathrm{D})$ & $0.974(14)$ & $\mathrm{C}(2 \mathrm{~A})-\mathrm{C}(3 \mathrm{~A})-\mathrm{C}(8 \mathrm{~A})$ & $122.54(12)$ \\
\hline $\mathrm{C}(17 \mathrm{~B})-\mathrm{H}(17 \mathrm{E})$ & $0.991(13)$ & $C(5 A)-C(4 A)-C(3 A)$ & $122.44(14)$ \\
\hline $\mathrm{C}(17 \mathrm{~B})-\mathrm{H}(17 \mathrm{~F})$ & $1.003(15)$ & $\mathrm{C}(5 \mathrm{~A})-\mathrm{C}(4 \mathrm{~A})-\mathrm{H}(4 \mathrm{~A})$ & $121.4(7)$ \\
\hline $\mathrm{C}(18 \mathrm{~B})-\mathrm{H}(18 \mathrm{D})$ & $0.97(2)$ & $\mathrm{C}(3 \mathrm{~A})-\mathrm{C}(4 \mathrm{~A})-\mathrm{H}(4 \mathrm{~A})$ & $116.2(7)$ \\
\hline $\mathrm{C}(18 \mathrm{~B})-\mathrm{H}(18 \mathrm{E})$ & $0.992(18)$ & $C(6 A)-C(5 A)-C(4 A)$ & $117.12(13)$ \\
\hline $\mathrm{C}(18 \mathrm{~B})-\mathrm{H}(18 \mathrm{~F})$ & $0.964(19)$ & $C(6 A)-C(5 A)-C(9 A)$ & $120.94(14)$ \\
\hline C(19B)-H(19D) & $0.959(17)$ & $C(4 A)-C(5 A)-C(9 A)$ & $121.94(14)$ \\
\hline C(19B)-H(19E) & $0.986(15)$ & $C(5 A)-C(6 A)-C(7 A)$ & $123.12(14)$ \\
\hline $\mathrm{C}(19 \mathrm{~B})-\mathrm{H}(19 \mathrm{~F})$ & $0.944(17)$ & $\mathrm{C}(5 \mathrm{~A})-\mathrm{C}(6 \mathrm{~A})-\mathrm{H}(6 \mathrm{~A})$ & $119.8(7)$ \\
\hline$C(20 B)-C(21 B)$ & $1.518(2)$ & $\mathrm{C}(7 \mathrm{~A})-\mathrm{C}(6 \mathrm{~A})-\mathrm{H}(6 \mathrm{~A})$ & $117.0(7)$ \\
\hline$C(20 B)-C(22 B)$ & $1.522(2)$ & $\mathrm{C}(6 \mathrm{~A})-\mathrm{C}(7 \mathrm{~A})-\mathrm{C}(2 \mathrm{~A})$ & $118.69(13)$ \\
\hline $\mathrm{C}(20 \mathrm{~B})-\mathrm{H}(20 \mathrm{~B})$ & $0.997(14)$ & $C(6 A)-C(7 A)-C(10 A)$ & $118.42(13)$ \\
\hline $\mathrm{C}(21 \mathrm{~B})-\mathrm{H}(21 \mathrm{D})$ & $0.987(17)$ & $C(2 A)-C(7 A)-C(10 A)$ & $122.82(12)$ \\
\hline C(21B)-H(21E) & $1.001(16)$ & $\mathrm{C}(3 \mathrm{~A})-\mathrm{C}(8 \mathrm{~A})-\mathrm{H}(8 \mathrm{~A})$ & $114.3(9)$ \\
\hline $\mathrm{C}(21 \mathrm{~B})-\mathrm{H}(21 \mathrm{~F})$ & $0.950(19)$ & $\mathrm{C}(3 \mathrm{~A})-\mathrm{C}(8 \mathrm{~A})-\mathrm{H}(8 \mathrm{~B})$ & 113.2(9) \\
\hline $\mathrm{C}(22 \mathrm{~B})-\mathrm{H}(22 \mathrm{D})$ & $1.004(18)$ & $\mathrm{H}(8 \mathrm{~A})-\mathrm{C}(8 \mathrm{~A})-\mathrm{H}(8 \mathrm{~B})$ & $102.7(12)$ \\
\hline $\mathrm{C}(22 \mathrm{~B})-\mathrm{H}(22 \mathrm{E})$ & $0.998(15)$ & $\mathrm{C}(3 \mathrm{~A})-\mathrm{C}(8 \mathrm{~A})-\mathrm{H}(8 \mathrm{C})$ & $111.9(8)$ \\
\hline $\mathrm{C}(22 \mathrm{~B})-\mathrm{H}(22 \mathrm{~F})$ & $0.948(19)$ & $\mathrm{H}(8 \mathrm{~A})-\mathrm{C}(8 \mathrm{~A})-\mathrm{H}(8 \mathrm{C})$ & $105.7(12)$ \\
\hline$C(23 B)-C(25 B)$ & $1.516(2)$ & $\mathrm{H}(8 \mathrm{~B})-\mathrm{C}(8 \mathrm{~A})-\mathrm{H}(8 \mathrm{C})$ & $108.3(12)$ \\
\hline$C(23 B)-C(24 B)$ & $1.523(2)$ & $\mathrm{C}(5 \mathrm{~A})-\mathrm{C}(9 \mathrm{~A})-\mathrm{H}(9 \mathrm{~A})$ & 113.2(11) \\
\hline C(23B)-H(23B) & $0.971(13)$ & $\mathrm{C}(5 \mathrm{~A})-\mathrm{C}(9 \mathrm{~A})-\mathrm{H}(9 \mathrm{~B})$ & $113.3(10)$ \\
\hline C(24B)-H(24D) & $1.013(18)$ & $\mathrm{H}(9 \mathrm{~A})-\mathrm{C}(9 \mathrm{~A})-\mathrm{H}(9 \mathrm{~B})$ & 111.1(15) \\
\hline C(24B)-H(24E) & $0.936(19)$ & $\mathrm{C}(5 \mathrm{~A})-\mathrm{C}(9 \mathrm{~A})-\mathrm{H}(9 \mathrm{C})$ & $111.5(10)$ \\
\hline C(24B)-H(24F) & $1.00(2)$ & $\mathrm{H}(9 \mathrm{~A})-\mathrm{C}(9 \mathrm{~A})-\mathrm{H}(9 \mathrm{C})$ & $103.8(15)$ \\
\hline $\mathrm{C}(25 \mathrm{~B})-\mathrm{H}(25 \mathrm{D})$ & $0.976(15)$ & $\mathrm{H}(9 \mathrm{~B})-\mathrm{C}(9 \mathrm{~A})-\mathrm{H}(9 \mathrm{C})$ & 103.0(14) \\
\hline $\mathrm{C}(25 \mathrm{~B})-\mathrm{H}(25 \mathrm{E})$ & $0.976(17)$ & $\mathrm{C}(7 \mathrm{~A})-\mathrm{C}(10 \mathrm{~A})-\mathrm{H}(10 \mathrm{~A})$ & $110.9(8)$ \\
\hline \multirow[t]{2}{*}{$\mathrm{C}(25 \mathrm{~B})-\mathrm{H}(25 \mathrm{~F})$} & $1.013(16)$ & $\mathrm{C}(7 \mathrm{~A})-\mathrm{C}(10 \mathrm{~A})-\mathrm{H}(10 \mathrm{~B})$ & $114.7(8)$ \\
\hline & & $\mathrm{H}(10 \mathrm{~A})-\mathrm{C}(10 \mathrm{~A})-\mathrm{H}(10 \mathrm{~B})$ & $106.7(11)$ \\
\hline $\mathrm{N}(3 \mathrm{~A})-\mathrm{P}(1 \mathrm{~A})-\mathrm{N}(1 \mathrm{~A})$ & $106.68(5)$ & $\mathrm{C}(7 \mathrm{~A})-\mathrm{C}(10 \mathrm{~A})-\mathrm{H}(10 \mathrm{C})$ & $111.4(9)$ \\
\hline $\mathrm{N}(3 \mathrm{~A})-\mathrm{P}(1 \mathrm{~A})-\mathrm{N}(2 \mathrm{~A})$ & $110.44(5)$ & $\mathrm{H}(10 \mathrm{~A})-\mathrm{C}(10 \mathrm{~A})-\mathrm{H}(10 \mathrm{C})$ & 109.1(12) \\
\hline $\mathrm{N}(1 \mathrm{~A})-\mathrm{P}(1 \mathrm{~A})-\mathrm{N}(2 \mathrm{~A})$ & $75.02(5)$ & $\mathrm{H}(10 \mathrm{~B})-\mathrm{C}(10 \mathrm{~A})-\mathrm{H}(10 \mathrm{C})$ & $103.6(11)$ \\
\hline $\mathrm{N}(3 \mathrm{~A})-\mathrm{P}(1 \mathrm{~A})-\mathrm{C}(1 \mathrm{~A})$ & $119.25(5)$ & $C(16 A)-C(11 A)-C(12 A)$ & $120.10(12)$ \\
\hline $\mathrm{N}(1 \mathrm{~A})-\mathrm{P}(1 \mathrm{~A})-\mathrm{C}(1 \mathrm{~A})$ & 37.63(4) & $\mathrm{C}(16 \mathrm{~A})-\mathrm{C}(11 \mathrm{~A})-\mathrm{N}(2 \mathrm{~A})$ & $123.16(12)$ \\
\hline $\mathrm{N}(2 \mathrm{~A})-\mathrm{P}(1 \mathrm{~A})-\mathrm{C}(1 \mathrm{~A})$ & $38.11(4)$ & $\mathrm{C}(12 \mathrm{~A})-\mathrm{C}(11 \mathrm{~A})-\mathrm{N}(2 \mathrm{~A})$ & $116.55(12)$ \\
\hline $\mathrm{C}(2 \mathrm{~A})-\mathrm{N}(1 \mathrm{~A})-\mathrm{C}(1 \mathrm{~A})$ & $134.14(10)$ & $C(13 A)-C(12 A)-C(11 A)$ & $118.73(13)$ \\
\hline $\mathrm{C}(2 \mathrm{~A})-\mathrm{N}(1 \mathrm{~A})-\mathrm{P}(1 \mathrm{~A})$ & $131.37(9)$ & $C(13 A)-C(12 A)-C(17 A)$ & $119.74(13)$ \\
\hline C(1A)-N(1A)-P(1A) & $94.32(8)$ & $\mathrm{C}(11 \mathrm{~A})-\mathrm{C}(12 \mathrm{~A})-\mathrm{C}(17 \mathrm{~A})$ & $121.52(12)$ \\
\hline $\mathrm{C}(11 \mathrm{~A})-\mathrm{N}(2 \mathrm{~A})-\mathrm{C}(1 \mathrm{~A})$ & $127.79(10)$ & $C(14 A)-C(13 A)-C(12 A)$ & $122.25(13)$ \\
\hline $\mathrm{C}(11 \mathrm{~A})-\mathrm{N}(2 \mathrm{~A})-\mathrm{P}(1 \mathrm{~A})$ & $120.18(8)$ & $\mathrm{C}(14 \mathrm{~A})-\mathrm{C}(13 \mathrm{~A})-\mathrm{H}(13 \mathrm{~A})$ & $120.1(7)$ \\
\hline $\mathrm{C}(1 \mathrm{~A})-\mathrm{N}(2 \mathrm{~A})-\mathrm{P}(1 \mathrm{~A})$ & $93.62(8)$ & $\mathrm{C}(12 \mathrm{~A})-\mathrm{C}(13 \mathrm{~A})-\mathrm{H}(13 \mathrm{~A})$ & $117.7(7)$ \\
\hline $\mathrm{C}(20 \mathrm{~A})-\mathrm{N}(3 \mathrm{~A})-\mathrm{C}(23 \mathrm{~A})$ & $116.31(11)$ & $C(15 A)-C(14 A)-C(13 A)$ & $117.81(13)$ \\
\hline$C(20 A)-N(3 A)-P(1 A)$ & $125.69(9)$ & $C(15 A)-C(14 A)-C(18 A)$ & $121.10(15)$ \\
\hline$C(23 A)-N(3 A)-P(1 A)$ & $117.82(9)$ & $C(13 A)-C(14 A)-C(18 A)$ & $121.09(14)$ \\
\hline $\mathrm{C}(1 \mathrm{~B})-\mathrm{C}(1 \mathrm{~A})-\mathrm{N}(1 \mathrm{~A})$ & $134.74(12)$ & $C(14 A)-C(15 A)-C(16 A)$ & $122.46(14)$ \\
\hline $\mathrm{C}(1 \mathrm{~B})-\mathrm{C}(1 \mathrm{~A})-\mathrm{N}(2 \mathrm{~A})$ & $129.75(12)$ & $\mathrm{C}(14 \mathrm{~A})-\mathrm{C}(15 \mathrm{~A})-\mathrm{H}(15 \mathrm{~A})$ & $117.6(8)$ \\
\hline $\mathrm{N}(1 \mathrm{~A})-\mathrm{C}(1 \mathrm{~A})-\mathrm{N}(2 \mathrm{~A})$ & $95.30(10)$ & $\mathrm{C}(16 \mathrm{~A})-\mathrm{C}(15 \mathrm{~A})-\mathrm{H}(15 \mathrm{~A})$ & $119.9(8)$ \\
\hline
\end{tabular}




\begin{tabular}{|c|c|}
\hline$C(15 A)-C(16 A)-C(11 A)$ & $118.48(13)$ \\
\hline$C(15 A)-C(16 A)-C(19 A)$ & $119.35(13)$ \\
\hline$C(11 A)-C(16 A)-C(19 A)$ & $122.18(13)$ \\
\hline $\mathrm{C}(12 \mathrm{~A})-\mathrm{C}(17 \mathrm{~A})-\mathrm{H}(17 \mathrm{~A})$ & $110.8(8)$ \\
\hline $\mathrm{C}(12 \mathrm{~A})-\mathrm{C}(17 \mathrm{~A})-\mathrm{H}(17 \mathrm{~B})$ & $111.5(7)$ \\
\hline $\mathrm{H}(17 \mathrm{~A})-\mathrm{C}(17 \mathrm{~A})-\mathrm{H}(17 \mathrm{~B})$ & $107.7(11)$ \\
\hline $\mathrm{C}(12 \mathrm{~A})-\mathrm{C}(17 \mathrm{~A})-\mathrm{H}(17 \mathrm{C})$ & $110.5(8)$ \\
\hline $\mathrm{H}(17 \mathrm{~A})-\mathrm{C}(17 \mathrm{~A})-\mathrm{H}(17 \mathrm{C})$ & $105.2(11)$ \\
\hline $\mathrm{H}(17 \mathrm{~B})-\mathrm{C}(17 \mathrm{~A})-\mathrm{H}(17 \mathrm{C})$ & $110.9(11)$ \\
\hline $\mathrm{C}(14 \mathrm{~A})-\mathrm{C}(18 \mathrm{~A})-\mathrm{H}(18 \mathrm{~A})$ & $113.8(9)$ \\
\hline $\mathrm{C}(14 \mathrm{~A})-\mathrm{C}(18 \mathrm{~A})-\mathrm{H}(18 \mathrm{~B})$ & $110.0(10)$ \\
\hline $\mathrm{H}(18 \mathrm{~A})-\mathrm{C}(18 \mathrm{~A})-\mathrm{H}(18 \mathrm{~B})$ & $105.6(13)$ \\
\hline $\mathrm{C}(14 \mathrm{~A})-\mathrm{C}(18 \mathrm{~A})-\mathrm{H}(18 \mathrm{C})$ & $112.5(11)$ \\
\hline $\mathrm{H}(18 \mathrm{~A})-\mathrm{C}(18 \mathrm{~A})-\mathrm{H}(18 \mathrm{C})$ & $107.2(15)$ \\
\hline $\mathrm{H}(18 \mathrm{~B})-\mathrm{C}(18 \mathrm{~A})-\mathrm{H}(18 \mathrm{C})$ & $107.4(14)$ \\
\hline $\mathrm{C}(16 \mathrm{~A})-\mathrm{C}(19 \mathrm{~A})-\mathrm{H}(19 \mathrm{~A})$ & $113.3(7)$ \\
\hline $\mathrm{C}(16 \mathrm{~A})-\mathrm{C}(19 \mathrm{~A})-\mathrm{H}(19 \mathrm{~B})$ & $112.7(8)$ \\
\hline $\mathrm{H}(19 \mathrm{~A})-\mathrm{C}(19 \mathrm{~A})-\mathrm{H}(19 \mathrm{~B})$ & $106.2(11)$ \\
\hline$C(16 A)-C(19 A)-H(19 C)$ & $111.2(8)$ \\
\hline $\mathrm{H}(19 \mathrm{~A})-\mathrm{C}(19 \mathrm{~A})-\mathrm{H}(19 \mathrm{C})$ & $107.1(11)$ \\
\hline H(19B)-C(19A)-H(19C) & $105.9(11)$ \\
\hline $\mathrm{N}(3 \mathrm{~A})-\mathrm{C}(20 \mathrm{~A})-\mathrm{C}(22 \mathrm{~A})$ & $112.94(12)$ \\
\hline$N(3 A)-C(20 A)-C(21 A)$ & $111.24(12)$ \\
\hline$C(22 \mathrm{~A})-\mathrm{C}(20 \mathrm{~A})-\mathrm{C}(21 \mathrm{~A})$ & $110.64(13)$ \\
\hline $\mathrm{N}(3 \mathrm{~A})-\mathrm{C}(20 \mathrm{~A})-\mathrm{H}(20 \mathrm{~A})$ & $104.9(7)$ \\
\hline $\mathrm{C}(22 \mathrm{~A})-\mathrm{C}(20 \mathrm{~A})-\mathrm{H}(20 \mathrm{~A})$ & $107.0(7)$ \\
\hline $\mathrm{C}(21 \mathrm{~A})-\mathrm{C}(20 \mathrm{~A})-\mathrm{H}(20 \mathrm{~A})$ & $109.9(7)$ \\
\hline $\mathrm{C}(20 \mathrm{~A})-\mathrm{C}(21 \mathrm{~A})-\mathrm{H}(21 \mathrm{~A})$ & $114.0(8)$ \\
\hline $\mathrm{C}(20 \mathrm{~A})-\mathrm{C}(21 \mathrm{~A})-\mathrm{H}(21 \mathrm{~B})$ & $112.1(8)$ \\
\hline $\mathrm{H}(21 \mathrm{~A})-\mathrm{C}(21 \mathrm{~A})-\mathrm{H}(21 \mathrm{~B})$ & $107.3(11)$ \\
\hline $\mathrm{C}(20 \mathrm{~A})-\mathrm{C}(21 \mathrm{~A})-\mathrm{H}(21 \mathrm{C})$ & $110.2(8)$ \\
\hline$H(21 A)-C(21 A)-H(21 C)$ & $107.5(11)$ \\
\hline $\mathrm{H}(21 \mathrm{~B})-\mathrm{C}(21 \mathrm{~A})-\mathrm{H}(21 \mathrm{C})$ & $105.3(11)$ \\
\hline $\mathrm{C}(20 \mathrm{~A})-\mathrm{C}(22 \mathrm{~A})-\mathrm{H}(22 \mathrm{~A})$ & $113.0(8)$ \\
\hline $\mathrm{C}(20 \mathrm{~A})-\mathrm{C}(22 \mathrm{~A})-\mathrm{H}(22 \mathrm{~B})$ & $112.0(8)$ \\
\hline $\mathrm{H}(22 \mathrm{~A})-\mathrm{C}(22 \mathrm{~A})-\mathrm{H}(22 \mathrm{~B})$ & $108.3(11)$ \\
\hline $\mathrm{C}(20 \mathrm{~A})-\mathrm{C}(22 \mathrm{~A})-\mathrm{H}(22 \mathrm{C})$ & $111.1(8)$ \\
\hline $\mathrm{H}(22 \mathrm{~A})-\mathrm{C}(22 \mathrm{~A})-\mathrm{H}(22 \mathrm{C})$ & $105.3(12)$ \\
\hline $\mathrm{H}(22 \mathrm{~B})-\mathrm{C}(22 \mathrm{~A})-\mathrm{H}(22 \mathrm{C})$ & $106.8(12)$ \\
\hline $\mathrm{N}(3 \mathrm{~A})-\mathrm{C}(23 \mathrm{~A})-\mathrm{C}(24 \mathrm{~A})$ & $113.22(12)$ \\
\hline $\mathrm{N}(3 \mathrm{~A})-\mathrm{C}(23 \mathrm{~A})-\mathrm{C}(25 \mathrm{~A})$ & $111.74(12)$ \\
\hline$C(24 A)-C(23 A)-C(25 A)$ & $112.07(14)$ \\
\hline $\mathrm{N}(3 \mathrm{~A})-\mathrm{C}(23 \mathrm{~A})-\mathrm{H}(23 \mathrm{~A})$ & $103.8(7)$ \\
\hline $\mathrm{C}(24 \mathrm{~A})-\mathrm{C}(23 \mathrm{~A})-\mathrm{H}(23 \mathrm{~A})$ & $107.2(7)$ \\
\hline $\mathrm{C}(25 \mathrm{~A})-\mathrm{C}(23 \mathrm{~A})-\mathrm{H}(23 \mathrm{~A})$ & $108.2(7)$ \\
\hline $\mathrm{C}(23 \mathrm{~A})-\mathrm{C}(24 \mathrm{~A})-\mathrm{H}(24 \mathrm{~A})$ & $110.2(8)$ \\
\hline $\mathrm{C}(23 \mathrm{~A})-\mathrm{C}(24 \mathrm{~A})-\mathrm{H}(24 \mathrm{~B})$ & $109.0(8)$ \\
\hline $\mathrm{H}(24 \mathrm{~A})-\mathrm{C}(24 \mathrm{~A})-\mathrm{H}(24 \mathrm{~B})$ & $109.5(11)$ \\
\hline $\mathrm{C}(23 \mathrm{~A})-\mathrm{C}(24 \mathrm{~A})-\mathrm{H}(24 \mathrm{C})$ & $111.5(8)$ \\
\hline $\mathrm{H}(24 \mathrm{~A})-\mathrm{C}(24 \mathrm{~A})-\mathrm{H}(24 \mathrm{C})$ & $109.5(12)$ \\
\hline $\mathrm{H}(24 \mathrm{~B})-\mathrm{C}(24 \mathrm{~A})-\mathrm{H}(24 \mathrm{C})$ & $107.1(11)$ \\
\hline $\mathrm{C}(23 \mathrm{~A})-\mathrm{C}(25 \mathrm{~A})-\mathrm{H}(25 \mathrm{~A})$ & $111.2(9)$ \\
\hline $\mathrm{C}(23 \mathrm{~A})-\mathrm{C}(25 \mathrm{~A})-\mathrm{H}(25 \mathrm{~B})$ & $112.0(8)$ \\
\hline $\mathrm{H}(25 \mathrm{~A})-\mathrm{C}(25 \mathrm{~A})-\mathrm{H}(25 \mathrm{~B})$ & $106.3(12)$ \\
\hline
\end{tabular}

\begin{tabular}{|c|c|}
\hline $\mathrm{C}(23 \mathrm{~A})-\mathrm{C}(25 \mathrm{~A})-\mathrm{H}(25 \mathrm{C})$ & $107.9(8)$ \\
\hline $\mathrm{H}(25 \mathrm{~A})-\mathrm{C}(25 \mathrm{~A})-\mathrm{H}(25 \mathrm{C})$ & $110.1(12)$ \\
\hline $\mathrm{H}(25 \mathrm{~B})-\mathrm{C}(25 \mathrm{~A})-\mathrm{H}(25 \mathrm{C})$ & $109.3(11)$ \\
\hline N(3B)-P(1B)-N(1B) & $107.08(6)$ \\
\hline $\mathrm{N}(3 \mathrm{~B})-\mathrm{P}(1 \mathrm{~B})-\mathrm{N}(2 \mathrm{~B})$ & $110.51(6)$ \\
\hline $\mathrm{N}(1 \mathrm{~B})-\mathrm{P}(1 \mathrm{~B})-\mathrm{N}(2 \mathrm{~B})$ & $74.82(5)$ \\
\hline $\mathrm{N}(3 \mathrm{~B})-\mathrm{P}(1 \mathrm{~B})-\mathrm{C}(1 \mathrm{~B})$ & $119.63(5)$ \\
\hline $\mathrm{N}(1 \mathrm{~B})-\mathrm{P}(1 \mathrm{~B})-\mathrm{C}(1 \mathrm{~B})$ & $37.55(4)$ \\
\hline $\mathrm{N}(2 \mathrm{~B})-\mathrm{P}(1 \mathrm{~B})-\mathrm{C}(1 \mathrm{~B})$ & $38.02(4)$ \\
\hline $\mathrm{C}(2 \mathrm{~B})-\mathrm{N}(1 \mathrm{~B})-\mathrm{C}(1 \mathrm{~B})$ & $132.99(11)$ \\
\hline $\mathrm{C}(2 \mathrm{~B})-\mathrm{N}(1 \mathrm{~B})-\mathrm{P}(1 \mathrm{~B})$ & 132.22(9) \\
\hline $\mathrm{C}(1 \mathrm{~B})-\mathrm{N}(1 \mathrm{~B})-\mathrm{P}(1 \mathrm{~B})$ & $94.66(8)$ \\
\hline $\mathrm{C}(11 \mathrm{~B})-\mathrm{N}(2 \mathrm{~B})-\mathrm{C}(1 \mathrm{~B})$ & $125.49(10)$ \\
\hline $\mathrm{C}(11 \mathrm{~B})-\mathrm{N}(2 \mathrm{~B})-\mathrm{P}(1 \mathrm{~B})$ & $121.68(8)$ \\
\hline $\mathrm{C}(1 \mathrm{~B})-\mathrm{N}(2 \mathrm{~B})-\mathrm{P}(1 \mathrm{~B})$ & $93.58(8)$ \\
\hline $\mathrm{C}(20 \mathrm{~B})-\mathrm{N}(3 \mathrm{~B})-\mathrm{C}(23 \mathrm{~B})$ & $116.52(12)$ \\
\hline C(20B)-N(3B)-P(1B) & $125.39(10)$ \\
\hline $\mathrm{C}(23 \mathrm{~B})-\mathrm{N}(3 \mathrm{~B})-\mathrm{P}(1 \mathrm{~B})$ & 117.91(10) \\
\hline $\mathrm{C}(1 \mathrm{~A})-\mathrm{C}(1 \mathrm{~B})-\mathrm{N}(1 \mathrm{~B})$ & $134.63(12)$ \\
\hline $\mathrm{C}(1 \mathrm{~A})-\mathrm{C}(1 \mathrm{~B})-\mathrm{N}(2 \mathrm{~B})$ & $130.02(12)$ \\
\hline $\mathrm{N}(1 \mathrm{~B})-\mathrm{C}(1 \mathrm{~B})-\mathrm{N}(2 \mathrm{~B})$ & $95.12(10)$ \\
\hline $\mathrm{C}(1 \mathrm{~A})-\mathrm{C}(1 \mathrm{~B})-\mathrm{P}(1 \mathrm{~B})$ & $167.84(10)$ \\
\hline $\mathrm{N}(1 \mathrm{~B})-\mathrm{C}(1 \mathrm{~B})-\mathrm{P}(1 \mathrm{~B})$ & $47.79(6)$ \\
\hline $\mathrm{N}(2 \mathrm{~B})-\mathrm{C}(1 \mathrm{~B})-\mathrm{P}(1 \mathrm{~B})$ & $48.40(6)$ \\
\hline$C(7 B)-C(2 B)-C(3 B)$ & $119.76(12)$ \\
\hline $\mathrm{C}(7 \mathrm{~B})-\mathrm{C}(2 \mathrm{~B})-\mathrm{N}(1 \mathrm{~B})$ & $120.92(12)$ \\
\hline $\mathrm{C}(3 \mathrm{~B})-\mathrm{C}(2 \mathrm{~B})-\mathrm{N}(1 \mathrm{~B})$ & $119.27(12)$ \\
\hline$C(4 B)-C(3 B)-C(2 B)$ & $118.61(13)$ \\
\hline $\mathrm{C}(4 \mathrm{~B})-\mathrm{C}(3 \mathrm{~B})-\mathrm{C}(8 \mathrm{~B})$ & $118.50(13)$ \\
\hline $\mathrm{C}(2 \mathrm{~B})-\mathrm{C}(3 \mathrm{~B})-\mathrm{C}(8 \mathrm{~B})$ & $122.86(13)$ \\
\hline$C(5 B)-C(4 B)-C(3 B)$ & $122.56(14)$ \\
\hline $\mathrm{C}(5 \mathrm{~B})-\mathrm{C}(4 \mathrm{~B})-\mathrm{H}(4 \mathrm{~B})$ & $120.6(8)$ \\
\hline $\mathrm{C}(3 \mathrm{~B})-\mathrm{C}(4 \mathrm{~B})-\mathrm{H}(4 \mathrm{~B})$ & $116.8(8)$ \\
\hline$C(4 B)-C(5 B)-C(6 B)$ & $117.49(13)$ \\
\hline$C(4 B)-C(5 B)-C(9 B)$ & $121.89(14)$ \\
\hline $\mathrm{C}(6 \mathrm{~B})-\mathrm{C}(5 \mathrm{~B})-\mathrm{C}(9 \mathrm{~B})$ & $120.62(15)$ \\
\hline$C(7 B)-C(6 B)-C(5 B)$ & $122.73(14)$ \\
\hline $\mathrm{C}(7 \mathrm{~B})-\mathrm{C}(6 \mathrm{~B})-\mathrm{H}(6 \mathrm{~B})$ & $118.8(7)$ \\
\hline $\mathrm{C}(5 \mathrm{~B})-\mathrm{C}(6 \mathrm{~B})-\mathrm{H}(6 \mathrm{~B})$ & $118.5(7)$ \\
\hline$C(6 B)-C(7 B)-C(2 B)$ & $118.77(13)$ \\
\hline $\mathrm{C}(6 \mathrm{~B})-\mathrm{C}(7 \mathrm{~B})-\mathrm{C}(10 \mathrm{~B})$ & $119.05(13)$ \\
\hline $\mathrm{C}(2 \mathrm{~B})-\mathrm{C}(7 \mathrm{~B})-\mathrm{C}(10 \mathrm{~B})$ & $122.17(12)$ \\
\hline $\mathrm{C}(3 \mathrm{~B})-\mathrm{C}(8 \mathrm{~B})-\mathrm{H}(8 \mathrm{D})$ & $109.5(11)$ \\
\hline $\mathrm{C}(3 \mathrm{~B})-\mathrm{C}(8 \mathrm{~B})-\mathrm{H}(8 \mathrm{E})$ & $114.9(9)$ \\
\hline $\mathrm{H}(8 \mathrm{D})-\mathrm{C}(8 \mathrm{~B})-\mathrm{H}(8 \mathrm{E})$ & $106.7(14)$ \\
\hline $\mathrm{C}(3 \mathrm{~B})-\mathrm{C}(8 \mathrm{~B})-\mathrm{H}(8 \mathrm{~F})$ & $113.4(10)$ \\
\hline $\mathrm{H}(8 \mathrm{D})-\mathrm{C}(8 \mathrm{~B})-\mathrm{H}(8 \mathrm{~F})$ & $109.6(14)$ \\
\hline $\mathrm{H}(8 \mathrm{E})-\mathrm{C}(8 \mathrm{~B})-\mathrm{H}(8 \mathrm{~F})$ & $102.4(13)$ \\
\hline $\mathrm{C}(5 \mathrm{~B})-\mathrm{C}(9 \mathrm{~B})-\mathrm{H}(9 \mathrm{D})$ & 110.3(9) \\
\hline $\mathrm{C}(5 \mathrm{~B})-\mathrm{C}(9 \mathrm{~B})-\mathrm{H}(9 \mathrm{E})$ & 111.6(10) \\
\hline $\mathrm{H}(9 \mathrm{D})-\mathrm{C}(9 \mathrm{~B})-\mathrm{H}(9 \mathrm{E})$ & $103.8(13)$ \\
\hline $\mathrm{C}(5 \mathrm{~B})-\mathrm{C}(9 \mathrm{~B})-\mathrm{H}(9 \mathrm{~F})$ & $113.3(10)$ \\
\hline $\mathrm{H}(9 \mathrm{D})-\mathrm{C}(9 \mathrm{~B})-\mathrm{H}(9 \mathrm{~F})$ & $112.4(14)$ \\
\hline $\mathrm{H}(9 \mathrm{E})-\mathrm{C}(9 \mathrm{~B})-\mathrm{H}(9 \mathrm{~F})$ & $104.8(14)$ \\
\hline
\end{tabular}




\begin{tabular}{|c|c|c|c|}
\hline $\mathrm{C}(7 \mathrm{~B})-\mathrm{C}(10 \mathrm{~B})-\mathrm{H}(10 \mathrm{D})$ & $111.5(8)$ & $\mathrm{C}(16 \mathrm{~B})-\mathrm{C}(19 \mathrm{~B})-\mathrm{H}(19 \mathrm{~F})$ & $113.8(10)$ \\
\hline C(7B)-C(10B)-H(10E) & $113.0(8)$ & $\mathrm{H}(19 \mathrm{D})-\mathrm{C}(19 \mathrm{~B})-\mathrm{H}(19 \mathrm{~F})$ & 109.9(14) \\
\hline $\mathrm{H}(10 \mathrm{D})-\mathrm{C}(10 \mathrm{~B})-\mathrm{H}(10 \mathrm{E})$ & 106.9(11) & $\mathrm{H}(19 \mathrm{E})-\mathrm{C}(19 \mathrm{~B})-\mathrm{H}(19 \mathrm{~F})$ & 103.4(13) \\
\hline C(7B)-C(10B)-H(10F) & $111.8(7)$ & N(3B)-C(20B)-C(21B) & $111.44(15)$ \\
\hline $\mathrm{H}(10 \mathrm{D})-\mathrm{C}(10 \mathrm{~B})-\mathrm{H}(10 \mathrm{~F})$ & $107.7(11)$ & $\mathrm{N}(3 \mathrm{~B})-\mathrm{C}(20 \mathrm{~B})-\mathrm{C}(22 \mathrm{~B})$ & $113.48(14)$ \\
\hline $\mathrm{H}(10 \mathrm{E})-\mathrm{C}(10 \mathrm{~B})-\mathrm{H}(10 \mathrm{~F})$ & $105.5(11)$ & $\mathrm{C}(21 \mathrm{~B})-\mathrm{C}(20 \mathrm{~B})-\mathrm{C}(22 \mathrm{~B})$ & $110.67(15)$ \\
\hline$C(16 B)-C(11 B)-C(12 B)$ & $119.97(12)$ & $\mathrm{N}(3 \mathrm{~B})-\mathrm{C}(20 \mathrm{~B})-\mathrm{H}(20 \mathrm{~B})$ & $103.9(8)$ \\
\hline $\mathrm{C}(16 \mathrm{~B})-\mathrm{C}(11 \mathrm{~B})-\mathrm{N}(2 \mathrm{~B})$ & $117.28(12)$ & $\mathrm{C}(21 \mathrm{~B})-\mathrm{C}(20 \mathrm{~B})-\mathrm{H}(20 \mathrm{~B})$ & $110.7(8)$ \\
\hline $\mathrm{C}(12 \mathrm{~B})-\mathrm{C}(11 \mathrm{~B})-\mathrm{N}(2 \mathrm{~B})$ & $122.68(12)$ & $\mathrm{C}(22 \mathrm{~B})-\mathrm{C}(20 \mathrm{~B})-\mathrm{H}(20 \mathrm{~B})$ & 106.3(8) \\
\hline $\mathrm{C}(13 \mathrm{~B})-\mathrm{C}(12 \mathrm{~B})-\mathrm{C}(11 \mathrm{~B})$ & 118.72(13) & $C(20 B)-C(21 B)-H(21 D)$ & $114.0(9)$ \\
\hline $\mathrm{C}(13 \mathrm{~B})-\mathrm{C}(12 \mathrm{~B})-\mathrm{C}(17 \mathrm{~B})$ & $119.25(14)$ & $\mathrm{C}(20 \mathrm{~B})-\mathrm{C}(21 \mathrm{~B})-\mathrm{H}(21 \mathrm{E})$ & 113.2(9) \\
\hline $\mathrm{C}(11 \mathrm{~B})-\mathrm{C}(12 \mathrm{~B})-\mathrm{C}(17 \mathrm{~B})$ & $122.02(12)$ & $\mathrm{H}(21 \mathrm{D})-\mathrm{C}(21 \mathrm{~B})-\mathrm{H}(21 \mathrm{E})$ & 100.7(13) \\
\hline $\mathrm{C}(14 \mathrm{~B})-\mathrm{C}(13 \mathrm{~B})-\mathrm{C}(12 \mathrm{~B})$ & $122.04(15)$ & $\mathrm{C}(20 \mathrm{~B})-\mathrm{C}(21 \mathrm{~B})-\mathrm{H}(21 \mathrm{~F})$ & 112.2(11) \\
\hline $\mathrm{C}(14 \mathrm{~B})-\mathrm{C}(13 \mathrm{~B})-\mathrm{H}(13 \mathrm{~B})$ & $120.4(8)$ & $\mathrm{H}(21 \mathrm{D})-\mathrm{C}(21 \mathrm{~B})-\mathrm{H}(21 \mathrm{~F})$ & 108.6(14) \\
\hline $\mathrm{C}(12 \mathrm{~B})-\mathrm{C}(13 \mathrm{~B})-\mathrm{H}(13 \mathrm{~B})$ & $117.6(8)$ & $\mathrm{H}(21 \mathrm{E})-\mathrm{C}(21 \mathrm{~B})-\mathrm{H}(21 \mathrm{~F})$ & 107.4(14) \\
\hline$C(15 B)-C(14 B)-C(13 B)$ & $117.79(14)$ & $\mathrm{C}(20 \mathrm{~B})-\mathrm{C}(22 \mathrm{~B})-\mathrm{H}(22 \mathrm{D})$ & $111.9(10)$ \\
\hline$C(15 B)-C(14 B)-C(18 B)$ & $121.80(16)$ & $C(20 B)-C(22 B)-H(22 E)$ & 113.1(9) \\
\hline $\mathrm{C}(13 \mathrm{~B})-\mathrm{C}(14 \mathrm{~B})-\mathrm{C}(18 \mathrm{~B})$ & $120.41(16)$ & $\mathrm{H}(22 \mathrm{D})-\mathrm{C}(22 \mathrm{~B})-\mathrm{H}(22 \mathrm{E})$ & 108.7(13) \\
\hline$C(14 B)-C(15 B)-C(16 B)$ & $122.49(15)$ & $\mathrm{C}(20 \mathrm{~B})-\mathrm{C}(22 \mathrm{~B})-\mathrm{H}(22 \mathrm{~F})$ & 110.1(11) \\
\hline $\mathrm{C}(14 \mathrm{~B})-\mathrm{C}(15 \mathrm{~B})-\mathrm{H}(15 \mathrm{~B})$ & 120.1(8) & $\mathrm{H}(22 \mathrm{D})-\mathrm{C}(22 \mathrm{~B})-\mathrm{H}(22 \mathrm{~F})$ & 108.2(14) \\
\hline $\mathrm{C}(16 \mathrm{~B})-\mathrm{C}(15 \mathrm{~B})-\mathrm{H}(15 \mathrm{~B})$ & $117.4(8)$ & $\mathrm{H}(22 \mathrm{E})-\mathrm{C}(22 \mathrm{~B})-\mathrm{H}(22 \mathrm{~F})$ & 104.6(13) \\
\hline$C(15 B)-C(16 B)-C(11 B)$ & $118.68(14)$ & $\mathrm{N}(3 \mathrm{~B})-\mathrm{C}(23 \mathrm{~B})-\mathrm{C}(25 \mathrm{~B})$ & $111.59(13)$ \\
\hline$C(15 B)-C(16 B)-C(19 B)$ & $120.01(14)$ & N(3B)-C(23B)-C(24B) & $112.35(14)$ \\
\hline$C(11 B)-C(16 B)-C(19 B)$ & 121.31(13) & $C(25 B)-C(23 B)-C(24 B)$ & $111.60(17)$ \\
\hline $\mathrm{C}(12 \mathrm{~B})-\mathrm{C}(17 \mathrm{~B})-\mathrm{H}(17 \mathrm{D})$ & $112.4(8)$ & N(3B)-C(23B)-H(23B) & 106.3(8) \\
\hline $\mathrm{C}(12 \mathrm{~B})-\mathrm{C}(17 \mathrm{~B})-\mathrm{H}(17 \mathrm{E})$ & $110.7(8)$ & $\mathrm{C}(25 \mathrm{~B})-\mathrm{C}(23 \mathrm{~B})-\mathrm{H}(23 \mathrm{~B})$ & 109.7(8) \\
\hline H(17D)-C(17B)-H(17E) & 108.9(11) & $\mathrm{C}(24 \mathrm{~B})-\mathrm{C}(23 \mathrm{~B})-\mathrm{H}(23 \mathrm{~B})$ & $105.0(7)$ \\
\hline $\mathrm{C}(12 \mathrm{~B})-\mathrm{C}(17 \mathrm{~B})-\mathrm{H}(17 \mathrm{~F})$ & $109.5(8)$ & $\mathrm{C}(23 \mathrm{~B})-\mathrm{C}(24 \mathrm{~B})-\mathrm{H}(24 \mathrm{D})$ & $108.4(10)$ \\
\hline $\mathrm{H}(17 \mathrm{D})-\mathrm{C}(17 \mathrm{~B})-\mathrm{H}(17 \mathrm{~F})$ & 105.1(11) & $C(23 B)-C(24 B)-H(24 E)$ & $110.0(11)$ \\
\hline $\mathrm{H}(17 \mathrm{E})-\mathrm{C}(17 \mathrm{~B})-\mathrm{H}(17 \mathrm{~F})$ & $110.0(11)$ & $\mathrm{H}(24 \mathrm{D})-\mathrm{C}(24 \mathrm{~B})-\mathrm{H}(24 \mathrm{E})$ & 108.7(14) \\
\hline $\mathrm{C}(14 \mathrm{~B})-\mathrm{C}(18 \mathrm{~B})-\mathrm{H}(18 \mathrm{D})$ & $110.2(11)$ & $\mathrm{C}(23 \mathrm{~B})-\mathrm{C}(24 \mathrm{~B})-\mathrm{H}(24 \mathrm{~F})$ & $110.9(12)$ \\
\hline $\mathrm{C}(14 \mathrm{~B})-\mathrm{C}(18 \mathrm{~B})-\mathrm{H}(18 \mathrm{E})$ & $110.9(10)$ & $\mathrm{H}(24 \mathrm{D})-\mathrm{C}(24 \mathrm{~B})-\mathrm{H}(24 \mathrm{~F})$ & 110.1(16) \\
\hline $\mathrm{H}(18 \mathrm{D})-\mathrm{C}(18 \mathrm{~B})-\mathrm{H}(18 \mathrm{E})$ & $107.7(15)$ & $\mathrm{H}(24 \mathrm{E})-\mathrm{C}(24 \mathrm{~B})-\mathrm{H}(24 \mathrm{~F})$ & $108.8(16)$ \\
\hline $\mathrm{C}(14 \mathrm{~B})-\mathrm{C}(18 \mathrm{~B})-\mathrm{H}(18 \mathrm{~F})$ & $111.5(10)$ & $C(23 B)-C(25 B)-H(25 D)$ & 111.7(9) \\
\hline $\mathrm{H}(18 \mathrm{D})-\mathrm{C}(18 \mathrm{~B})-\mathrm{H}(18 \mathrm{~F})$ & 109.0(16) & $C(23 B)-C(25 B)-H(25 E)$ & $110.6(9)$ \\
\hline $\mathrm{H}(18 \mathrm{E})-\mathrm{C}(18 \mathrm{~B})-\mathrm{H}(18 \mathrm{~F})$ & $107.5(14)$ & $\mathrm{H}(25 \mathrm{D})-\mathrm{C}(25 \mathrm{~B})-\mathrm{H}(25 \mathrm{E})$ & 107.3(12) \\
\hline$C(16 B)-C(19 B)-H(19 D)$ & $111.6(10)$ & $\mathrm{C}(23 \mathrm{~B})-\mathrm{C}(25 \mathrm{~B})-\mathrm{H}(25 \mathrm{~F})$ & $110.4(9)$ \\
\hline$C(16 B)-C(19 B)-H(19 E)$ & $111.0(9)$ & $\mathrm{H}(25 \mathrm{D})-\mathrm{C}(25 \mathrm{~B})-\mathrm{H}(25 \mathrm{~F})$ & 109.2(12) \\
\hline H(19D)-C(19B)-H(19E) & $106.7(12)$ & $\mathrm{H}(25 \mathrm{E})-\mathrm{C}(25 \mathrm{~B})-\mathrm{H}(25 \mathrm{~F})$ & 107.6(13) \\
\hline
\end{tabular}


Table 4. Anisotropic displacement parameters $\left(\AA^{2} \times 10^{4}\right)$ for 4. The anisotropic displacement factor exponent takes the form: $-2 \pi^{2}\left[h^{2} a^{* 2} U^{11}+\ldots+2 h k^{*} b^{*} U^{12}\right]$

\begin{tabular}{|c|c|c|c|c|c|c|}
\hline & $\mathrm{U}^{11}$ & $\mathrm{U}^{22}$ & $\mathrm{U}^{33}$ & $\mathrm{U}^{23}$ & $\mathrm{U}^{13}$ & $\mathrm{U}^{12}$ \\
\hline $\mathrm{P}(1 \mathrm{~A})$ & $156(2)$ & $154(2)$ & $148(2)$ & $-12(2)$ & $38(2)$ & $-17(2)$ \\
\hline $\mathrm{N}(1 \mathrm{~A})$ & $142(6)$ & $170(6)$ & $127(6)$ & $-37(5)$ & $30(5)$ & $-32(5)$ \\
\hline $\mathrm{N}(2 \mathrm{~A})$ & $122(6)$ & 151(6) & $157(6)$ & $-28(5)$ & $36(5)$ & $-26(5)$ \\
\hline $\mathrm{N}(3 \mathrm{~A})$ & $203(6)$ & $155(6)$ & 141(6) & $-22(5)$ & $67(5)$ & $-5(5)$ \\
\hline$C(1 \mathrm{~A})$ & $127(7)$ & $130(7)$ & 163(7) & $6(6)$ & $17(6)$ & $-7(6)$ \\
\hline $\mathrm{C}(2 \mathrm{~A})$ & $127(7)$ & $135(7)$ & 189(8) & $-41(6)$ & $31(6)$ & $-3(6)$ \\
\hline$C(3 \mathrm{~A})$ & $168(7)$ & $160(7)$ & 193(8) & $-22(6)$ & $42(6)$ & $11(6)$ \\
\hline$C(4 A)$ & $205(8)$ & 231(9) & $196(8)$ & $-71(7)$ & $-15(7)$ & $11(7)$ \\
\hline$C(5 A)$ & $166(8)$ & $215(8)$ & 299(9) & $-50(7)$ & $29(7)$ & $-41(6)$ \\
\hline$C(6 A)$ & 203(8) & $180(8)$ & 274(9) & 2(7) & $86(7)$ & $-31(6)$ \\
\hline$C(7 A)$ & $165(7)$ & $149(7)$ & 191(8) & $-24(6)$ & $47(6)$ & $5(6)$ \\
\hline $\mathrm{C}(8 \mathrm{~A})$ & 203(8) & $263(9)$ & 173(8) & $8(7)$ & $5(7)$ & $21(7)$ \\
\hline $\mathrm{C}(9 \mathrm{~A})$ & $225(9)$ & $361(11)$ & $440(12)$ & $-52(10)$ & $6(8)$ & $-114(9)$ \\
\hline$C(10 A)$ & $224(9)$ & $206(9)$ & $206(9)$ & $20(7)$ & $52(7)$ & $-39(7)$ \\
\hline$C(11 A)$ & 171(7) & 184(8) & 131(7) & $-39(6)$ & $53(6)$ & $-36(6)$ \\
\hline $\mathrm{C}(12 \mathrm{~A})$ & $164(7)$ & 211(8) & $163(7)$ & $-32(6)$ & $55(6)$ & $-9(6)$ \\
\hline$C(13 A)$ & 139(8) & $290(9)$ & $210(8)$ & $-42(7)$ & $34(6)$ & $-37(7)$ \\
\hline$C(14 A)$ & $225(8)$ & $245(9)$ & $207(8)$ & $-16(7)$ & $53(7)$ & $-101(7)$ \\
\hline $\mathrm{C}(15 \mathrm{~A})$ & $286(9)$ & $172(8)$ & $219(8)$ & 13(7) & $81(7)$ & $-43(7)$ \\
\hline$C(16 A)$ & $195(8)$ & $200(8)$ & $164(7)$ & $-10(6)$ & $54(6)$ & $-22(6)$ \\
\hline $\mathrm{C}(17 \mathrm{~A})$ & $163(8)$ & $223(9)$ & $240(9)$ & $-41(7)$ & $31(7)$ & 2(7) \\
\hline $\mathrm{C}(18 \mathrm{~A})$ & $320(11)$ & $327(11)$ & $409(12)$ & $22(10)$ & $33(9)$ & $-165(9)$ \\
\hline$C(19 A)$ & $238(9)$ & 181(9) & $230(9)$ & $37(7)$ & $40(7)$ & $-17(7)$ \\
\hline$C(20 A)$ & 274(8) & 163(8) & 193(8) & $-8(7)$ & $96(7)$ & $12(6)$ \\
\hline$C(21 A)$ & 272(9) & 186(9) & $342(10)$ & $5(8)$ & $98(8)$ & $-24(7)$ \\
\hline $\mathrm{C}(22 \mathrm{~A})$ & $328(10)$ & $185(9)$ & $217(9)$ & $13(7)$ & $32(8)$ & $24(7)$ \\
\hline$C(23 A)$ & $216(8)$ & $182(8)$ & 177(8) & $-44(7)$ & $73(6)$ & $1(6)$ \\
\hline$C(24 A)$ & $286(9)$ & $314(10)$ & 185(9) & $-46(8)$ & $65(7)$ & $10(8)$ \\
\hline$C(25 A)$ & 233(9) & $406(12)$ & $307(10)$ & $-116(9)$ & $137(8)$ & $-49(8)$ \\
\hline $\mathrm{P}(1 \mathrm{~B})$ & $170(2)$ & $195(2)$ & $162(2)$ & $-21(2)$ & $41(2)$ & $17(2)$ \\
\hline $\mathrm{N}(1 \mathrm{~B})$ & 133(6) & $193(7)$ & $140(6)$ & $-28(5)$ & $34(5)$ & $0(5)$ \\
\hline $\mathrm{N}(2 \mathrm{~B})$ & $135(6)$ & $162(6)$ & $142(6)$ & $-21(5)$ & $18(5)$ & $5(5)$ \\
\hline $\mathrm{N}(3 \mathrm{~B})$ & $254(7)$ & $233(7)$ & 193(7) & $-32(6)$ & $47(5)$ & $86(6)$ \\
\hline$C(1 B)$ & $122(7)$ & $143(7)$ & $153(7)$ & $9(6)$ & $12(6)$ & $-10(6)$ \\
\hline $\mathrm{C}(2 \mathrm{~B})$ & $144(7)$ & $168(8)$ & $202(8)$ & $-51(6)$ & $48(6)$ & $11(6)$ \\
\hline $\mathrm{C}(3 \mathrm{~B})$ & $190(8)$ & 192(8) & $217(8)$ & $-39(6)$ & $82(6)$ & $-1(6)$ \\
\hline$C(4 B)$ & 203(8) & $246(9)$ & 298(9) & $-59(7)$ & $127(7)$ & $-55(7)$ \\
\hline$C(5 B)$ & $148(7)$ & $265(9)$ & $302(9)$ & $-91(7)$ & $43(7)$ & $-14(6)$ \\
\hline$C(6 B)$ & $186(8)$ & 261(9) & 184(8) & $-38(7)$ & $9(7)$ & $44(6)$ \\
\hline $\mathrm{C}(7 \mathrm{~B})$ & $161(7)$ & $167(8)$ & 196(8) & $-37(6)$ & $49(6)$ & $37(6)$ \\
\hline $\mathrm{C}(8 \mathrm{~B})$ & $286(10)$ & $271(10)$ & $262(9)$ & $20(8)$ & $113(8)$ & $-31(8)$ \\
\hline $\mathrm{C}(9 \mathrm{~B})$ & 161(9) & $471(13)$ & $393(12)$ & $-112(10)$ & 37(8) & $-69(8)$ \\
\hline $\mathrm{C}(10 \mathrm{~B})$ & $184(8)$ & $227(9)$ & $174(8)$ & $19(7)$ & $6(7)$ & $27(7)$ \\
\hline$C(11 B)$ & $147(7)$ & $220(8)$ & $114(7)$ & $-49(6)$ & $35(6)$ & $-5(6)$ \\
\hline $\mathrm{C}(12 \mathrm{~B})$ & 198(8) & $250(9)$ & $119(7)$ & $-41(6)$ & $36(6)$ & $32(6)$ \\
\hline $\mathrm{C}(13 \mathrm{~B})$ & $230(8)$ & $317(10)$ & $165(8)$ & $-34(7)$ & $16(6)$ & $84(7)$ \\
\hline $\mathrm{C}(14 \mathrm{~B})$ & $176(8)$ & $414(11)$ & 179(8) & $-106(7)$ & $1(6)$ & $28(7)$ \\
\hline $\mathrm{C}(15 \mathrm{~B})$ & $216(8)$ & $303(10)$ & $238(9)$ & $-119(7)$ & $52(7)$ & $-65(7)$ \\
\hline
\end{tabular}




$\begin{array}{llllcrr}\mathrm{C}(16 \mathrm{~B}) & 184(8) & 236(8) & 177(8) & -63(6) & 38(6) & -19(6) \\ \mathrm{C}(17 \mathrm{~B}) & 233(9) & 205(9) & 211(9) & 16(7) & 29(7) & 58(7) \\ \mathrm{C}(18 \mathrm{~B}) & 208(9) & 598(15) & 392(12) & -169(11) & -40(9) & 36(9) \\ \mathrm{C}(19 \mathrm{~B}) & 270(9) & 226(9) & 344(11) & -61(8) & 41(9) & -66(8) \\ \mathrm{C}(20 \mathrm{~B}) & 422(11) & 279(10) & 240(9) & -14(8) & 46(8) & 169(8) \\ \mathrm{C}(21 \mathrm{~B}) & 476(13) & 375(12) & 360(12) & -91(10) & -114(10) & 211(10) \\ \mathrm{C}(22 \mathrm{~B}) & 530(14) & 287(11) & 403(12) & 45(9) & 117(11) & 145(9) \\ \mathrm{C}(23 \mathrm{~B}) & 296(9) & 255(9) & 274(9) & -78(7) & 96(7) & 69(7) \\ \mathrm{C}(24 \mathrm{~B}) & 624(16) & 489(15) & 685(16) & -251(13) & 505(14) & -93(12) \\ \mathrm{C}(25 \mathrm{~B}) & 477(12) & 313(11) & 251(10) & -78(9) & 20(9) & 92(10)\end{array}$


Table 5. Hydrogen coordinates $\left(\times 10^{4}\right)$ and isotropic displacement parameters $\left(\AA^{2} \times 10^{3}\right)$ for 4.

\begin{tabular}{|c|c|c|c|c|}
\hline & $\mathrm{x}$ & $\mathrm{y}$ & $\mathrm{z}$ & $\mathrm{U}_{\text {iso }}$ \\
\hline $\mathrm{H}(4 \mathrm{~A})$ & $-9(9)$ & $1825(8)$ & $-871(6)$ & $14(3)$ \\
\hline $\mathrm{H}(6 \mathrm{~A})$ & 233(9) & $960(8)$ & $924(6)$ & $16(4)$ \\
\hline $\mathrm{H}(8 \mathrm{~A})$ & $2105(11)$ & $2547(9)$ & $-898(7)$ & $37(5)$ \\
\hline $\mathrm{H}(8 \mathrm{~B})$ & $1750(11)$ & $3316(10)$ & $-607(7)$ & $41(5)$ \\
\hline $\mathrm{H}(8 \mathrm{C})$ & 1019(10) & $2817(8)$ & $-1128(7)$ & $28(4)$ \\
\hline $\mathrm{H}(9 \mathrm{~A})$ & $-1611(15)$ & 1199(12) & $-203(9)$ & $73(7)$ \\
\hline $\mathrm{H}(9 \mathrm{~B})$ & $-1057(12)$ & $360(12)$ & 64(8) & $61(6)$ \\
\hline $\mathrm{H}(9 \mathrm{C})$ & $-1107(12)$ & $629(11)$ & $-622(9)$ & $65(6)$ \\
\hline $\mathrm{H}(10 \mathrm{~A})$ & $1503(10)$ & $1279(8)$ & $1719(6)$ & $27(4)$ \\
\hline $\mathrm{H}(10 \mathrm{~B})$ & 2150(9) & 2098(9) & $1697(6)$ & $26(4)$ \\
\hline $\mathrm{H}(10 \mathrm{C})$ & $2517(11)$ & $1281(9)$ & $1467(7)$ & $37(5)$ \\
\hline $\mathrm{H}(13 \mathrm{~A})$ & 7163(9) & $4024(8)$ & 1576(6) & $18(4)$ \\
\hline $\mathrm{H}(15 \mathrm{~A})$ & 5189(9) & $5740(9)$ & $770(6)$ & $22(4)$ \\
\hline $\mathrm{H}(17 \mathrm{~A})$ & 6103(9) & 2377(9) & $1108(7)$ & $26(4)$ \\
\hline $\mathrm{H}(17 \mathrm{~B})$ & $5499(10)$ & 2439(8) & $1675(6)$ & $20(4)$ \\
\hline $\mathrm{H}(17 \mathrm{C})$ & $6663(11)$ & 2692(9) & $1766(7)$ & $32(4)$ \\
\hline $\mathrm{H}(18 \mathrm{~A})$ & $6900(11)$ & $6168(11)$ & 1092(8) & $52(5)$ \\
\hline $\mathrm{H}(18 \mathrm{~B})$ & $7666(12)$ & $5458(10)$ & $1232(7)$ & $43(5)$ \\
\hline $\mathrm{H}(18 \mathrm{C})$ & 7221(13) & $5819(11)$ & 1783(10) & $73(7)$ \\
\hline $\mathrm{H}(19 \mathrm{~A})$ & $3059(9)$ & $4956(8)$ & $765(6)$ & $24(4)$ \\
\hline $\mathrm{H}(19 \mathrm{~B})$ & $3229(9)$ & $4464(8)$ & $165(6)$ & $21(4)$ \\
\hline $\mathrm{H}(19 \mathrm{C})$ & $3559(10)$ & $5388(9)$ & $242(7)$ & $30(4)$ \\
\hline $\mathrm{H}(20 \mathrm{~A})$ & $3814(9)$ & 1413(8) & 1036(6) & $16(4)$ \\
\hline $\mathrm{H}(21 \mathrm{~A})$ & 2617(10) & $650(8)$ & $265(6)$ & $25(4)$ \\
\hline $\mathrm{H}(21 \mathrm{~B})$ & $3496(9)$ & $92(9)$ & $85(7)$ & $27(4)$ \\
\hline $\mathrm{H}(21 \mathrm{C})$ & $3221(10)$ & $36(9)$ & 771(7) & $36(4)$ \\
\hline $\mathrm{H}(22 \mathrm{~A})$ & $5350(10)$ & $426(9)$ & $645(7)$ & $29(4)$ \\
\hline $\mathrm{H}(22 \mathrm{~B})$ & $5521(10)$ & 1137(9) & 1190(7) & $35(4)$ \\
\hline $\mathrm{H}(22 \mathrm{C})$ & $4968(10)$ & 302(9) & $1273(7)$ & $31(4)$ \\
\hline $\mathrm{H}(23 \mathrm{~A})$ & $4651(8)$ & $861(8)$ & $-263(6)$ & 11(3) \\
\hline $\mathrm{H}(24 \mathrm{~A})$ & $3149(11)$ & 1262(9) & $-927(7)$ & $34(4)$ \\
\hline $\mathrm{H}(24 \mathrm{~B})$ & $4067(9)$ & $1227(8)$ & $-1296(6)$ & $23(4)$ \\
\hline $\mathrm{H}(24 \mathrm{C})$ & 3681(10) & 2082(10) & $-1094(6)$ & $29(4)$ \\
\hline $\mathrm{H}(25 \mathrm{~A})$ & $5405(11)$ & $2482(11)$ & $-430(7)$ & $45(5)$ \\
\hline $\mathrm{H}(25 \mathrm{~B})$ & $5785(10)$ & 1677(9) & $-715(7)$ & $28(4)$ \\
\hline $\mathrm{H}(25 \mathrm{C})$ & $5974(10)$ & 1758(9) & 45(7) & $31(4)$ \\
\hline $\mathrm{H}(4 \mathrm{~B})$ & $-1249(9)$ & $2515(8)$ & $1567(6)$ & $19(4)$ \\
\hline $\mathrm{H}(6 \mathrm{~B})$ & $-793(8)$ & $3692(7)$ & 4(6) & $9(3)$ \\
\hline $\mathrm{H}(8 \mathrm{D})$ & $340(12)$ & 3103(11) & 2606(9) & $62(6)$ \\
\hline $\mathrm{H}(8 \mathrm{E})$ & 1139(12) & 2551(10) & $2430(7)$ & $47(5)$ \\
\hline $\mathrm{H}(8 \mathrm{~F})$ & $128(12)$ & 2199(11) & 2397(8) & $51(5)$ \\
\hline $\mathrm{H}(9 \mathrm{D})$ & $-2708(12)$ & $3262(10)$ & $473(7)$ & $48(5)$ \\
\hline $\mathrm{H}(9 \mathrm{E})$ & $-2454(12)$ & $2319(12)$ & $541(8)$ & $58(6)$ \\
\hline $\mathrm{H}(9 \mathrm{~F})$ & $-2266(12)$ & $2766(11)$ & $-65(9)$ & $60(6)$ \\
\hline $\mathrm{H}(10 \mathrm{D})$ & 663(10) & $4367(8)$ & $-56(7)$ & $27(4)$ \\
\hline $\mathrm{H}(10 \mathrm{E})$ & $1633(10)$ & $4008(8)$ & $345(6)$ & $24(4)$ \\
\hline $\mathrm{H}(10 \mathrm{~F})$ & 1184(9) & 4813(9) & $591(6)$ & $28(4)$ \\
\hline
\end{tabular}




\begin{tabular}{|c|c|c|c|c|}
\hline $\mathrm{H}(13 \mathrm{~B})$ & $5816(9)$ & 2671(9) & $3030(6)$ & $22(4)$ \\
\hline $\mathrm{H}(15 \mathrm{~B})$ & $6159(10)$ & 5129(9) & 2781(6) & $25(4)$ \\
\hline $\mathrm{H}(17 \mathrm{D})$ & $3895(9)$ & 2209(9) & $2134(7)$ & $27(4)$ \\
\hline $\mathrm{H}(17 \mathrm{E})$ & $3253(10)$ & $2645(8)$ & $2581(6)$ & $22(4)$ \\
\hline $\mathrm{H}(17 \mathrm{~F})$ & $4238(10)$ & 2100(9) & $2863(7)$ & $32(4)$ \\
\hline $\mathrm{H}(18 \mathrm{D})$ & $7362(13)$ & $3471(12)$ & $3593(10)$ & $73(7)$ \\
\hline $\mathrm{H}(18 \mathrm{E})$ & $7577(12)$ & $4356(11)$ & $3337(8)$ & $59(6)$ \\
\hline $\mathrm{H}(18 \mathrm{~F})$ & $7629(13)$ & $3566(11)$ & 2922(9) & $65(6)$ \\
\hline H(19D) & $4010(11)$ & $5789(10)$ & $2529(8)$ & $47(5)$ \\
\hline $\mathrm{H}(19 \mathrm{E})$ & 3901(11) & $5539(9)$ & $1824(7)$ & $33(4)$ \\
\hline $\mathrm{H}(19 \mathrm{~F})$ & $4850(12)$ & $5948(11)$ & $2156(8)$ & $53(5)$ \\
\hline $\mathrm{H}(20 \mathrm{~B})$ & 1793(10) & $5326(9)$ & $1497(7)$ & $29(4)$ \\
\hline $\mathrm{H}(21 \mathrm{D})$ & 15(11) & $5066(11)$ & $1475(7)$ & $40(5)$ \\
\hline $\mathrm{H}(21 \mathrm{E})$ & $-60(11)$ & $5864(10)$ & 1839(8) & $48(5)$ \\
\hline$H(21 F)$ & 172(13) & $5915(11)$ & 1159(9) & $65(6)$ \\
\hline $\mathrm{H}(22 \mathrm{D})$ & $2584(14)$ & $6455(10)$ & $2084(8)$ & $59(6)$ \\
\hline $\mathrm{H}(22 \mathrm{E})$ & $1520(10)$ & $6790(9)$ & $2200(7)$ & $35(4)$ \\
\hline $\mathrm{H}(22 \mathrm{~F})$ & $1734(12)$ & $6758(11)$ & $1530(9)$ & $60(6)$ \\
\hline $\mathrm{H}(23 \mathrm{~B})$ & $928(9)$ & $5832(8)$ & $2816(6)$ & $17(4)$ \\
\hline $\mathrm{H}(24 \mathrm{D})$ & 107(13) & $4603(11)$ & $2845(9)$ & $58(6)$ \\
\hline $\mathrm{H}(24 \mathrm{E})$ & $451(12)$ & $4969(11)$ & $3530(9)$ & $62(6)$ \\
\hline $\mathrm{H}(24 \mathrm{~F})$ & $1066(15)$ & $4225(14)$ & $3342(10)$ & $86(8)$ \\
\hline $\mathrm{H}(25 \mathrm{D})$ & $2658(10)$ & $5144(10)$ & $3592(7)$ & $32(4)$ \\
\hline $\mathrm{H}(25 \mathrm{E})$ & 2003(11) & $5838(10)$ & $3810(8)$ & $48(5)$ \\
\hline $\mathrm{H}(25 \mathrm{~F})$ & $2627(11)$ & $6054(10)$ & $3279(7)$ & $45(5)$ \\
\hline
\end{tabular}




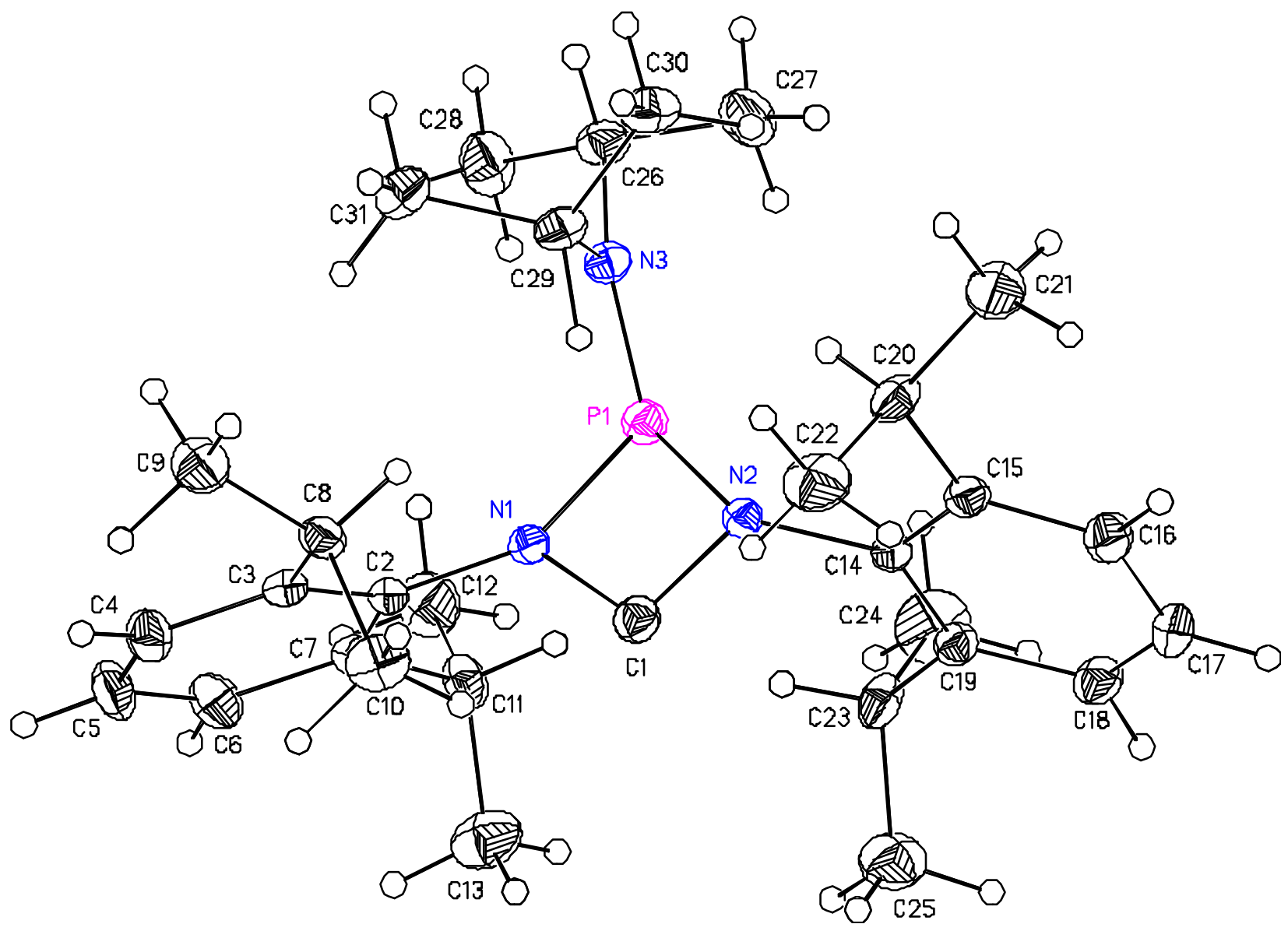

\section{Special Refinement Details}

Refinement of $\mathrm{F}^{2}$ against ALL reflections. The weighted R-factor $(w \mathrm{R})$ and goodness of fit (S) are based on $F^{2}$, conventional $R$-factors $(R)$ are based on $F$, with $F$ set to zero for negative $F^{2}$. The threshold expression of $F^{2}>2 \sigma\left(F^{2}\right)$ is used only for calculating R-factors(gt) etc. and is not relevant to the choice of reflections for refinement. R-factors based on $\mathrm{F}^{2}$ are statistically about twice as large as those based on $\mathrm{F}$, and R-factors based on ALL data will be even larger.

All esds (except the esd in the dihedral angle between two l.s. planes) are estimated using the full covariance matrix. The cell esds are taken into account individually in the estimation of esds in distances, angles and torsion angles; correlations between esds in cell parameters are only used when they are defined by crystal symmetry. An approximate (isotropic) treatment of cell esds is used for estimating esds involving 1.s. planes. 
Table 1. Crystal data and structure refinement for 5 .

Identification code

Empirical formula

Formula weight

Crystal size

Crystal color

Wavelength

Data Collection Temperature

Unit cell dimensions

Volume

$\mathrm{Z}$

Crystal system

Space group

Density (calculated)

$\mathrm{F}(000)$

$\theta$ range for data collection

Completeness to $\theta=28.38^{\circ}$

Index ranges

Reflections collected

Independent reflections

Absorption coefficient

Absorption correction

Max. and min. transmission

Refinement method

Data / restraints / parameters

Goodness-of-fit on $\mathrm{F}^{2}$

Final $R$ indices [I>2 $\sigma(\mathrm{I}), 4684$ reflections]

$\mathrm{R}$ indices (all data)

Largest diff. peak and hole
5

$\mathrm{C}_{31} \mathrm{H}_{48} \mathrm{~N}_{3} \mathrm{P}$

493.69

$0.41 \times 0.22 \times 0.07 \mathrm{~mm}^{3}$

Colorless

$0.71073 \AA \mathrm{MoK} \alpha$

100(2) K

$a=8.9994(10) \AA$

$\mathrm{b}=26.366(3) \AA$

$\mathrm{c}=12.6593(14) \AA$

$\beta=94.240(2)^{\circ}$

2995.5(6) $\AA^{3}$

4

Monoclinic

$\mathrm{P}_{1} / \mathrm{n}$

$1.095 \mathrm{Mg} / \mathrm{m}^{3}$

1080

1.79 to $28.38^{\circ}$

$92.1 \%$

$-11 \leq \mathrm{h} \leq 11,-34 \leq \mathrm{k} \leq 33,-16 \leq 1 \leq 15$

26662

$6905\left[\mathrm{R}_{\mathrm{int}}=0.0643\right]$

$0.114 \mathrm{~mm}^{-1}$

None

0.9921 and 0.9547

Full matrix least-squares on $\mathrm{F}^{2}$

6905 / 0 / 508

1.496

$\mathrm{R} 1=0.0525, w \mathrm{R} 2=0.0810$

$\mathrm{R} 1=0.0822, w \mathrm{R} 2=0.0846$

1.025 and -0.551 e. $\AA^{-3}$ 
Table 2. Atomic coordinates ( $x \mathbf{1 0}^{4}$ ) and equivalent isotropic displacement parameters $\left(\AA^{2} \times 1^{3}\right)$ for 5. $U(e q)$ is defined as the trace of the orthogonalized $U^{i j}$ tensor.

\begin{tabular}{|c|c|c|c|c|}
\hline & $\mathrm{x}$ & $\mathrm{y}$ & $\mathrm{z}$ & $\mathrm{U}_{\mathrm{eq}}$ \\
\hline $\mathrm{P}(1)$ & $8866(1)$ & 1379(1) & $7257(1)$ & $19(1)$ \\
\hline $\mathrm{N}(1)$ & $7306(1)$ & $1418(1)$ & $8029(1)$ & $16(1)$ \\
\hline $\mathrm{N}(2)$ & $7625(1)$ & $876(1)$ & $6894(1)$ & $16(1)$ \\
\hline $\mathrm{N}(3)$ & $10296(1)$ & 1167(1) & $8011(1)$ & $18(1)$ \\
\hline $\mathrm{C}(1)$ & 6464(2) & $1078(1)$ & $7419(1)$ & $20(1)$ \\
\hline $\mathrm{C}(2)$ & $6751(2)$ & 1796(1) & $8713(1)$ & $17(1)$ \\
\hline$C(3)$ & $6447(2)$ & $1653(1)$ & $9748(1)$ & $18(1)$ \\
\hline $\mathrm{C}(4)$ & $5939(2)$ & $2024(1)$ & $10406(2)$ & $25(1)$ \\
\hline$C(5)$ & $5713(2)$ & $2514(1)$ & $10073(2)$ & $29(1)$ \\
\hline$C(6)$ & $5979(2)$ & $2648(1)$ & $9049(2)$ & $26(1)$ \\
\hline$C(7)$ & $6484(2)$ & 2294(1) & 8344(1) & $20(1)$ \\
\hline $\mathrm{C}(8)$ & $6578(2)$ & 1107(1) & $10123(1)$ & $20(1)$ \\
\hline $\mathrm{C}(9)$ & $6996(3)$ & $1052(1)$ & $11300(2)$ & $30(1)$ \\
\hline$C(10)$ & $5116(2)$ & $824(1)$ & $9829(2)$ & $30(1)$ \\
\hline $\mathrm{C}(11)$ & $6637(2)$ & $2455(1)$ & $7203(1)$ & $23(1)$ \\
\hline$C(12)$ & $7758(3)$ & $2882(1)$ & $7118(2)$ & $35(1)$ \\
\hline$C(13)$ & $5132(2)$ & $2607(1)$ & $6658(2)$ & $37(1)$ \\
\hline$C(14)$ & $7365(2)$ & 587(1) & $5929(1)$ & $17(1)$ \\
\hline$C(15)$ & $7671(2)$ & $66(1)$ & $5965(1)$ & $19(1)$ \\
\hline$C(16)$ & $7319(2)$ & $-218(1)$ & $5055(2)$ & $25(1)$ \\
\hline $\mathrm{C}(17)$ & $6691(2)$ & $5(1)$ & $4142(2)$ & $25(1)$ \\
\hline $\mathrm{C}(18)$ & $6443(2)$ & $518(1)$ & $4118(2)$ & $23(1)$ \\
\hline $\mathrm{C}(19)$ & $6759(2)$ & $822(1)$ & $5005(1)$ & $18(1)$ \\
\hline $\mathrm{C}(20)$ & $8310(2)$ & $-184(1)$ & $6977(2)$ & $23(1)$ \\
\hline $\mathrm{C}(21)$ & $9298(3)$ & $-638(1)$ & $6790(2)$ & $34(1)$ \\
\hline$C(22)$ & $7083(3)$ & $-322(1)$ & $7690(2)$ & $35(1)$ \\
\hline $\mathrm{C}(23)$ & $6476(2)$ & 1387(1) & $4920(2)$ & $24(1)$ \\
\hline $\mathrm{C}(24)$ & $7643(3)$ & $1638(1)$ & $4282(2)$ & $42(1)$ \\
\hline $\mathrm{C}(25)$ & 4912(3) & $1516(1)$ & $4466(2)$ & $37(1)$ \\
\hline$C(26)$ & $11787(2)$ & $1412(1)$ & $7921(2)$ & $23(1)$ \\
\hline$C(27)$ & $12342(2)$ & $1328(1)$ & $6829(2)$ & $30(1)$ \\
\hline $\mathrm{C}(28)$ & $11790(3)$ & 1969(1) & $8228(2)$ & $33(1)$ \\
\hline $\mathrm{C}(29)$ & $10196(2)$ & 794(1) & $8878(1)$ & $22(1)$ \\
\hline$C(30)$ & $11281(2)$ & $352(1)$ & $8786(2)$ & $26(1)$ \\
\hline $\mathrm{C}(31)$ & $10423(2)$ & 1051(1) & $9952(2)$ & $26(1)$ \\
\hline
\end{tabular}


Table 3. Bond lengths $[\AA]$ and angles $\left[{ }^{\circ}\right]$ for 5 .

\begin{tabular}{|c|c|c|c|}
\hline $\mathrm{P}(1)-\mathrm{N}(3)$ & $1.6429(14)$ & $\mathrm{C}(21)-\mathrm{H}(21 \mathrm{~A})$ & $0.99(2)$ \\
\hline $\mathrm{P}(1)-\mathrm{N}(1)$ & $1.7720(13)$ & $\mathrm{C}(21)-\mathrm{H}(21 \mathrm{~B})$ & $0.970(19)$ \\
\hline $\mathrm{P}(1)-\mathrm{N}(2)$ & $1.7731(14)$ & $\mathrm{C}(21)-\mathrm{H}(21 \mathrm{C})$ & $0.948(19)$ \\
\hline $\mathrm{N}(1)-\mathrm{C}(1)$ & $1.373(2)$ & $\mathrm{C}(22)-\mathrm{H}(22 \mathrm{~A})$ & $0.959(19)$ \\
\hline $\mathrm{N}(1)-\mathrm{C}(2)$ & $1.435(2)$ & $\mathrm{C}(22)-\mathrm{H}(22 \mathrm{~B})$ & $0.99(2)$ \\
\hline $\mathrm{N}(2)-\mathrm{C}(1)$ & $1.387(2)$ & $\mathrm{C}(22)-\mathrm{H}(22 \mathrm{C})$ & $1.029(19)$ \\
\hline $\mathrm{N}(2)-\mathrm{C}(14)$ & $1.443(2)$ & $\mathrm{C}(23)-\mathrm{C}(25)$ & $1.519(3)$ \\
\hline $\mathrm{N}(3)-\mathrm{C}(29)$ & $1.481(2)$ & $\mathrm{C}(23)-\mathrm{C}(24)$ & $1.523(3)$ \\
\hline $\mathrm{N}(3)-\mathrm{C}(26)$ & $1.501(2)$ & $\mathrm{C}(23)-\mathrm{H}(23)$ & $0.921(16)$ \\
\hline $\mathrm{C}(2)-\mathrm{C}(7)$ & $1.406(2)$ & $\mathrm{C}(24)-\mathrm{H}(24 \mathrm{~A})$ & $1.01(2)$ \\
\hline$C(2)-C(3)$ & $1.410(2)$ & $\mathrm{C}(24)-\mathrm{H}(24 \mathrm{~B})$ & $0.98(2)$ \\
\hline$C(3)-C(4)$ & $1.386(2)$ & $\mathrm{C}(24)-\mathrm{H}(24 \mathrm{C})$ & $0.982(19)$ \\
\hline$C(3)-C(8)$ & $1.518(2)$ & $\mathrm{C}(25)-\mathrm{H}(25 \mathrm{~A})$ & $1.02(2)$ \\
\hline$C(4)-C(5)$ & $1.370(3)$ & $\mathrm{C}(25)-\mathrm{H}(25 \mathrm{~B})$ & $0.95(2)$ \\
\hline $\mathrm{C}(4)-\mathrm{H}(4)$ & $0.926(17)$ & $\mathrm{C}(25)-\mathrm{H}(25 \mathrm{C})$ & $0.97(2)$ \\
\hline$C(5)-C(6)$ & $1.381(3)$ & $C(26)-C(28)$ & $1.520(3)$ \\
\hline $\mathrm{C}(5)-\mathrm{H}(5)$ & $0.920(17)$ & $C(26)-C(27)$ & $1.519(3)$ \\
\hline$C(6)-C(7)$ & $1.391(2)$ & $\mathrm{C}(26)-\mathrm{H}(26)$ & $1.046(16)$ \\
\hline $\mathrm{C}(6)-\mathrm{H}(6)$ & $0.970(16)$ & $\mathrm{C}(27)-\mathrm{H}(27 \mathrm{~A})$ & $0.98(2)$ \\
\hline $\mathrm{C}(7)-\mathrm{C}(11)$ & $1.522(2)$ & $\mathrm{C}(27)-\mathrm{H}(27 \mathrm{~B})$ & $0.981(19)$ \\
\hline $\mathrm{C}(8)-\mathrm{C}(9)$ & $1.517(3)$ & $\mathrm{C}(27)-\mathrm{H}(27 \mathrm{C})$ & $0.991(19)$ \\
\hline$C(8)-C(10)$ & $1.534(3)$ & $\mathrm{C}(28)-\mathrm{H}(28 \mathrm{~A})$ & $0.985(17)$ \\
\hline $\mathrm{C}(8)-\mathrm{H}(8)$ & $0.952(15)$ & $\mathrm{C}(28)-\mathrm{H}(28 \mathrm{~B})$ & $0.98(2)$ \\
\hline $\mathrm{C}(9)-\mathrm{H}(9 \mathrm{~A})$ & $0.940(19)$ & $\mathrm{C}(28)-\mathrm{H}(28 \mathrm{C})$ & $1.018(19)$ \\
\hline $\mathrm{C}(9)-\mathrm{H}(9 \mathrm{~B})$ & $0.976(19)$ & $\mathrm{C}(29)-\mathrm{C}(31)$ & $1.519(2)$ \\
\hline $\mathrm{C}(9)-\mathrm{H}(9 \mathrm{C})$ & $1.024(18)$ & $\mathrm{C}(29)-\mathrm{C}(30)$ & $1.531(2)$ \\
\hline $\mathrm{C}(10)-\mathrm{H}(10 \mathrm{~A})$ & $1.011(19)$ & $\mathrm{C}(29)-\mathrm{H}(29)$ & $1.098(16)$ \\
\hline $\mathrm{C}(10)-\mathrm{H}(10 \mathrm{~B})$ & $0.955(19)$ & $\mathrm{C}(30)-\mathrm{H}(30 \mathrm{~A})$ & $0.969(17)$ \\
\hline $\mathrm{C}(10)-\mathrm{H}(10 \mathrm{C})$ & $0.960(17)$ & $\mathrm{C}(30)-\mathrm{H}(30 \mathrm{~B})$ & $0.997(19)$ \\
\hline$C(11)-C(12)$ & $1.520(3)$ & $\mathrm{C}(30)-\mathrm{H}(30 \mathrm{C})$ & $0.901(17)$ \\
\hline $\mathrm{C}(11)-\mathrm{C}(13)$ & $1.527(3)$ & $\mathrm{C}(31)-\mathrm{H}(31 \mathrm{~A})$ & $0.964(16)$ \\
\hline $\mathrm{C}(11)-\mathrm{H}(11)$ & $0.966(15)$ & $\mathrm{C}(31)-\mathrm{H}(31 \mathrm{~B})$ & $0.982(19)$ \\
\hline $\mathrm{C}(12)-\mathrm{H}(12 \mathrm{~A})$ & $0.992(19)$ & $\mathrm{C}(31)-\mathrm{H}(31 \mathrm{C})$ & $0.99(2)$ \\
\hline $\mathrm{C}(12)-\mathrm{H}(12 \mathrm{~B})$ & $0.986(19)$ & $\mathrm{N}(3)-\mathrm{P}(1)-\mathrm{N}(1)$ & $108.53(7)$ \\
\hline $\mathrm{C}(12)-\mathrm{H}(12 \mathrm{C})$ & $0.93(2)$ & $\mathrm{N}(3)-\mathrm{P}(1)-\mathrm{N}(2)$ & $110.30(7)$ \\
\hline $\mathrm{C}(13)-\mathrm{H}(13 \mathrm{~A})$ & $1.04(2)$ & $\mathrm{N}(1)-\mathrm{P}(1)-\mathrm{N}(2)$ & 71.13(6) \\
\hline $\mathrm{C}(13)-\mathrm{H}(13 \mathrm{~B})$ & $1.024(19)$ & $\mathrm{N}(3)-\mathrm{P}(1)-\mathrm{C}(1)$ & $121.72(7)$ \\
\hline $\mathrm{C}(13)-\mathrm{H}(13 \mathrm{C})$ & $0.917(19)$ & $\mathrm{N}(1)-\mathrm{P}(1)-\mathrm{C}(1)$ & $36.04(6)$ \\
\hline$C(14)-C(19)$ & $1.398(2)$ & $\mathrm{N}(2)-\mathrm{P}(1)-\mathrm{C}(1)$ & $36.49(6)$ \\
\hline$C(14)-C(15)$ & $1.402(2)$ & $\mathrm{C}(1)-\mathrm{N}(1)-\mathrm{C}(2)$ & $126.21(13)$ \\
\hline$C(15)-C(16)$ & $1.391(2)$ & $\mathrm{C}(1)-\mathrm{N}(1)-\mathrm{P}(1)$ & 94.54(10) \\
\hline$C(15)-C(20)$ & $1.515(2)$ & $\mathrm{C}(2)-\mathrm{N}(1)-\mathrm{P}(1)$ & 134.31(11) \\
\hline$C(16)-C(17)$ & $1.380(3)$ & $\mathrm{C}(1)-\mathrm{N}(2)-\mathrm{C}(14)$ & $121.87(13)$ \\
\hline $\mathrm{C}(16)-\mathrm{H}(16)$ & $0.968(18)$ & $\mathrm{C}(1)-\mathrm{N}(2)-\mathrm{P}(1)$ & 93.99(10) \\
\hline $\mathrm{C}(17)-\mathrm{C}(18)$ & $1.372(3)$ & $\mathrm{C}(14)-\mathrm{N}(2)-\mathrm{P}(1)$ & $132.34(11)$ \\
\hline $\mathrm{C}(17)-\mathrm{H}(17)$ & $0.939(18)$ & $\mathrm{C}(29)-\mathrm{N}(3)-\mathrm{C}(26)$ & $116.46(13)$ \\
\hline $\mathrm{C}(18)-\mathrm{C}(19)$ & $1.393(2)$ & C(29)-N(3)-P(1) & $124.68(11)$ \\
\hline $\mathrm{C}(18)-\mathrm{H}(18)$ & $0.963(16)$ & $\mathrm{C}(26)-\mathrm{N}(3)-\mathrm{P}(1)$ & $118.39(11)$ \\
\hline$C(19)-C(23)$ & $1.513(2)$ & $\mathrm{N}(1)-\mathrm{C}(1)-\mathrm{N}(2)$ & 96.72(13) \\
\hline$C(20)-C(21)$ & $1.521(3)$ & $\mathrm{N}(1)-\mathrm{C}(1)-\mathrm{P}(1)$ & $49.42(8)$ \\
\hline$C(20)-C(22)$ & $1.521(3)$ & $\mathrm{N}(2)-\mathrm{C}(1)-\mathrm{P}(1)$ & 49.51(8) \\
\hline $\mathrm{C}(20)-\mathrm{H}(20)$ & $0.917(15)$ & $C(7)-C(2)-C(3)$ & $121.27(15)$ \\
\hline
\end{tabular}




$\begin{array}{ll}\mathrm{C}(7)-\mathrm{C}(2)-\mathrm{N}(1) & 120.39(15) \\ \mathrm{C}(3)-\mathrm{C}(2)-\mathrm{N}(1) & 118.32(15) \\ \mathrm{C}(4)-\mathrm{C}(3)-\mathrm{C}(2) & 117.66(16) \\ \mathrm{C}(4)-\mathrm{C}(3)-\mathrm{C}(8) & 120.26(16) \\ \mathrm{C}(2)-\mathrm{C}(3)-\mathrm{C}(8) & 121.99(15) \\ \mathrm{C}(5)-\mathrm{C}(4)-\mathrm{C}(3) & 121.96(18) \\ \mathrm{C}(5)-\mathrm{C}(4)-\mathrm{H}(4) & 119.4(11) \\ \mathrm{C}(3)-\mathrm{C}(4)-\mathrm{H}(4) & 118.6(11) \\ \mathrm{C}(4)-\mathrm{C}(5)-\mathrm{C}(6) & 119.89(19) \\ \mathrm{C}(4)-\mathrm{C}(5)-\mathrm{H}(5) & 118.1(11) \\ \mathrm{C}(6)-\mathrm{C}(5)-\mathrm{H}(5) & 121.9(11) \\ \mathrm{C}(5)-\mathrm{C}(6)-\mathrm{C}(7) & 121.16(18) \\ \mathrm{C}(5)-\mathrm{C}(6)-\mathrm{H}(6) & 118.4(9) \\ \mathrm{C}(7)-\mathrm{C}(6)-\mathrm{H}(6) & 120.5(9) \\ \mathrm{C}(6)-\mathrm{C}(7)-\mathrm{C}(2) & 117.98(16) \\ \mathrm{C}(6)-\mathrm{C}(7)-\mathrm{C}(11) & 118.56(16) \\ \mathrm{C}(2)-\mathrm{C}(7)-\mathrm{C}(11) & 123.36(16) \\ \mathrm{C}(3)-\mathrm{C}(8)-\mathrm{C}(9) & 113.93(16) \\ \mathrm{C}(3)-\mathrm{C}(8)-\mathrm{C}(10) & 109.79(15) \\ \mathrm{C}(9)-\mathrm{C}(8)-\mathrm{C}(10) & 109.79(16) \\ \mathrm{C}(3)-\mathrm{C}(8)-\mathrm{H}(8) & 109.1(9) \\ \mathrm{C}(9)-\mathrm{C}(8)-\mathrm{H}(8) & 107.3(9) \\ \mathrm{C}(10)-\mathrm{C}(8)-\mathrm{H}(8) & 106.7(9) \\ \mathrm{C}(8)-\mathrm{C}(9)-\mathrm{H}(9 \mathrm{~A}) & 113.3(12) \\ \mathrm{C}(8)-\mathrm{C}(9)-\mathrm{H}(9 \mathrm{~B}) & 111.9(11) \\ \mathrm{H}(9 \mathrm{~A})-\mathrm{C}(9)-\mathrm{H}(9 \mathrm{~B}) & 107.2(15) \\ \mathrm{C}(8)-\mathrm{C}(9)-\mathrm{H}(9 \mathrm{C}) & 109.9(10) \\ \mathrm{H}(9 \mathrm{~A})-\mathrm{C}(9)-\mathrm{H}(9 \mathrm{C}) & 107.9(15) \\ \mathrm{H}(9 \mathrm{~B})-\mathrm{C}(9)-\mathrm{H}(9 \mathrm{C}) & 106.4(14) \\ \mathrm{C}(8)-\mathrm{C}(10)-\mathrm{H}(10 \mathrm{~A}) & 111.0(11) \\ \mathrm{C}(8)-\mathrm{C}(10)-\mathrm{H}(10 \mathrm{~B}) & 111.6(11) \\ \mathrm{H}(10 \mathrm{~A})-\mathrm{C}(10)-\mathrm{H}(10 \mathrm{~B}) & 104.6(15) \\ \mathrm{C}(8)-\mathrm{C}(10)-\mathrm{H}(10 \mathrm{C}) & 111.0(10) \\ \mathrm{H}(10 \mathrm{~A})-\mathrm{C}(10)-\mathrm{H}(10 \mathrm{C}) & 110.0(15) \\ \mathrm{H}(10 \mathrm{~B})-\mathrm{C}(10)-\mathrm{H}(10 \mathrm{C}) & 108.4(15) \\ \mathrm{C}(12)-\mathrm{C}(11)-\mathrm{C}(7) & 112.33(17) \\ \mathrm{C}(12)-\mathrm{C}(11)-\mathrm{C}(13) & 110.11(18) \\ \mathrm{C}(7)-\mathrm{C}(11)-\mathrm{C}(13) & 111.27(16) \\ \mathrm{C}(12)-\mathrm{C}(11)-\mathrm{H}(11) & 105.7(9) \\ \mathrm{C}(7)-\mathrm{C}(11)-\mathrm{H}(11) & 109.2(9) \\ \mathrm{C}(13)-\mathrm{C}(11)-\mathrm{H}(11) & 107.9(9) \\ \mathrm{C}(11)-\mathrm{C}(12)-\mathrm{H}(12 \mathrm{~A}) & 113.6(11) \\ \mathrm{C}(11)-\mathrm{C}(12)-\mathrm{H}(12 \mathrm{~B}) & 111.4(11) \\ \mathrm{H}(12 \mathrm{~A})-\mathrm{C}(12)-\mathrm{H}(12 \mathrm{~B}) & 106.6(15) \\ \mathrm{C}(11)-\mathrm{C}(12)-\mathrm{H}(12 \mathrm{C}) & 109.4(12) \\ \mathrm{H}(12 \mathrm{~A})-\mathrm{C}(12)-\mathrm{H}(12 \mathrm{C}) & 106.9(16) \\ \mathrm{H}(12 \mathrm{~B})-\mathrm{C}(12)-\mathrm{H}(12 \mathrm{C}) & 108.9(16) \\ \mathrm{C}(11)-\mathrm{C}(13)-\mathrm{H}(13 \mathrm{~A}) & 110.6(11) \\ \mathrm{C}(11)-\mathrm{C}(13)-\mathrm{H}(13 \mathrm{~B}) & 110.7(10) \\ \mathrm{H}(13 \mathrm{~A})-\mathrm{C}(13)-\mathrm{H}(13 \mathrm{~B}) & 106.3(15) \\ \mathrm{C}(11)-\mathrm{C}(13)-\mathrm{H}(13 \mathrm{C}) & 109.5(12) \\ \mathrm{H}(13 \mathrm{~A})-\mathrm{C}(13)-\mathrm{H}(13 \mathrm{C}) & 110.6(16) \\ \mathrm{H}(13 \mathrm{~B})-\mathrm{C}(13)-\mathrm{H}(13 \mathrm{C}) & 109.1(16) \\ \mathrm{C}(19)-\mathrm{C}(14)-\mathrm{C}(15) & 121.65(16) \\ & \end{array}$

$\begin{array}{ll}\mathrm{C}(19)-\mathrm{C}(14)-\mathrm{N}(2) & 120.22(15) \\ \mathrm{C}(15)-\mathrm{C}(14)-\mathrm{N}(2) & 118.07(15) \\ \mathrm{C}(16)-\mathrm{C}(15)-\mathrm{C}(14) & 118.03(16) \\ \mathrm{C}(16)-\mathrm{C}(15)-\mathrm{C}(20) & 120.97(16) \\ \mathrm{C}(14)-\mathrm{C}(15)-\mathrm{C}(20) & 120.95(15) \\ \mathrm{C}(17)-\mathrm{C}(16)-\mathrm{C}(15) & 121.21(18) \\ \mathrm{C}(17)-\mathrm{C}(16)-\mathrm{H}(16) & 121.5(11) \\ \mathrm{C}(15)-\mathrm{C}(16)-\mathrm{H}(16) & 117.2(11) \\ \mathrm{C}(18)-\mathrm{C}(17)-\mathrm{C}(16) & 119.65(18) \\ \mathrm{C}(18)-\mathrm{C}(17)-\mathrm{H}(17) & 122.0(11) \\ \mathrm{C}(16)-\mathrm{C}(17)-\mathrm{H}(17) & 118.4(11) \\ \mathrm{C}(17)-\mathrm{C}(18)-\mathrm{C}(19) & 121.84(18) \\ \mathrm{C}(17)-\mathrm{C}(18)-\mathrm{H}(18) & 119.5(10) \\ \mathrm{C}(19)-\mathrm{C}(18)-\mathrm{H}(18) & 118.6(10) \\ \mathrm{C}(18)-\mathrm{C}(19)-\mathrm{C}(14) & 117.58(16) \\ \mathrm{C}(18)-\mathrm{C}(19)-\mathrm{C}(23) & 119.10(16) \\ \mathrm{C}(14)-\mathrm{C}(19)-\mathrm{C}(23) & 123.29(15) \\ \mathrm{C}(15)-\mathrm{C}(20)-\mathrm{C}(21) & 113.64(16) \\ \mathrm{C}(15)-\mathrm{C}(20)-\mathrm{C}(22) & 111.07(16) \\ \mathrm{C}(21)-\mathrm{C}(20)-\mathrm{C}(22) & 111.15(18) \\ \mathrm{C}(15)-\mathrm{C}(20)-\mathrm{H}(20) & 105.7(9) \\ \mathrm{C}(21)-\mathrm{C}(20)-\mathrm{H}(20) & 107.8(9) \\ \mathrm{C}(22)-\mathrm{C}(20)-\mathrm{H}(20) & 107.1(9) \\ \mathrm{C}(20)-\mathrm{C}(21)-\mathrm{H}(21 \mathrm{~A}) & 113.2(11) \\ \mathrm{C}(20)-\mathrm{C}(21)-\mathrm{H}(21 \mathrm{~B}) & 111.1(11) \\ \mathrm{H}(21 \mathrm{~A})-\mathrm{C}(21)-\mathrm{H}(21 \mathrm{~B}) & 103.2(15) \\ \mathrm{C}(20)-\mathrm{C}(21)-\mathrm{H}(21 \mathrm{C}) & 111.1(11) \\ \mathrm{H}(21 \mathrm{~A})-\mathrm{C}(21)-\mathrm{H}(21 \mathrm{C}) & 106.1(16) \\ \mathrm{H}(21 \mathrm{~B})-\mathrm{C}(21)-\mathrm{H}(21 \mathrm{C}) & 111.8(16) \\ \mathrm{C}(20)-\mathrm{C}(22)-\mathrm{H}(22 \mathrm{~A}) & 112.1(11) \\ \mathrm{C}(20)-\mathrm{C}(22)-\mathrm{H}(22 \mathrm{~B}) & 110.3(11) \\ \mathrm{H}(22 \mathrm{~A})-\mathrm{C}(22)-\mathrm{H}(22 \mathrm{~B}) & 107.2(15) \\ \mathrm{C}(20)-\mathrm{C}(22)-\mathrm{H}(22 \mathrm{C}) & 110.4(11) \\ \mathrm{H}(22 \mathrm{~A})-\mathrm{C}(22)-\mathrm{H}(22 \mathrm{C}) & 110.2(15) \\ \mathrm{H}(22 \mathrm{~B})-\mathrm{C}(22)-\mathrm{H}(22 \mathrm{C}) & 106.5(15) \\ \mathrm{C}(19)-\mathrm{C}(23)-\mathrm{C}(25) & 113.15(16) \\ \mathrm{C}(19)-\mathrm{C}(23)-\mathrm{C}(24) & 110.31(17) \\ \mathrm{C}(25)-\mathrm{C}(23)-\mathrm{C}(24) & 110.99(19) \\ \mathrm{C}(19)-\mathrm{C}(23)-\mathrm{H}(23) & 108.2(10) \\ \mathrm{C}(25)-\mathrm{C}(23)-\mathrm{H}(23) & 105.3(10) \\ \mathrm{C}(24)-\mathrm{C}(23)-\mathrm{H}(23) & 108.6(10) \\ \mathrm{C}(23)-\mathrm{C}(24)-\mathrm{H}(24 \mathrm{~A}) & 109.1(12) \\ \mathrm{C}(23)-\mathrm{C}(24)-\mathrm{H}(24 \mathrm{~B}) & 111.0(11) \\ \mathrm{H}(24 \mathrm{~A})-\mathrm{C}(24)-\mathrm{H}(24 \mathrm{~B}) & 109.1(16) \\ \mathrm{C}(23)-\mathrm{C}(24)-\mathrm{H}(24 \mathrm{C}) & 110.8(11) \\ \mathrm{H}(24 \mathrm{~A})-\mathrm{C}(24)-\mathrm{H}(24 \mathrm{C}) & 110.4(17) \\ \mathrm{H}(24 \mathrm{~B})-\mathrm{C}(24)-\mathrm{H}(24 \mathrm{C}) & 106.4(16) \\ \mathrm{C}(23)-\mathrm{C}(25)-\mathrm{H}(25 \mathrm{~A}) & 111.5(11) \\ \mathrm{C}(23)-\mathrm{C}(25)-\mathrm{H}(25 \mathrm{~B}) & 112.1(12) \\ \mathrm{H}(25 \mathrm{~A})-\mathrm{C}(25)-\mathrm{H}(25 \mathrm{~B}) & 106.7(16) \\ \mathrm{C}(23)-\mathrm{C}(25)-\mathrm{H}(25 \mathrm{C}) & 112.1(12) \\ \mathrm{H}(25 \mathrm{~A})-\mathrm{C}(25)-\mathrm{H}(25 \mathrm{C}) & 108.6(16) \\ \mathrm{H}(25 \mathrm{~B})-\mathrm{C}(25)-\mathrm{H}(25 \mathrm{C}) & 105.5(16) \\ \mathrm{N}(3)-\mathrm{C}(26)-\mathrm{C}(28) & 112.37(15) \\ & \end{array}$




$\begin{array}{lc}\mathrm{N}(3)-\mathrm{C}(26)-\mathrm{C}(27) & 111.26(15) \\ \mathrm{C}(28)-\mathrm{C}(26)-\mathrm{C}(27) & 112.26(17) \\ \mathrm{N}(3)-\mathrm{C}(26)-\mathrm{H}(26) & 103.0(8) \\ \mathrm{C}(28)-\mathrm{C}(26)-\mathrm{H}(26) & 108.7(8) \\ \mathrm{C}(27)-\mathrm{C}(26)-\mathrm{H}(26) & 108.8(9) \\ \mathrm{C}(26)-\mathrm{C}(27)-\mathrm{H}(27 \mathrm{~A}) & 110.1(11) \\ \mathrm{C}(26)-\mathrm{C}(27)-\mathrm{H}(27 \mathrm{~B}) & 109.1(11) \\ \mathrm{H}(27 \mathrm{~A})-\mathrm{C}(27)-\mathrm{H}(27 \mathrm{~B}) & 113.1(15) \\ \mathrm{C}(26)-\mathrm{C}(27)-\mathrm{H}(27 \mathrm{C}) & 111.6(10) \\ \mathrm{H}(27 \mathrm{~A})-\mathrm{C}(27)-\mathrm{H}(27 \mathrm{C}) & 103.2(15) \\ \mathrm{H}(27 \mathrm{~B})-\mathrm{C}(27)-\mathrm{H}(27 \mathrm{C}) & 109.6(15) \\ \mathrm{C}(26)-\mathrm{C}(28)-\mathrm{H}(28 \mathrm{~A}) & 109.3(10) \\ \mathrm{C}(26)-\mathrm{C}(28)-\mathrm{H}(28 \mathrm{~B}) & 111.0(12) \\ \mathrm{H}(28 \mathrm{~A})-\mathrm{C}(28)-\mathrm{H}(28 \mathrm{~B}) & 111.0(16) \\ \mathrm{C}(26)-\mathrm{C}(28)-\mathrm{H}(28 \mathrm{C}) & 113.1(11) \\ \mathrm{H}(28 \mathrm{~A})-\mathrm{C}(28)-\mathrm{H}(28 \mathrm{C}) & 103.0(14) \\ \mathrm{H}(28 \mathrm{~B})-\mathrm{C}(28)-\mathrm{H}(28 \mathrm{C}) & 109.2(15) \\ \mathrm{N}(3)-\mathrm{C}(29)-\mathrm{C}(31) & 110.83(15) \\ \mathrm{N}(3)-\mathrm{C}(29)-\mathrm{C}(30) & 112.09(15) \\ \mathrm{C}(31)-\mathrm{C}(29)-\mathrm{C}(30) & 111.30(16) \\ \mathrm{N}(3)-\mathrm{C}(29)-\mathrm{H}(29) & 96.7(9) \\ \mathrm{C}(31)-\mathrm{C}(29)-\mathrm{H}(29) & 110.9(9) \\ \mathrm{C}(30)-\mathrm{C}(29)-\mathrm{H}(29) & 114.2(9) \\ \mathrm{C}(29)-\mathrm{C}(30)-\mathrm{H}(30 \mathrm{~A}) & 112.0(10) \\ \mathrm{C}(29)-\mathrm{C}(30)-\mathrm{H}(30 \mathrm{~B}) & 107.8(10) \\ \mathrm{H}(30 \mathrm{~A})-\mathrm{C}(30)-\mathrm{H}(30 \mathrm{~B}) & 110.2(14) \\ \mathrm{C}(29)-\mathrm{C}(30)-\mathrm{H}(30 \mathrm{C}) & 110.8(11) \\ \mathrm{H}(30 \mathrm{~A})-\mathrm{C}(30)-\mathrm{H}(30 \mathrm{C}) & 111.0(14) \\ \mathrm{H}(30 \mathrm{~B})-\mathrm{C}(30)-\mathrm{H}(30 \mathrm{C}) & 104.8(15) \\ \mathrm{C}(29)-\mathrm{C}(31)-\mathrm{H}(31 \mathrm{~A}) & 110.4(9) \\ \mathrm{C}(29)-\mathrm{C}(31)-\mathrm{H}(31 \mathrm{~B}) & 110.6(11) \\ \mathrm{H}(31 \mathrm{~A})-\mathrm{C}(31)-\mathrm{H}(31 \mathrm{~B}) & 108.6(14) \\ \mathrm{C}(29)-\mathrm{C}(31)-\mathrm{H}(31 \mathrm{C}) & 109.6(11) \\ \mathrm{H}(31 \mathrm{~A})-\mathrm{C}(31)-\mathrm{H}(31 \mathrm{C}) & 108.1(14) \\ \mathrm{H}(31 \mathrm{~B})-\mathrm{C}(31)-\mathrm{H}(31 \mathrm{C}) & 109.4(15) \\ & \end{array}$


Table 4. Anisotropic displacement parameters $\left(\AA^{2} \times 10^{4}\right)$ for 5. The anisotropic displacement factor exponent takes the form: $-2 \pi^{2}\left[h^{2} a^{* 2} U^{11}+\ldots+2 h k^{*} b^{*} U^{12}\right]$

\begin{tabular}{|c|c|c|c|c|c|c|}
\hline & $\mathrm{U}^{11}$ & $\mathrm{U}^{22}$ & $\mathrm{U}^{33}$ & $\mathrm{U}^{23}$ & $\mathrm{U}^{13}$ & $\mathrm{U}^{12}$ \\
\hline $\mathrm{P}(1)$ & $187(2)$ & $186(3)$ & 193(3) & $-4(2)$ & $9(2)$ & $0(2)$ \\
\hline $\mathrm{N}(1)$ & $149(7)$ & $158(8)$ & $159(8)$ & $-7(7)$ & $-4(6)$ & $5(6)$ \\
\hline $\mathrm{N}(2)$ & $142(8)$ & $154(8)$ & $174(8)$ & $-21(6)$ & $-1(6)$ & 1(6) \\
\hline $\mathrm{N}(3)$ & $160(8)$ & 173(8) & $192(8)$ & $6(6)$ & $-2(6)$ & $-16(6)$ \\
\hline $\mathrm{C}(1)$ & $218(10)$ & 198(10) & 189(10) & 1(8) & $-2(8)$ & $8(8)$ \\
\hline$C(2)$ & $125(9)$ & $200(10)$ & $182(10)$ & $-40(8)$ & $-11(7)$ & $18(7)$ \\
\hline$C(3)$ & $125(9)$ & $222(10)$ & $195(10)$ & $-18(8)$ & $-14(7)$ & $6(7)$ \\
\hline$C(4)$ & $256(11)$ & $313(12)$ & $185(11)$ & 4(9) & $56(9)$ & $31(9)$ \\
\hline$C(5)$ & $330(12)$ & $269(11)$ & $275(12)$ & $-83(10)$ & $75(9)$ & $69(9)$ \\
\hline$C(6)$ & $285(11)$ & $202(11)$ & $304(12)$ & $-7(9)$ & $50(9)$ & $50(9)$ \\
\hline$C(7)$ & 161(9) & 208(10) & $217(10)$ & $-13(8)$ & $8(8)$ & $16(8)$ \\
\hline$C(8)$ & 161(10) & $258(11)$ & 193(10) & $8(8)$ & $39(8)$ & $24(8)$ \\
\hline C(9) & $296(13)$ & 339(13) & $260(12)$ & $40(10)$ & $26(10)$ & $48(11)$ \\
\hline$C(10)$ & $276(12)$ & 294(13) & $318(13)$ & $53(11)$ & 21(10) & $-55(10)$ \\
\hline $\mathrm{C}(11)$ & 294(11) & $182(10)$ & $225(11)$ & $-9(9)$ & $55(9)$ & $64(9)$ \\
\hline$C(12)$ & $344(14)$ & $408(15)$ & $312(14)$ & $35(12)$ & $79(11)$ & $-53(11)$ \\
\hline$C(13)$ & $340(13)$ & $470(16)$ & $282(14)$ & 131(12) & $-27(10)$ & $-35(12)$ \\
\hline$C(14)$ & 123(9) & 208(10) & $174(10)$ & $-36(8)$ & 14(7) & $-18(7)$ \\
\hline$C(15)$ & 164(9) & 188(10) & 201(10) & $-10(8)$ & $-4(8)$ & $-4(8)$ \\
\hline$C(16)$ & $267(11)$ & 195(11) & 273(11) & $-45(9)$ & $-15(9)$ & $23(9)$ \\
\hline $\mathrm{C}(17)$ & $282(11)$ & $255(11)$ & $205(11)$ & $-76(9)$ & $-5(9)$ & $-1(9)$ \\
\hline $\mathrm{C}(18)$ & $238(11)$ & 281(12) & $165(10)$ & $26(9)$ & $-14(8)$ & 7(9) \\
\hline C(19) & $168(9)$ & 199(10) & $175(10)$ & $-9(8)$ & $12(7)$ & $-18(8)$ \\
\hline$C(20)$ & $253(11)$ & 179(10) & $235(11)$ & $-23(9)$ & $-76(9)$ & $-4(9)$ \\
\hline $\mathrm{C}(21)$ & $403(14)$ & $280(13)$ & $329(14)$ & $-15(11)$ & $-89(12)$ & $110(11)$ \\
\hline$C(22)$ & $365(14)$ & 399(14) & $280(13)$ & $117(11)$ & $-24(11)$ & $52(12)$ \\
\hline$C(23)$ & $323(11)$ & 228(10) & $158(10)$ & $-10(9)$ & $-46(8)$ & 6(9) \\
\hline$C(24)$ & $484(17)$ & $285(14)$ & $506(17)$ & $78(12)$ & $62(13)$ & $-89(11)$ \\
\hline$C(25)$ & $356(14)$ & $265(13)$ & $463(16)$ & $13(11)$ & $-49(11)$ & $83(10)$ \\
\hline$C(26)$ & $178(10)$ & $253(11)$ & $252(11)$ & 4(9) & $9(8)$ & $-35(8)$ \\
\hline$C(27)$ & $247(12)$ & $332(13)$ & $327(13)$ & $-6(11)$ & $90(10)$ & $-3(10)$ \\
\hline$C(28)$ & $313(13)$ & 293(12) & 398(14) & $-104(11)$ & $96(11)$ & $-104(10)$ \\
\hline$C(29)$ & 199(10) & $217(10)$ & $222(10)$ & 31(8) & $-38(8)$ & $-2(8)$ \\
\hline$C(30)$ & $208(11)$ & 211(11) & $350(13)$ & $29(10)$ & $-37(10)$ & 7(9) \\
\hline $\mathrm{C}(31)$ & $245(12)$ & 298(12) & 233(12) & $14(10)$ & $-33(9)$ & $-12(10)$ \\
\hline
\end{tabular}


Table 5. Hydrogen coordinates $\left(\times 10^{4}\right)$ and isotropic displacement parameters $\left(\AA^{2} \times 10^{3}\right)$ for 5 .

\begin{tabular}{|c|c|c|c|c|}
\hline & $\mathrm{x}$ & $\mathrm{y}$ & $\mathrm{z}$ & $\mathrm{U}_{\mathrm{iso}}$ \\
\hline $\mathrm{H}(4)$ & $5709(17)$ & $1933(6)$ & 11081(14) & $26(5)$ \\
\hline $\mathrm{H}(5)$ & $5329(19)$ & $2741(7)$ & $10533(14)$ & $29(5)$ \\
\hline $\mathrm{H}(6)$ & $5773(16)$ & 2994(6) & 8823(12) & $13(4)$ \\
\hline $\mathrm{H}(8)$ & $7330(17)$ & $940(6)$ & $9760(12)$ & $15(4)$ \\
\hline $\mathrm{H}(9 \mathrm{~A})$ & $7840(20)$ & $1241(7)$ & $11534(15)$ & $37(6)$ \\
\hline $\mathrm{H}(9 \mathrm{~B})$ & $7192(18)$ & 699(7) & $11500(14)$ & $33(6)$ \\
\hline $\mathrm{H}(9 \mathrm{C})$ & $6130(20)$ & $1169(6)$ & $11722(14)$ & $32(5)$ \\
\hline $\mathrm{H}(10 \mathrm{~A})$ & $4260(20)$ & $982(7)$ & $10188(15)$ & $41(6)$ \\
\hline $\mathrm{H}(10 \mathrm{~B})$ & $5157(19)$ & $482(7)$ & $10075(14)$ & $35(6)$ \\
\hline $\mathrm{H}(10 \mathrm{C})$ & 4893(17) & $821(6)$ & $9075(15)$ & $25(5)$ \\
\hline $\mathrm{H}(11)$ & $7016(16)$ & 2173(6) & $6814(12)$ & $15(4)$ \\
\hline $\mathrm{H}(12 \mathrm{~A})$ & $7470(20)$ & $3201(7)$ & $7459(15)$ & $39(6)$ \\
\hline $\mathrm{H}(12 \mathrm{~B})$ & 7899(19) & $2965(7)$ & $6373(15)$ & $33(5)$ \\
\hline $\mathrm{H}(12 \mathrm{C})$ & $8660(20)$ & $2785(7)$ & $7449(15)$ & $45(7)$ \\
\hline $\mathrm{H}(13 \mathrm{~A})$ & $4680(20)$ & 2911(8) & $7052(16)$ & $55(7)$ \\
\hline $\mathrm{H}(13 \mathrm{~B})$ & $4380(20)$ & $2316(7)$ & $6682(14)$ & $40(6)$ \\
\hline $\mathrm{H}(13 \mathrm{C})$ & $5250(20)$ & $2690(7)$ & $5965(16)$ & $36(6)$ \\
\hline $\mathrm{H}(16)$ & 7483(19) & $-581(7)$ & $5101(14)$ & $34(5)$ \\
\hline $\mathrm{H}(17)$ & $6453(18)$ & $-203(7)$ & $3550(14)$ & $31(5)$ \\
\hline $\mathrm{H}(18)$ & $5988(17)$ & 671(6) & $3484(13)$ & $19(5)$ \\
\hline $\mathrm{H}(20)$ & $8888(16)$ & 59(6) & $7325(12)$ & $9(4)$ \\
\hline$H(21 A)$ & $8740(20)$ & $-930(8)$ & $6475(15)$ & $36(6)$ \\
\hline $\mathrm{H}(21 \mathrm{~B})$ & $9740(20)$ & $-773(7)$ & $7455(16)$ & $37(6)$ \\
\hline $\mathrm{H}(21 \mathrm{C})$ & $10030(20)$ & $-556(7)$ & $6318(15)$ & $38(6)$ \\
\hline $\mathrm{H}(22 \mathrm{~A})$ & $6470(20)$ & $-36(7)$ & $7833(14)$ & $36(6)$ \\
\hline $\mathrm{H}(22 \mathrm{~B})$ & $7520(20)$ & $-449(7)$ & $8381(16)$ & $43(6)$ \\
\hline $\mathrm{H}(22 \mathrm{C})$ & $6440(20)$ & $-612(7)$ & $7358(15)$ & $45(6)$ \\
\hline $\mathrm{H}(23)$ & $6548(17)$ & $1521(6)$ & $5593(13)$ & $21(5)$ \\
\hline $\mathrm{H}(24 \mathrm{~A})$ & $8670(30)$ & 1547(8) & $4602(16)$ & $55(7)$ \\
\hline $\mathrm{H}(24 \mathrm{~B})$ & $7530(20)$ & 2008(8) & $4283(15)$ & $44(6)$ \\
\hline $\mathrm{H}(24 \mathrm{C})$ & $7520(20)$ & $1532(7)$ & $3537(16)$ & $40(6)$ \\
\hline $\mathrm{H}(25 \mathrm{~A})$ & $4750(20)$ & 1406(8) & $3693(17)$ & $50(6)$ \\
\hline $\mathrm{H}(25 \mathrm{~B})$ & $4720(20)$ & 1872(8) & $4483(15)$ & $47(6)$ \\
\hline $\mathrm{H}(25 \mathrm{C})$ & $4150(20)$ & $1360(7)$ & $4864(15)$ & $45(6)$ \\
\hline $\mathrm{H}(26)$ & $12479(17)$ & $1214(6)$ & $8478(13)$ & $19(5)$ \\
\hline $\mathrm{H}(27 \mathrm{~A})$ & 12205(19) & 973(8) & $6619(14)$ & $37(6)$ \\
\hline $\mathrm{H}(27 \mathrm{~B})$ & $13380(20)$ & 1441(7) & $6834(14)$ & $44(6)$ \\
\hline $\mathrm{H}(27 \mathrm{C})$ & $11730(20)$ & $1514(7)$ & $6275(15)$ & $35(6)$ \\
\hline $\mathrm{H}(28 \mathrm{~A})$ & $11120(20)$ & $2158(7)$ & $7716(14)$ & $27(5)$ \\
\hline $\mathrm{H}(28 \mathrm{~B})$ & $12800(20)$ & $2109(7)$ & $8261(15)$ & $48(6)$ \\
\hline $\mathrm{H}(28 \mathrm{C})$ & $11340(20)$ & $2034(7)$ & $8929(15)$ & $42(6)$ \\
\hline $\mathrm{H}(29)$ & 9020(19) & 693(6) & $8698(13)$ & $30(5)$ \\
\hline $\mathrm{H}(30 \mathrm{~A})$ & $11208(17)$ & $204(6)$ & $8082(14)$ & $22(5)$ \\
\hline $\mathrm{H}(30 \mathrm{~B})$ & 11048(19) & $92(7)$ & $9321(15)$ & $39(6)$ \\
\hline $\mathrm{H}(30 \mathrm{C})$ & $12220(20)$ & 449(6) & 8976(13) & $25(5)$ \\
\hline $\mathrm{H}(31 \mathrm{~A})$ & $11427(18)$ & $1178(6)$ & $10063(12)$ & $15(4)$ \\
\hline $\mathrm{H}(31 \mathrm{~B})$ & 10244(19) & $811(7)$ & $10522(15)$ & $41(6)$ \\
\hline $\mathrm{H}(31 \mathrm{C})$ & $9730(20)$ & $1343(8)$ & 9981(14) & $43(6)$ \\
\hline
\end{tabular}

